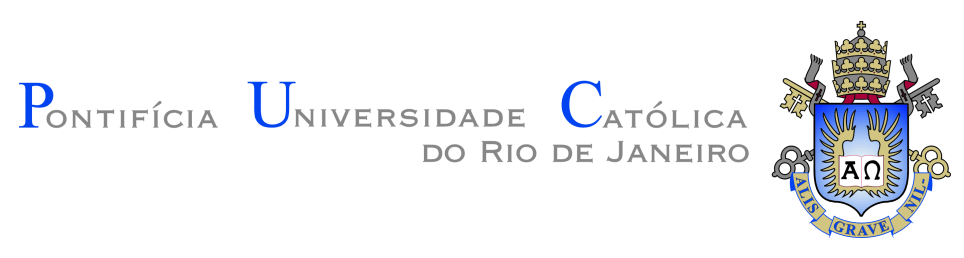

André Milhorance de Castro

Fluxo de Potência Probabilístico via Simulação Monte Carlo e Método da Entropia Cruzada

Dissertação de Mestrado

Dissertação apresentada como requisito parcial para obtenção do grau de Mestre pelo Programa de Pós-Graduação em Engenharia Elétrica do Departamento de Engenharia Elétrica do Centro Técnico Científico da PUC-Rio.

Orientador: Prof. Armando Martins Leite da Silva 


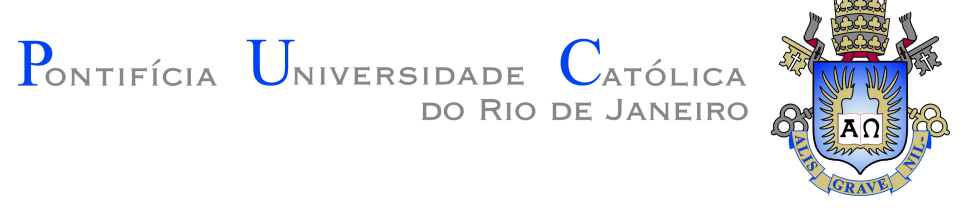

André Milhorance de Castro

\section{Fluxo de Potência Probabilístico via Simulação Monte Carlo e Método da Entropia Cruzada}

Dissertação apresentada como requisito parcial para obtenção do grau de Mestre pelo Programa de Pós-Graduação em Engenharia Elétrica da PUC-Rio. Aprovada pela Comissão Examinadora abaixo assinada.

Prof. Armando Martins Leite da Silva

Orientador

Departamento de Engenharia Elétrica - PUC-Rio

Prof. Alexandre Street de Aguiar

Departamento de Engenharia Elétrica - PUC-Rio

Prof. Marcus Theodor Schilling Universidade Federal Fluminense - UFF

Prof. Marcio da Silveira Carvalho Coordenador Setorial do Centro Técnico Científico - PUC-Rio 
Todos os direitos reservados. É proibida a reprodução total ou parcial do trabalho sem autorização da universidade, do autor e do orientador.

\section{André Milhorance de Castro}

Graduou-se em Engenharia de Controle e Automação, pela Universidade Federal do Rio de Janeiro, em 2013. Realizou Iniciação Científica no GSCAR/COPPE-UFRJ, trabalhando no desenvolvimento de tecnologia para Robótica Submarina. Trabalhou, ainda, como Engenheiro de Projetos (Automação \& Instrumentação), nas empresas Promon Engenharia e Kongsberg Maritime, em projetos de Óleo \& Gás e Mineração.

Ingressou em 2015 no Mestrado em Sistemas de Energia, na PUC-Rio, onde teve, também, a oportunidade de participar em projetos de pesquisa pela INESC Brasil e pelo LAMPS/PUC-Rio.

Ficha Catalográfica

Castro, André Milhorance de

Fluxo de potência probabilístico via simulação Monte Carlo e método de entropia cruzada / André Milhorance de Castro; orientador: Armando Martins Leite da Silva. - 2017.

91 f.: il. color. ; $30 \mathrm{~cm}$

Dissertação (mestrado) - Pontifícia Universidade Católica do Rio de Janeiro, Departamento de Engenharia Elétrica, 2017.

Inclui bibliografia

1. Engenharia Elétrica - Teses. 2. Confiabilidade;. 3. Entropia cruzada;. 4. Fluxo de potência probabilístico;. 5. Simulação Monte Carlo;. 6. Técnicas de redução de variância.. I. Leite da Silva, Armando Martins. II. Pontifícia Universidade Católica do Rio de Janeiro. Departamento de Engenharia Elétrica. III. Título. 


\section{Agradecimentos}

Sem dúvidas, é impossível atingir o sucesso, em qualquer grau, apenas com esforços individuais. Estes são fundamentais, mas é preciso reconhecer o auxílio direto e indireto dos que caminham ao nosso lado. Nada mais justo, então, que agradecer a todos que participaram dessa minha jornada até aqui.

Começo agradecendo aos meus pais, Carlos Frederico e Maria das Graças, que entendem o valor da educação como uma união de instrução acadêmica e valores sociais. Agradeço, também, as minhas irmãs pelo exemplo de dedicação.

Reconheço a extrema importância de Lilian Maria, que me ilumina com seu amor, amizade e sabedoria.

Não seria possível realizar um trabalho de qualidade sem a estimada orientação do professor Armando Leite da Silva. Muito obrigado pela confiança, conhecimentos transmitidos, valiosas discussões e orientações.

Agradeço ao José Filho, que me auxiliou no início desse trabalho.

Ao $\mathrm{CNPq}$, que patrocinou minha participação nesse Programa de PósGraduação.

Por fim, a todos os mestres, queridos professores, com os quais aprendi o valor do conhecimento. 


\section{Resumo}

Castro, André Milhorance de; Leite da Silva, Armando Martins. Fluxo de Potência Probabilístico via Simulação Monte Carlo e Método da Entropia Cruzada. Rio de Janeiro, 2017. 91p. Dissertação de Mestrado - Departamento de Engenharia Elétrica, Pontifícia Universidade Católica do Rio de Janeiro.

Em planejamento e operação de sistemas de energia elétrica, é necessário realizar diversas avaliações utilizando o algoritmo de fluxo de potência, para obter e monitorar o ponto de operação da rede em estudo. Em sua utilização determinística, devem ser especificados valores de geração e níveis de carga por barra, bem como considerar uma configuração especifica da rede elétrica. Existe, porém, uma restrição evidente em se trabalhar com algoritmo de fluxo de potência determinístico: não há qualquer percepção do impacto gerado por incertezas nas variáveis de entrada que o algoritmo utiliza. O algoritmo de fluxo de potência probabilístico (FPP) visa extrapolar as limitações impostas pelo uso da ferramenta convencional determinística, permitindo a consideração das incertezas de entrada. Obtém-se maior sensibilidade na avaliação dos resultados, visto que possíveis regiões de operação são mais claramente examinadas. Consequentemente, estima-se o risco do sistema funcionar fora de suas condições operativas nominais. Essa dissertação propõe uma metodologia baseada na simulação Monte Carlo (SMC) utilizando técnicas de amostragem por importância via o método de entropia cruzada. Índices de risco para eventos selecionados (e.g., sobrecargas em equipamentos de transmissão) são avaliados, mantendo-se a precisão e flexibilidade permitidas pela SMC convencional, porém em tempo computacional muito reduzido. Ao contrário das técnicas analíticas concebidas para solução do FPP, que visam primordialmente à elaboração de curvas de densidade de probabilidade para as variáveis de saída (fluxos, etc.) e sempre necessitam ter a precisão obtida comparada à SMC, o método proposto avalia somente as áreas das "caudas" dessas densidades, obtendo resultados com maior exatidão nas regiões de interesse do ponto de vista do risco operativo. O método proposto é aplicado nos sistemas IEEE 14 barras, IEEE RTS e IEEE 118 barras, sendo os resultados obtidos amplamente discutidos. Em todos os casos, há claros ganhos de desempenho computacional, mantendo-se a precisão, quando comparados à SMC convencional. As possíveis aplicações do método e suas derivações futuras também fazem parte da dissertação.

\section{Palavras-chave}

Confiabilidade; Entropia cruzada; Fluxo de potência probabilístico; Simulação Monte Carlo; Técnicas de redução de variância. 


\section{Abstract}

Castro, André Milhorance de; Leite da Silva, Armando Martins (Advisor). Probabilistic Load Flow via Monte Carlo Simulation and Cross-Entropy Method. Rio de Janeiro, 2017. 91p. Dissertação de Mestrado - Departamento de Engenharia Elétrica, Pontifícia Universidade Católica do Rio de Janeiro.

In planning and operation of electric energy systems, it is necessary to perform several evaluations using the power flow algorithm to obtain and monitor the operating point of the network under study. Bearing in mind its deterministic use, generation values and load levels per bus must be specified, as well as a specific configuration of the power network. There is, however, an obvious constraint in running a deterministic power flow tool: there is no perception of the impact produced by uncertainties on the input variables used by the conventional algorithm. The probabilistic power flow (PLF) algorithm aims to solve the limitations imposed by the use of the deterministic conventional tool, allowing the consideration of input uncertainties. Superior sensitivity is obtained in the evaluation of results, as possible regions of operation are more clearly examined. Consequently, the risk of the system operating outside its nominal conditions is duly estimated. This dissertation proposes a methodology based on Monte Carlo simulation (MCS) using importance sampling techniques via the cross-entropy method. Risk indices for selected events (e.g., overloads on transmission equipment) are evaluated, keeping the same accuracy and flexibility tolerable by the conventional MCS, but in much less computational time. Unlike the FPP solution obtained by analytical techniques, which primarily aim at assessing probability density curves for the output variables (flows, etc.) and always need to have the accuracy compared to MCS, the proposed method evaluates only the "tail" areas of these densities, obtaining results with greater accuracy in the regions of interest from the operational risk point of view. The proposed method is applied to IEEE 14, IEEE RTS and IEEE 118 bus systems, and the results are widely discussed. In all cases, there are clear gains in computational performance, maintaining accuracy when compared to conventional SMC. The possible applications of the method and future developments are also part of the dissertation.

\section{Keywords}

Cross-entropy; Monte Carlo simulation; Probabilistic load flow; Reliability; Variance reduction techniques. 


\section{Sumário}

$\begin{array}{lll}1 & \text { Introdução } & 13\end{array}$

1.1 Considerações Iniciais 13

$\begin{array}{ll}1.2 \text { Desenvolvimento Histórico } & 16\end{array}$

1.2.1 Fluxo de Potência Probabilístico 16

1.2.2 Aplicação de Entropia Cruzada em Sistemas Elétricos de Energia 19

$\begin{array}{lll}1.3 & \text { Estrutura da Dissertação } & 21\end{array}$

2 Técnicas de Fluxo de Potência Probabilístico 23

2.1 Introdução 23

2.2 Formulação do Problema 25

2.3 Métodos Analíticos 26

2.3.1 Convolução de Distribuições de Entrada 26

2.3.2 Cumulantes Estatísticos e Gram-Charlier 28

2.3.3 Point Estimate Method 28

2.4 Métodos de Simulação Monte Carlo 29

2.4.1 Estimativa de Evento de Risco em Fluxo de Potência Probabilístico 31

2.5 Comentários Finais 36

3 Estimativa de Eventos com Monte Carlo e Entropia Cruzada 38

$\begin{array}{lll}3.1 \text { Introdução } & 38\end{array}$

3.2 Técnicas de Redução de Variância 39

3.2.1 Variáveis Antitéticas $\quad 39$

3.2.2 Variáveis de Controle $\quad 40$

3.2.3 Amostragem por Importância 41

3.3 Método da Entropia Cruzada 42

3.3.1 Formulação Matemática para Estimação de Eventos Raros com Entropia Cruzada 43

3.3.2 Algoritmo para Simulação Monte Carlo e Entropia Cruzada 49

3.3.3 Exemplos Introdutórios $\quad 50$

3.4 Formulação Completa do Problema e Metodologia Proposta 54

3.5 Comentários Finais 56

4 Simulações e Resultados $\quad 57$

$\begin{array}{lll}4.1 & \text { Introdução } & 57\end{array}$

4.2 Considerações Gerais de Simulação 57

4.3 IEEE 14 Barras 58

4.3.1 Exemplo Detalhado 59

4.4 IEEE RTS $79 \quad 62$

4.4.1 Exemplo Detalhado 63

4.4.2 Outros Resultados 66

4.5 IEEE 118 barras 68

4.5.1 Exemplo Detalhado 70

$\begin{array}{lll}4.6 & \text { Comentários Finais } & 73\end{array}$ 
$\begin{array}{lll}5 & \text { Conclusões } & \mathbf{7 5}\end{array}$

5.1 Propostas para trabalhos futuros 76

$\begin{array}{ll}\text { Referências bibliográficas } & 78\end{array}$

A Dados de Sistema IEEE 14 Barras $\quad 84$

B Dados de Sistema IEEE RTS 79 $\quad 86$

C Dados de Sistema IEEE 118 Barras $\quad 88$ 


\section{Lista de Figuras}

3.1 Distribuição normal $N(100,30)$. 51

3.2 Histograma para $S(x)=x^{2}$ para $x \in \mathbf{X} \sim N(100,30)$ (esquerda) e $x \in \mathbf{X} \sim N(208,4068,30)$ (direita).

3.3 Distribuição discreta.

3.4 Distribuição discreta após a distorção com CE. 53

4.1 Diagrama unifilar para sistema IEEE 14 barras, com destaque para linha 3-4.

4.2 Histograma para fluxo aparente na linha 3-4, a partir das distribuições original (esquerda) e distorcida (direita).

4.3 Diagrama unifilar para sistema IEEE RTS 79, com destaque para barra 4.

4.4 Histograma para magnitude de tensão na barra 4, a partir das distribuições original (esquerda) e distorcida (direita).

4.5 Diagrama unifilar para sistema IEEE 118 barras, com destaque para linha 74-75

4.6 Histograma para fluxo aparente na linha 74-75, a partir das distribuições originais (esquerda) e distorcidas (direita).

A.1 Diagrama unifilar para sistema IEEE 14 barras 84

$\begin{array}{lll}\text { B.1 Diagrama unifilar para sistema IEEE RTS } 79 & 87\end{array}$

C.1 Diagrama unifilar para sistema IEEE 118 barras 89 


\section{Lista de Tabelas}

3.1 Evolução das Iterações para Simulação com Entropia Cruzada 52

3.2 Desempenho de SMC e SMC-CE para Estimativa de Probabilidade Alvo

3.3 Desempenho de SMC e SMC-CE para Estimativa de Probabilidade Alvo

4.1 Resultados Comparativos para Estimativa de Probabilidade de Sobrecarga na Linha 3-4.

4.2 Comparação entre Valores Esperados Normais e Distorcidos para Cargas Ativas e Reativas.

4.3 Comparação entre Valores Esperados Normais e Distorcidos para Geração Ativa.

4.4 Comparação entre Valores Esperados para Fluxo na Linha 3-4.

4.5 Comparação entre Valores Esperados para Potência Injetada na Barra Swing.

4.6 Resultados Comparativos para Estimativa de Probabilidade de Subtensão na Barra 4.

4.7 Comparação entre Valores Esperados Normais e Distorcidos para Cargas Ativa.

4.8 Comparação entre Valores Esperados Normais e Distorcidos para Geração Ativa.

4.9 Comparação entre Valores Esperados para Fluxo na Linha 4 (barra 2 para 4).

4.10 Comparação entre Valores Esperados para Fluxo na Linha 8 (barra 9 para 4).

4.11 Resultados Comparativos para Estimativa de Probabilidade de Subtensão em Barra 8.

4.12 Resultados Comparativos para Estimativa de Probabilidade de Subtensão em Barra 11.

4.13 Resultados Comparativos para Estimativa de Probabilidade de Subtensão em Barra 12.

4.14 Resultados Comparativos para Estimativa de Probabilidade de Sobrecarga em Linha 8-9.

4.15 Resultados Comparativos para Estimativa de Probabilidade de Sobrecarga em Linha 16-17.

4.16 Resultados Comparativos para Estimativa de Probabilidade de Sobrecarga na Linha 74-75.

4.17 Comparação entre Valores Esperados Normais e Distorcidos para Geração Ativa.

4.18 Comparação entre Valores Esperados para Fluxo na Linha 74-75. 72

A.1 Dados Nodais Probabilísticos - Distribuições Normais 85

A.2 Dados Nodais Probabilísticos - Distribuições Binomiais 85

A.3 Dados Nodais Probabilísticos - Distribuições Discretas 85 
B.1 Dados Nodais Probabilísticos - Distribuições Discretas

C.1 Dados Nodais Probabilísticos - Distribuições Discretas

90

C.2 Dados de Geração - Indisponibilidade e Ordem de Mérito 


\section{Lista de Abreviaturas}

AHL - Amostragem por Hipercubo Latino

CE - Entropia Cruzada (Cross-Entropy)

DASGI - Dimension-Adaptive Sparse Grid Interpolation

DC - Direct Current

EPNS - Expected Power Not Supplied

fda - Função de Distribuição Acumulada

fdp - Função Densidade de Probabilidade

FFT - Fast Fourier Transform

FPP - Fluxo de Potência Probabilístico

iid - Independentes e identicamente distribuídos

IS - Amostragem por Importância (Importance Sampling)

LOLD - Loss of Load Duration

LOLF - Loss of Load Frequency

LOLP - Loss of Load Probability

SMC - Simulação Monte Carlo

SMC-AF - Simulação Monte Carlo por Amostragem Fixa

SMC-CE - Simulação Monte Carlo combinada com Entropia Cruzada

VEC - Valor Esperado Condicional

VRT - Técnicas de Redução de Variância (Variance Reduction Technique) 


\section{Introdução}

\section{1}

\section{Considerações Iniciais}

Fluxo de potência é sabidamente a principal ferramenta disposta por um analista de sistemas elétricos de energia para estudos em seu setor. Desde a concepção de um projeto (na etapa de planejamento) à operação em temporeal, é sempre necessário utilizar algoritmo de fluxo de potência.

Quando usado de forma determinística, a partir de um conjunto de dados conhecidos, é possível caracterizar com completude o estado de operação do sistema. Pode-se, assim, avaliá-lo quanto as condições operativas estáticas do sistema. Por exemplo, é concebível afirmar se aquele estado leva o sistema a trabalhar fora das margens nominais de segurança de linhas de transmissão (sobrecarga) ou de magnitude de tensão em barras (sub ou sobretensão). Conhecer estas condições de operação é fundamental do ponto de vista da segurança e qualidade de serviço na entrega da energia ao seu consumidor final. Bem como é importante saber o quão afastado das "zonas normais" está o funcionamento do sistema em um determinado ponto de operação.

Existe, porém, uma restrição evidente em se trabalhar com algoritmo de fluxo de potência determinístico: não há mapeamento do impacto gerado pela incerteza nos valores que as variáveis de entrada do algoritmo podem assumir.

Em 1974, foi proposto por Borkowska [1] um método para avaliação de fluxo de potência, levando em consideração as características estatísticas (ditas conhecidas) das variáveis de entrada. Assim, foi concebido o fluxo de potência probabilístico (FPP).

Há, desde então, um crescente interesse pelo assunto, visto que independentemente da etapa de utilização de fluxo de potência (planejamento ou operação), há uma possível distribuição de probabilidade que rege os valores que as variáveis de entrada podem assumir.

Com a progressiva inserção de fontes de energia intermitentes (e.g., eólica e solar), estudar o comportamento do sistema elétrico, frente aos possíveis cenários de geração, se torna ainda mais fundamental. Outro fator, que faz o assunto ainda mais necessário, é a incerteza nas condições de demanda, 
principalmente com tecnologias emergentes, como os carros elétricos. Essas são razões impactantes na revitalização recente (última década) do assunto, quanto ao volume de publicação e proposição de aplicações.

A metodologia probabilística leva em consideração as incertezas estatísticas nos valores de entrada, mapeando-as em funções densidade de probabilidade (fdp) para as variáveis calculadas pelo algoritmo. O conhecimento do formato da fdp tem sido o principal objetivo de pesquisadores na área de FPP, desde de sua concepção com Borkowska, em 1974. Os trabalhos visam criar metodologias que possibilitem aumentar a precisão dos resultados estimados (principalmente dos momentos estatísticos), bem como requerer um menor tempo computacional para a realização da tarefa.

Por outro lado, as tomadas de decisão no setor elétrico levam em consideração índices baseados em probabilidade, frequência e duração de eventos de risco, como por exemplo: LOLP (Loss of Load Probability), LOLF (Loss of Load Frequency) e LOLD (Loss of Load Duration). Entende-se, dessa forma, que para haver uma tomada de decisão assertiva sobre ações mitigadoras do risco de um determinado cenário, é preciso a estimativa de sua probabilidade de ocorrência, com a maior precisão possível, no menor tempo possível. Normalmente, esses índices são estimados pelas "caudas" das distribuições a eles referentes. Métodos que visam fornecer distribuições como dados de saída, normalmente não garantem elevada precisão nas regiões das "caudas".

A simulação Monte Carlo (SMC) é uma ferramenta usual para a estimativa de eventos de riscos. Na área de FPP, ela pode ser utilizada de duas formas distintas:

i Estimativa de probabilidade de ocorrência de um evento alvo, adotando um critério de convergência;

ii Estimativa de funções densidade, utilizando um número determinado (e fixo) de amostras.

Os trabalhos publicados em FPP recorrem à segunda forma de utilização de SMC. Determina-se um número de amostras, sorteia-se os parâmetros de entrada do algoritmo (a partir das funções de distribuições conhecidas para essas variáveis) e calcula-se os valores de saída. Ao término de toda a amostragem, tem-se uma estimativa para as funções de densidade para as variáveis de saída. Quanto maior o número de amostras escolhido, maior será a precisão da fdp resultante e, também, maior será o tempo dispendido pela SMC. 
Para estimativa de probabilidade de eventos, sorteia-se as variáveis de entrada, calcula-se o estado resultante e verifica-se sua adequação quanto ao evento estudado (por exemplo, se há ou não sobrecarga em uma determinada linha naquele estado amostrado). A simulação é interrompida quando a estimativa estiver dentro dos parâmetros adotados como critérios de convergência.

Ambas as formas de utilização são computacionalmente exigentes, o que influenciou diversos trabalhos para a criação de alternativas que visam manter o grau de precisão tido pela SMC, em um tempo menor. Para a primeira forma de utilização, surgiram as técnicas de redução de variância (variance reduction technique - VRT); para a segunda, métodos analíticos e aproximações.

Uma das VRT criadas é baseada no conceito de entropia cruzada ou Kullback-Leibler (Cross-Entropy - CE) [2,3]. Essa metodologia, aliada à SMC, já vem sendo amplamente utilizada em estudos na área elétrica, principalmente em confiabilidade de sistemas, com resultados expressivos na precisão das estimativas e redução do tempo exigido para a convergência da simulação.

Essa dissertação tem, como objetivo, propor a utilização de simulação Monte Carlo e entropia cruzada para estimativa de eventos de riscos (probabilidade e valor esperado condicional em relação à região normal de operação), relacionados a fluxo de potência Probabilístico. Utiliza-se a formulação matemática padrão (não linear) para as equações de fluxo de potência. Não se pretende, dessa forma, ter funções de densidade como resultado final, porém índices verdadeiramente utilizáveis para a tomada de decisão, com elevado grau de precisão e em tempo computacional reduzido. A proposição é justificada por sua potencial aplicabilidade na estimativa de risco de magnitude de tensão em barras fora da região nominal ou ramos com sobrecarga, ou outras métricas de qualidade de serviço convenientes.

Nesse capítulo é apresentado o desenvolvimento histórico do tema FPP, na Seção 1.2. Nela, são discutidas as metodologias de solução propostas e algumas aplicações publicadas em que se utiliza FPP como ferramenta chave. Aproveita-se para mostrar a evolução da aplicação de VRT, com destaque para o método da entropia cruzada em estudos de sistemas elétricos. Na Seção 1.3 é descrito como está estruturada essa dissertação. 


\section{2 \\ Desenvolvimento Histórico}

\subsection{1}

\section{Fluxo de Potência Probabilístico}

O tema fluxo de potência probabilístico (FPP) vem sido amplamente discutido, desde sua concepção por Borkowska [1]. As referências bibliográficas, publicadas até o ano de 1988, são analisadas em [5]. Já a referência [6] mapeia os trabalhos entre os anos de 1988 e 2008. Uma revisão de métodos de cálculos de fluxo de potência, aplicados a sistemas de distribuição, é feita em [7]. Nesse trabalho, estão incluídos os principais métodos de FPP e suas aplicações em distribuição. Para metodologias que levem em consideração a correlação entre as variáveis de entrada, pode-se verificar a referência [8].

Estes trabalhos são extensas revisões da literatura e dos principais aspectos e métodos atrelados a FPP. Dessa forma, essa seção tem, como intuito, a descrição dos conceitos mais importantes na área, bem com a evolução dos trabalhos e suas aplicações mais recentes.

Os métodos de resolução de FPP podem ser classificados dois tipos: (i) simulação (com especial atenção à SMC) e (ii) analíticos.

Em 1974, Allan, Borkowska e Grigg [9] propõem um modelo de solução baseado na operação de convolução das funções de probabilidade das variáveis de entrada. Como essa é uma metodologia computacionalmente exigente, foram estabelecidas as seguintes restrições:

- Fluxos dos ramos são linearmente relacionadas a potência nodal líquida e todas as magnitudes de tensão nodais são iguais;

- Fluxos de potência ativa e reativa são independentes entre si;

- O balanço de potência é restrito a uma barra (referência) e as perdas de potência do sistema são desconsideradas;

- A rede elétrica é considerada imutável.

Em 1975, Dopazzo, Klitin e Sasson [10] também publicam trabalho considerando propagação da incerteza das injeções nodais às variáveis de saída de fluxo de potência, em um método nominado fluxo de potência estocástico, cujo princípio se assemelha ao proposto por Borkowska [1]

As restrições assumidas são equivalentes a utilização de um fluxo de potência linear. Essas mesmas considerações são utilizadas em 1976, quando Allan, Grigg e Al-Shakarchi propõem a utilização de Transformada de Laplace para a resolução das operações de convolução necessárias [11]. 
Em 1981, Allan, Leite da Silva e Burchett propõem a utilização de Transformada Rápida de Fourier (Fast Fourier Transform - FFT) e a linearização das equações de fluxo de potência, com intuito de se aproveitar de características exponenciais das fdp de entrada para realizar, de maneira mais rápida, a convolução dessas funções [12]. Ainda nesse ano, Allan e Leite da Silva descrevem um método de solução analítica através da combinação de duas etapas: (i) linearização das equações de fluxo de potência em pontos distintos e (ii) convolução das fdp de entrada em cada região linearizada [13]. Após, combina-se o conjunto de fdp para fornecer a representação final da distribuição da variável de saída desejada. Em ambos os trabalhos, os resultados são comparadas com os obtidos através de SMC.

Em 1985, Brucoli, Torelli e Napoli incluíram o termo de segunda ordem da expansão por Séries de Taylor das equações de fluxo de potência [14]. Porém, o termo não linear da expansão é substituído pelo termo de primeira ordem de sua própria expansão. Concluiu-se que a adição de uma ordem não agrega valor expressivo aos resultados calculados para os momentos das fdp, exceto em condições de elevados carregamento e variabilidade de demanda [14].

Também em 1985, Leite da Silva, Allan, Soares e Arienti [15] publicam trabalho, no qual a topologia da rede é considerada como uma variável aleatória. As incertezas levam em consideração a disponibilidade de componentes que são sujeitos a falhas e manutenção programada. A solução propõe que as fdp de estado do sistema e demais saídas de fluxo de potência sejam obtidas através de uma soma ponderada de densidades, avaliadas para cada topologia possível.

Leite da Silva e Arienti, em 1990, propõem a combinação de SMC e equações de fluxo de potência multilinearizadas [16]. O algoritmo utiliza um critério baseado na demanda total de potência ativa do sistema para determinar os pontos de linearização. Ainda nesse ano, Leite da Silva, Ribeiro, Arienti, Allan e Coutto Filho utilizam FPP como uma ferramenta de análise de alternativas de expansão de um sistema elétrico [17].

Em 1998, FPP, com SMC, foi aplicado a estudos em sistemas de distribuição, avaliando impacto da inserção de geração eólica. Jorgensen, Christensen e Tande tinham como objetivo mensurar o número de horas que um sistema de distribuição estaria exposto à sobretensão em um ano [18].

Zhang e Lee, em 2004, propõem a combinação de cumulantes estatísticos e expansão por Gram-Charlier [19]. O objetivo é utilizar séries Gram-Charlier para expressar as fdp e funções de distribuição acumulada (fda) das variáveis de qualquer tipo como uma soma ponderada de distribuições normais em diferentes ordem de derivada. O trabalho adota, também, fluxo de potência 
linear. Os resultados necessitam ser comparados com os obtidos através de SMC para garantir que a ordem selecionada possibilite a precisão das curvas encontradas.

A versão probabilística de fluxo de potência também foi utilizada em planejamento de estratégias de controle de tensão. Hatziargyriou, Karakatsanis e Lorentzou, em 2005, publicam trabalho em que utilizam FPP a fim de determinar violações de restrições de tensão, bem como as suas probabilidades [20]. Para isso, utilizam convolução com FFT.

$\mathrm{Su}$, em 2005, propõe a utilização de point estimate method [21]. Para um sistema com $m$ parâmetros incertos, foi dado como necessários $2 m$ cálculos de fluxo de potência para a estimação dos momentos estatísticos das variáveis de saída. Além de utilizar distribuições para a geração e demanda, o trabalho inclui a possibilidade de variação nos parâmetros de linhas, como a impedância. Outra vantagem do método é permitir a utilização das equações originais de fluxo. Point estimate method também foi a metodologia utilizada por Morales e Pérez-Ruiz, em 2007, alterando o número de cálculos de fluxo de potência necessários para $2 m+1$ [22]. Novamente, resultados necessitam ser comparados com os obtidos através de SMC, para garantir a correta utilização dos parâmetros necessários ao método.

Min, Lee, Zhang, Rose e Cole, em 2008, exploram a SMC como ferramenta de FPP, a fim de realizar a previsão de congestionamento de transmissão no curto prazo [23]. Ainda em 2008, flutuações de tensão, como consequência da integração de fazendas eólicas, são estudas em [24]. Este trabalho utiliza equações linearizadas e cumulantes estatísticos.

Yu, Chung, Wong, Lee e Zhang, em 2009, publicaram trabalho em que a utilização de Amostragem por Hipercubo Latino (AHL), combinada com decomposição pelo método de Cholesky, inseridas em contexto de simulação de Monte Carlo, a fim de resolver problemas em FPP [25]. Já, em [26], utiliza-se Transformação Nataf combinado com AHL.

Ainda visando garantir precisão, ao mesmo tempo em que reduz o fardo computacional, um novo método foi proposto por Oke, Thomas, Asher e Menezes, em 2011 [27]: unscented transform. Uma versão baseada em quadratura Gaussiana é utilizada para determinar os pontos e pesos para os quais as equações não lineares de FPP serão resolvidas. A função de distribuição de saída é estimada utilizando expansão por Cornish-Fisher. O mesmo método foi utilizado em [28].

Tang, Ni, Ponci e Monti introduzem, em 2016, um método cujo objetivo é ser adotado em problemas de elevada dimensão de incerteza: dimensionadaptive sparse grid interpolation (DASGI) [29]. Em termos técnicos, essa é 
uma metodologia por métodos aproximados, porém, próxima à SMC.

Recentemente, FPP também tem sido aplicado a problemas de gerenciamento de emissões de carbono [30]; controle de potência reativa em sistemas de distribuição [31]; previsão de condições de falha em eventos cascata [32]; operação e planejamento da expansão de microredes [33], levando em consideração a inserção de fontes renováveis; análise de cenários de carregamento de carros elétricos [34].

\subsection{2}

\section{Aplicação de Entropia Cruzada em Sistemas Elétricos de Energia}

A avaliação de sistemas elétricos de energia sob o ponto de vista do risco de sua operação (não ser capaz de entregar a energia à demanda, ou fazê-lo fora das margens de segurança dos equipamentos) é uma necessidade em etapa de planejamento da expansão ou da operação. Avalia-se diversos pontos de operação (ou estados) viáveis (ditos, pertencentes ao espaço de estados) de ocorrerem e contingências possíveis nesses pontos, tendo ao final uma perspectiva geral do grau de confiabilidade do sistema.

A análise probabilística de sistemas de potência é fonte de diversos trabalhos no setor [35] e SMC é uma ferramenta rotineira para essa tarefa devido a elevada precisão dos resultados obtidos, bem como sua flexibilidade $[2,4]$. A principal desvantagem em se utilizar SMC é sua elevada exigência computacional. Em linhas gerais, a metodologia realiza um abrangente mapeamento do espaço de estados operativos do sistema elétrico estudado, através de sorteios. Para cada estado amostrado, avalia-se o que se requer. Por exemplo:

- Há geração suficiente para atendimento à demanda?

- Há estrutura de transmissão capaz de transferir energia a todos os pontos de carga?

- Há sobrecarga em elementos de transmissão?

- Os níveis de tensão dos barramentos são adequados?

Quando o objetivo é específico, como responder a "qual a probabilidade da geração ser insuficiente frente à demanda?", precisa-se ter um critério de convergência que permita garantir a precisão da resposta, bem como interromper a simulação, pois seu avanço não melhoraria a "qualidade" do resultado (utilização (i) de SMC - Ver Seção 1.1).

Pode-se também não ter um alvo definido, para o qual se deseja avaliar risco, mas propagar a incerteza associada às variáveis de entrada para as de saída, em forma de curva de densidade de probabilidade. Por exemplo, 
diversos trabalhos em FPP visam obter histogramas de fluxos de potência em determinados ramos (utilização (ii) de SMC - Ver Seção 1.1).

Em ambos os casos, há elevada exigência computacional. Diversas metodologias, conhecidas como técnicas de redução de variância (variance reduction technique - VRT), com objetivo de acelerar a convergência de SMC (quando existe algum evento alvo e critério de parada) foram desenvolvidas [2, 3].

Uma metodologia de VRT, conhecida por regressão generalizada, e suas aplicações aos estudos de confiabilidade composta de sistemas elétricos são apresentados em [36]. VRT baseadas em variáveis de controle e variáveis antitéticas, combinadas com SMC, foram utilizadas em avaliação de confiabilidade de sistemas elétricos [37, 38]. Em 1999, Lieber, Nemirovskii e Rubinstein utilizaram uma VRT baseada em amostragem por importância (importance sampling - IS) para acelerar a convergência da simulação [39]. Pretende-se, nesse caso, reduzir a variância do processo de amostragem de tal forma que os eventos pretendidos sejam amostrados com maior frequência.

Dentre as VRT, com IS, uma destaca-se pela precisão de seus resultados, flexibilidade de utilização e redução do fardo computacional inerente a SMC: entropia cruzada (cross-entropy - CE). Em 2002, Homem-de-Mello e Rubinstein publicam uma metodologia adaptativa, em dois estágios, baseada em IS e função de Kullback-Liebler (conhecida como CE) [40]. Especificamente, o primeiro estágio realizaria um problema de otimização matemática, cujo resultado seriam parâmetros-chave das distribuições de entrada do processo estocástico estudado. O segundo estágio seria utilizar as novas distribuições, compensadas por funções de verosimilhança, para estimação da probabilidade do evento alvo.

As principais características de Monte Carlo, bem como VRT e, enfaticamente, Entropia Cruzada, são abordadas em livro, publicado em 2004 [2]. Também nesse ano, um livro focado exclusivamente em CE foi publicado [3].

As primeiras aplicações de CE em problemas relacionados a sistemas de potência foram publicadas em 2007 e 2008. Em [41], problemas de despacho são objetos de estudos. Já, em [42], é discutida uma abordagem geral para estimação de eventos raros em sistemas de potência.

Em 2010, Leite da Silva, Fernández e Singh apresentam uma metodologia cujo objetivo é reduzir o tempo de computação necessário para cálculo de índices de confiabilidade (LOLP, LOLF, EPNS), através de SMC e CE [43]. A indisponibilidade dos geradores é distorcida para parâmetros ótimos (ou quase ótimos, pois não se garante ótimo global nesse caso) que tornam o sorteio de estados de falha (nos quais não há geração suficiente) mais frequente, acelerando a convergência de SMC. Compara-se o método analítico (baseado 
em convolução [44]), SMC convencional e o SMC baseado em CE, com claro destaque para a utilização da Entropia Cruzada.

Leite da Silva e Fernández utilizam SMC Cronológico com CE para estimação de índices de confiabilidade [45]. Faz-se isso distorcendo a taxa de falha dos geradores, a fim de tornar eventos raros mais frequentes.

Em 2013, Carvalho, Fernández, Leite da Silva, Rosa e Miranda apresentam um novo algoritmo para estimação dos parâmetros para distribuição de probabilidade ótima [46]. O método proposto é a combinação de CE com ferramentas analíticas padrão em resolução de problemas de confiabilidade de capacidade de geração.

A integração da rede de transmissão para avaliação da confiabilidade de sistemas elétricos, com a combinação de SMC e CE é feita em [47].

A avaliação do impacto da inserção de fontes renováveis na confiabilidade de uma rede elétrica composta (geração e transmissão), utilizando SMC e CE é feita em [48].

Em 2016, Leite da Silva, Castro e Fernández propõem uma metodologia, baseada em SMC e CE, de avaliação de requisitos para reserva girante, levando em consideração o risco de perda de carga devido a falhas de geração e transmissão [49].

\section{3 \\ Estrutura da Dissertação}

O objetivo dessa dissertação é propor uma metodologia baseada em Simulação Monte Carlo e Entropia Cruzada, que permita estimativa, em tempo computacional reduzido, de índices de probabilidade e valor esperado condicional para eventos de risco (como sobrecargas em linhas e sub ou sobretensão em barramentos) em sistemas elétricos.

No Capítulo 2, é realizada a formulação matemática padrão de um problema de FPP, independentemente do método de solução. Descreve-se, também, algumas das técnicas utilizadas atualmente para a geração das fdp para as variáveis de saída do algoritmo de fluxo de potência. Os métodos analíticos e de simulação (SMC) serão discutidos para que se tenha embasamento que justifique a adoção de SMC com ferramenta básica na dissertação. As limitações dos métodos analíticos e suas vantagens são exploradas, bem como é analisada toda a flexibilidade permitida pela SMC (e sua principal - talvez única - desvantagem, o esforço computacional). Também, nesse capítulo, darse-á ênfase a exposição das variações de utilização de SMC em problemas de FPP. São discutidas também as funções estratégias para corte de carga, por insuficiência de geração, e despacho de geradores adotadas nessa dissertação. 
Apresenta-se no capítulo um algoritmo de SMC para estimativa de eventos de risco ilustrativo.

Por se tratar de estimativa de eventos de risco, sendo que não se sabe a priori o grau de raridade do evento estudado, a utilização de SMC pode acarretar em um número elevado de amostras, até que a estimativa possua grau de confiança dentro do padrão estipulado. As VRT são abordagens que alteram as distribuições de entrada originais de tal forma que os eventos alvo sejam mais frequentemente amostrados (com a devida compensação matemática). O Capítulo 3 tem como objetivo a discussão de opções de VRT com destaque para o Método da Entropia Cruzada (CE). A reformulação do problema, para combinação de SMC e CE, é apresentada nesse capítulo.

A estrutura da rotina proposta e as condições de simulação são apresentadas no Capítulo 4. São estudados os sistemas IEEE 14 Barras, IEEE RTS 79 e IEEE 118 Barras para apresentação do desempenho comparativo da metodologia proposta frente a SMC sem CE.

As conclusões, considerações finais e as propostas para trabalhos futuros são descritos no Capítulo 5. 


\section{2}

\section{Técnicas de Fluxo de Potência Probabilístico}

\section{1}

\section{Introdução}

Em planejamento e operação de sistemas de potência, é necessário realizar estudos de fluxo de potência para determinar e monitorar a segurança de um sistema proposto [9]. Para sua utilização, precisa-se especificar valores para a geração de cada unidade e os patamares de carga, bem como considerar a rede elétrica constante. Sabe-se, porém, que a capacidade disponível de geração e a carga requerida em cada ponto são variáveis aleatórias (considerando-as constante em um período pequeno de tempo), regidas por funções de probabilidade contínuas ou discretas. Para expandir a avaliação com o algoritmo de fluxo de potência, diversos cálculos eram realizados utilizando-se os valores médios, os extremos e alguns valores intermediários que pudessem ser assumidos pelas variáveis a serem especificadas. Essa metodologia não pode garantir um exame adequado da segurança do sistema [9]. Além disso, apesar da grande acurácia dos cálculos determinísticos, os resultados são somente tão acurados quanto os dados de entrada. [9].

A técnica de fluxo de potência probabilístico (FPP) visa extrapolar a capacidade do algoritmo de fluxo de potência para o mapeamento de toda a zona de operação viável (ao menos da parte mais significativa). Ganha-se sensibilidade maior na avaliação dos resultados, visto que regiões de operação anormal (como linhas com sobrecarga e barras com sub ou sobretensão) são mais claramente examinadas. É possível, assim, estimar o risco de o sistema funcionar fora de suas condições operativas nominais.

Em 1974, o primeiro trabalho na área foi publicado por Borkowska [1], no qual se discute a importância e os ganhos em se propagar a incerteza das variáveis de entrada do fluxo de potência para as variáveis de saída, o estado operativo e fluxos nos ramos. Desde esse trabalho, houve progressiva evolução do interesse pelo tema, com reforço crescente nos últimos anos devido a massiva inserção de fontes intermitentes. Discutiu-se nesse anos as diversas aplicações para FPP, mas, com mais intensidade, potenciais metodologias que permitissem sua resolução com precisão e em tempo computacional reduzido. 
O métodos de solução são classificados em dois tipos: analíticos e de simulação (como simulação Monte Carlo).

Métodos análitcos se caracterizam por procedimento aritméticos, como convolução, aplicados as funções de probabilidade das variáveis de entrada [6]. Surgem duas principais complicações: as equações de fluxo de potência são não lineares e podem existir variáveis de entrada correlacionadas. Algumas simplificações são usuais quando se trabalha com métodos analíticos [6]:

- Linearização das equações de fluxo de potência;

- Variáveis de entrada independentes ou linearmente correlacionadas;

- Variáveis de entrada regidas por distribuições normais ou discreta;

- A rede elétrica (e seus parâmetros) é mantida constante.

Em geral, esses métodos conseguem realizar a estimativa das distribuições das variáveis de saída em tempos computacionais reduzidos (quando comparados aos métodos de simulação), porém suas simplificações limitam a sua aplicabilidade e seus resultados necessitam ser comparados com métodos de simulação para que se averigue a precisão.

Métodos de simulação, com especial atenção a simulação Monte Carlo (SMC), requerem normalmente tempo computacional maior do que o exigido pelos métodos analíticos. Porém, permitem enorme flexibilidade de utilização e removem a exigência de simplificações. Pode-se adotar as equações não lineares originais, bem como simular metodologias de operação usuais a sistemas de potência, como função despacho de geração e corte de carga. Além disso, as variáveis de entrada podem seguir qualquer distribuição cuja lei é conhecida (como normal e binomial) ou não. Sucintamente, SMC avalia o processo estocástico estudado amostrando, por sorteio, as variáveis de entrada e simulando a resposta do sistema a esse estado específico. Os resultados vão sendo reservados conforme a estratégia adotada para a SMC.

Esse capítulo discute a formulação matemática do problema de fluxo de potência probabilístico na Seção 2.2 e os principais métodos de solução: analíticos, na Seção 2.3, e de simulação, na Seção 2.4. Por fim, os comentários finais e as conclusões referentes a problematização e estratégias de solução são apresentadas na Seção 2.5. 


\section{2}

\section{Formulação do Problema}

O problema padrão de fluxo de potência pode ser dado pelo seguinte conjunto de equações [12]:

$$
\begin{aligned}
& \mathbf{Y}=f(\mathbf{X}) \\
& \mathbf{Z}=g(\mathbf{X})
\end{aligned}
$$

onde, para um sistema com $n$ barras, se define $\mathbf{Y}$ como o vetor de injeções de potência ativa e reativa (com dimensão $n \times 1$ ), sendo a variável de entrada do algoritmo, $\mathbf{X}$ é o vetor de estado (magnitudes e ângulos de tensões, com dimensão $2 n \times 1$ ) e $\mathbf{Z}$ é vetor de saída fluxos de potência (conjunto de $m$ variáveis de interesse que possam se calculadas a partir do estado $\mathbf{X}$, como fluxo nos ramos e perdas - dimensão $m \times 1$ ). As variáveis $\mathbf{X}$ e $\mathbf{Z}$ são calculadas pelo algoritmo e as funções $f$ e $g$ são intrinsecamente não lineares.

Em FPP, a variável de entrada $\mathbf{Y}$ é regida por um conjunto de funções de probabilidade, que podem ser contínuas ou discretas. Quando se estuda os impactos de diferentes topologias de rede (contigências na rede de transmissão) e variações nos parâmetros elétricos dos ramos, acrescenta-se às funções $f$ e $g$ variáveis aleatórias relacionadas a esse tipo de análise [15]. Assim, as variáveis de saída não podem mais ser representadas por valores singulares, mas por funções de probabilidade que deverão ser estimadas. Ao final, tem-se distribuições tanto para o estado $\mathbf{X}$, quanto para variáveis diversas de saída $\mathrm{Z}$.

As incertezas das variáveis de entrada podem ser consideradas fixas (distribuições fixas) ou variarem ao longo do tempo. No caso dos estudos dessa dissertação, sempre serão consideradas as incertezas como constante, o que significa uma janela fixa de tempo estudado (não se considera evolução temporal). Além disso, as distribuições são consideradas conhecidas, contínuas ou discretas, mesmo que não possuam uma lei de regência (como a normal ou binomial).

As dificuldades inerentes ao problema de FPP são duas: a não linearidade das funções de fluxo de potência e a escala do sistema (que varia de acordo com o sistema elétrico estudado e o número de variáveis aleatórias consideradas). As metodologias de resolução de FPP levam em consideração a exigência computacional e a precisão de seus resultados. Métodos analíticos recorrem a simplificações (como linearização das equações) para reduzir o tempo de 
computação, ao passo que métodos de simulação possuem enorme flexibilidade e precisão, ao mesmo tempo requerem grande esforço computacional.

\section{3}

\section{Métodos Analíticos}

Métodos analíticos usados em FPP são metodologias que visam primeiramente estimar os momentos estatísticos (com particular interesse na média e desvio padrão) e a curva de densidade de probabilidade para os fluxos dos ramos. O tempo computacional e a qualidade (precisão) dos resultados estimados são sempre duas variáveis importantes nas comparações entre os métodos desenvolvidos ao longo dos anos.

Alguns métodos para esse fim foram elaborados e alguns serão discutidos nessa seção. Esses, porém, possuem semelhanças: exigem simplificações (por exemplo, utiliza-se fluxo linearizado na maioria dos métodos) e possuem limitações (não permitem estratégias operativas, como função despacho e corte de carga).

\subsection{1}

\section{Convolução de Distribuições de Entrada}

Seja então um problema definido pelo conjunto de equações 2.1. Considere-se $\overline{\mathbf{X}}, \overline{\mathbf{Y}}$ e $\overline{\mathbf{Z}}$ como os valores esperados para as distribuições de vetores de estado, injeções nodais e fluxos nos ramos, respectivamente. Suponha, então, uma solução determinística para o fluxo de potência (dado pelo conjunto de equações 2.1), no qual se considera injeções de entrada $\overline{\mathbf{Y}}$. A solução será dada por [12]:

$$
\begin{aligned}
\overline{\mathbf{Y}} & =f(\hat{\mathbf{X}}) \\
\hat{\mathbf{Z}} & =g(\hat{\mathbf{X}})
\end{aligned}
$$

As soluções $\hat{\mathbf{X}}$ e $\hat{\mathbf{Z}}$ para o vetor de estado e fluxo nos ramos são aproximações de $\overline{\mathbf{X}}$ e $\overline{\mathbf{Z}}$, respectivamente. Devido às não linearidades intrínsecas ao problema de fluxo de potência, a solução para a média da variável de entrada não é a média das variáveis de saída.

Linearizando as equações $f$ e $g$ (definidas na equação 2.1), em torno dos pontos $(\hat{\mathbf{X}}, \overline{\mathbf{Y}})$ e $(\hat{\mathbf{X}}, \hat{\mathbf{Z}})$, respectivamente, tem-se: 


$$
\begin{aligned}
\mathbf{X} & \approx \hat{\mathbf{X}}+\mathbf{A} \cdot \Delta \mathbf{Y} \\
\mathbf{Z} & \approx \hat{\mathbf{Z}}+\mathbf{B} \cdot \Delta \mathbf{Y}
\end{aligned}
$$

onde:

$$
\begin{aligned}
\mathbf{A} & =\left[\left.\frac{\partial f}{\partial \mathbf{X}}\right|_{\mathbf{X}=\hat{\mathbf{X}}}\right]^{-1} \\
\mathbf{B} & =\left[\left.\frac{\partial g}{\partial \mathbf{X}}\right|_{\mathbf{X}=\hat{\mathbf{X}}}\right] \cdot \mathbf{A} \\
\Delta \mathbf{Y} & =\mathbf{Y}-\overline{\mathbf{Y}}
\end{aligned}
$$

As equações 2.3 ilustram que cada elemento aleatório dos vetores $\mathbf{X}$ e $\mathbf{Z}$ pode ser calculado através de uma "soma" ponderada de elementos do vetor $\Delta \mathrm{Y}[12]$. Essa soma de variáveis aleatórias (assumidas como independentes) pode ser realizada através de convolução matemática [11]. Para se resolver essa etapa, alguns trabalhos realizam a convolução de funções contínuas e discretas separadamente, constituindo dois equivalentes. A seguir, realiza-se a convolução dos equivalentes [11].

A convolução de distribuições discretas requer maior esforço computacional. Considerando duas distribuições discretas, uma com $r$ impulsos e outra com $s$ impulsos, tem-se, como resultado da convolução, uma distribuição com $r \times s$ impulsos. Quanto maior o número de impulsos por distribuição e maior o número de distribuições, maior será o número de cálculos necessários e memória computacional dispendida.

A convolução, ao menos, é uma abordagem matemática consolidada. Além disso, algumas alternativas foram criadas para realizar esse procedimento. Em [11], foi utilizada a Transformada de Laplace, enquanto, em [12], utilizou-se Transformada Rápida de Fourier.

Por considerar a linearização em torno das aproximações dos pontos médios, as curvas de densidade estimadas perdem precisão quando se afastam desses pontos. Em outras palavras, as "caudas" das distribuições, regiões consideradas para cálculos de índices de risco, possuem qualidade comprometida. Em [13] foi proposto a definição de uma região de operação provável para as variáveis de saída, através de um algoritmo chamado boundary load flow, e dentro 
dessa região são determinados diversos pontos utilizados para a linearização. Após essa etapa, realiza-se o procedimento de convolução para em todas as regiões linearizadas criadas. Aumenta-se, assim, a aderência do resultado frente as características não-lineares das equações de fluxo de potência.

\subsection{2}

\section{Cumulantes Estatísticos e Gram-Charlier}

A exigência de um número elevado de cálculos e requisitos de memória por técnicas que envolvem convolução matemática das distribuições de entrada motivou a publicação do trabalho [19]. Nesse artigo, a convolução é substituída por um processo aritmético simples baseado em cumulantes e expansão por Gram-Charlier. Ainda é necessário utilizar as mesmas simplificações exigidas na modelagem por convolução. Em outras palavras, adota-se fluxo linear convencional. O objetivo principal continua sendo estimar as curvas de distribuição de probabilidade, com a vantagem de se obter simultaneamente as curvas de probabilidade acumulada.

Cumulantes são parâmetros alternativos aos momento estatísticos de uma determinada distribuição. Existe uma relação próxima entre ambos: o primeiro cumulante de uma distribuição é a própria média (primeiro momento) e o segundo é a variância (segundo momento). A partir do cumulante de quarta ordem existe diferença entre ambos.

O trabalho estima os momentos após a obtenção dos cumulantes. Com os momentos de cada fluxo de ramo definidos, utiliza-se Gram-Charlier para obter as curvas de distribuição de probabilidade e probabilidade acumulada. A ordem da expansão é um parâmetro a ser definido na simulação e afeta diretamente a precisão dos resultados. Estes necessitam ser comparados com SMC, para verificar qual ordem gera boa precisão em tempo computacional reduzido. Portanto, a vantagem adquirida se perde ao passo que é necessário confirmar a qualidade da sintonia dos parâmetros, utilizando SMC.

\subsection{3}

\section{Point Estimate Method}

Métodos baseados em convolução e cumulantes requerem uso de equações linearizadas para fluxo de potência. Assim, uma vantagem clara de Point Estimate Method desenvolvido em [21] é a possibilidade de se utilizar as equações originais. O trabalho adota um método de estimação de dois pontos das distribuições (média e variância) e pode ser utilizado para estimar momentos estatísticos de variáveis aleatórias que são funções de uma ou mais variáveis aleatórias. Em um sistema com $m$ parâmetros incertos, são considerados $2 m$ 
cálculos de fluxo de potência para estimar os momento das distribuições dos fluxos nos ramos, ponderando os valores das distribuições em dois pontos.

Esse método mostra algumas outras vantagens de aplicação em relação aos dois anteriores: é possível estimar momentos estatísticos para os estados do sistema (magnitude e ângulo de tensão), além dos fluxos dos ramos, e condições da rede elétrica podem ser parâmetros aleatórios (como resistência e reatância de ramos). Os resultados, porém, ainda são comparados com SMC (utilizandose 5000 amostras).

Os estudos com Point Estimate Method são aprofundados em [22] e é mostrado que o desempenho, quando o número de entradas aleatórias é grande, é aprimorado utilizando-se $2 m+1$ cálculos. Resultados similares são provenientes de estudos com $4 m+1$, porém exigindo maior fardo computacional. Conclui-se que o esquema com $2 m$ cálculos é inapropriado para sistemas de larga escala, com elevado número de variáveis aleatórias a serem consideradas.

\section{4}

\section{Métodos de Simulação Monte Carlo}

Classificada com uma metodologia numérica, a Simulação Monte Carlo (SMC) é uma ferramenta poderosa quando se trata de estudos de processos estocásticos. Caracteriza-se por sua enorme flexibilidade, podendo representar as mais diversas e complexas particularidades do sistema em trabalho e sem requisitar aproximações. Em FPP, torna-se especialmente relevante por permitir trabalhar com as equações não lineares originais de fluxo de potência. Outras estratégias operativas usuais a sistemas de potência, como função despacho de geração, corte de carga e redespacho podem ser inseridas no estudo, aumentado a qualidade representativa dos resultados.

A SMC baseia-se no mapeamento do espaço de estados probabilísticos que podem ser assumidos pelo sistema através de sorteio das variáveis de entrada, cuja distribuição se sabe a priori (não necessariamente se conhece a lei que rege a distribuição). Com posse dos dados amostrados, realiza-se a simulação e cálculos que representem o comportamento do sistema frente àquela amostra. No caso de FPP, realiza-se o cálculo de fluxo de potência para os dados de geração e carga sorteados.

Duas formas de utilização de SMC são adequadas quando aplicada a problemas de FPP:

i Estimativa de risco (probabilidade de ocorrência) para eventos alvo, adotando critério de parada por convergência. 
ii Geração de distribuições para as variáveis de saída, a partir de um número fixo de amostras (sorteios das variáveis de entrada).

Ambas as estratégias possuem o mesmo princípio básico, porém diferem no que se pretende com cada uma delas. A primeira visa a estimativa de probabilidade de ocorrência de algum evento alvo, por exemplo sobrecarga em uma determinada linha ou subtensão em um determinada barra. Não se pretende, nesse caso, estimar a distribuição completa, mas somente a área (probabilidade) da região alvo predeterminada. Para garantir a precisão do resultado, adota-se, como critério de parada, um determinado valor para a convergência da estimativa. A segunda estratégia visa gerar as distribuições das variáveis de saída, sem que se garanta a precisão ponto-a-ponto da distribuição. Nesse caso, normalmente as "caudas" das distribuições são as regiões com menor precisão.

Em ambos os casos, tem-se enorme flexibilidade quanto às condições de simulação. Pode-se utilizar as equações não lineares, haver correlação entre as variáveis de entrada e variação da rede elétrica e seus parâmetros. As simplificações são pautadas a cada escopo de estudo e visam, primordialmente, reduzir a exigência computacional.

Uma possível simplificação ao se adotar SMC é a linearização das equações de fluxo. A resolução de um conjunto de equações não lineares dispende de métodos iterativos, como Newton-Raphson. Isso significa que, para cada amostra realizada no sorteio de SMC, um procedimento iterativo se sucederá, cuja convergência pode ou não ocorrer dentro dos critérios estipulados. Assim, optar por utilizar as equações linearizadas reduz significativamente a exigência computacional, por estado amostrado. Comumente, a linearização é realizada nos pontos médios das distribuições.

Uma evolução da adoção de equações linearizadas é a multilinearização, combinada com SMC, proposta em [16]. São escolhidos diversos pontos de linearização, não só a média das distribuições, criando diferentes equações de fluxo para cada região operativa escolhida em uma pré-simulação. Essa estratégia é um exemplo da utilização (ii) de SMC, visando a criação de distribuições das variáveis de saída.

Por fim, a total flexibilidade de SMC permite que nenhuma simplificação de equações seja realizada e, inclusive, regras operativas como função despacho e corte de carga sejam incluídas na simulação. Evidentemente, quanto maior a fidelidade da rotina criada ao sistema estudado, maior será a exigência computacional do programa desenvolvido.

Foi discutido até aqui a variante Não-Cronológica ou Não-Sequencial de SMC. Existe, ainda, a variante cronológica da SMC, utilizada para sistemas 
com fator tempo preponderante. Sua utilização pode ser coerente em estudos de FPP quando se pretende modelar a variação das incertezas de geração e carga ao longo do tempo. Certamente, aumentar-se-ia muito a exigência computacional. No caso dos estudos dessa dissertação, sempre que se utilizar o termo SMC, refere-se a SMC Não-Sequencial.

\subsection{1}

\section{Estimativa de Evento de Risco em Fluxo de Potência Probabilístico}

Fluxo de potência probabilístico, via SMC, pode ser entendido com uma ferramenta importante na fase de planejamento da expensão ou da operação, quando se necessita ter uma estimativa de risco precisa para ser tomada uma decisão. As distribuições estimadas para a saída não costumam ser utilizadas para esse fim, visto que se pretende exatamente a probabilidade de ocorrência de determinado estado operativo (como sobrecarga em determinada linha) com a máxima precisão. Os métodos que visam retornar distribuições não possuem garantia de precisão nas "caudas" das distribuições, regiões cuja área pretendese avaliar. A proposta dessa dissertação é, exatamente, abordar a utilização de SMC como estratégia de estimativa de evento de risco em aplicações de FPP.

Considere, por exemplo, que o fluxo aparente em um ramo da rede é dado pela variável aleatória $S(\mathbf{Y})$, onde $\mathbf{Y}$ é o vetor aleatório de injeções de potência (variável de entrada do fluxo de potência). Pretende-se estimar a probabilidade de ocorrência de sobrecarga nesse ramo, sendo que se conhece o limite térmico da linha $S_{\text {limite. Assim, busca-se saber: }}$

$$
l=P\left[S(\mathbf{Y}) \geq S_{\text {limite }}\right]
$$

A estimativa $\hat{l}$ pode ser encontrada via SMC por meio da equação:

$$
\hat{l}=\hat{E}[H]=\frac{\sum_{i=1}^{N} H\left(\mathbf{Y}_{\mathbf{i}}\right)}{N}
$$

onde $N$ é o número de amostras, $i$ é o índice de um estado amostrado e $H(\mathbf{Y})$ é a função teste dada por:

$$
H(\mathbf{Y})= \begin{cases}1 & , \text { se } S(\mathbf{Y}) \geq S_{\text {limite }} \\ 0 & , \text { caso contrário }\end{cases}
$$


A incerteza da estimativa é dada pela variância do estimador, representado por

$$
\operatorname{Var}(\hat{E}[H])=\frac{V(H)}{N}
$$

Para garantir a qualidade da estimativa, adota-se, como critério de parada, o coeficiente de variação $\beta$, dado por:

$$
\beta=\frac{\sqrt{\operatorname{Var}(\hat{E}[H])}}{\hat{l}}
$$

Assim, a SMC somente é interrompida quando a estimativa para $\hat{l}$ está dentro de um intervalo pré estabelecido, como 1\%. Quanto mais raro o evento que se pretende estimar, maior será o número de amostras necessárias para a convergência e, por consequência, maior será o tempo computacional exigido para a tarefa. Não se sabe, porém, o grau de raridade do evento a priori ou se a probabilidade de ocorrência é considerada preocupante (probabilidade muito pequenas podem não levantar interesse por ações corretivas). Sempre é necessário a estimativa precisa advinda da SMC.

Também se pode com SMC, sendo objeto dessa dissertação, realizar a estimativa do valor esperado condicional para a região normal de operação. Faz-se um paralelo com o índice EPNS (Expected Power Not Supplied) que mede a potência média não suprida à carga em um determinado sistema elétrico [4]. A alteração, em comparação a estimativa da probabilidade, se dá na função teste. Define-se, nesse caso, a seguinte função:

$$
H_{\mathrm{VEC}}(\mathbf{Y})= \begin{cases}S(\mathbf{Y})-S_{\text {limite }} & , \text { se } S(\mathbf{Y}) \geq S_{\text {limite }} \\ 0 & , \text { caso contrário }\end{cases}
$$

Ao final do procedimento, tem-se, por exemplo, o nível esperado de sobrecarga (além do valor limite). Esse pode ser um índice útil para medir a severidade do risco analisado.

Assim, a principal desvantagem da utilização de SMC para problemas de estimação de eventos de risco em FPP decorre de sua elevada exigência computacional, principalmente frente a eventos raros. Esforços no tanger das VRT visam exatamente a redução do número de amostras necessárias para a convergência da simulação e, assim, redução do tempo de computação. Essas 
técnicas, bem como o método da entropia cruzada, utilizada nessa dissertação, serão discutidas no Capítulo 3.

\subsubsection{1}

\section{Corte de Carga por Insuficiência de Geração}

A principal finalidade de um sistema elétrico é ser capaz de transferir energia das estações de geração aos pontos de carga, com qualidade e segurança. Porém, não há sistema de engenharia que possua confiabilidade total e irrestrita. Equipamentos são passíveis de falha ou devem ser retirados de operação para manutenção programada. Isso significa que existem condições viáveis de ocorrer, nas quais não é possível cumprir, na totalidade, os objetivos pré-programados.

Realizar corte de carga é um procedimento necessário quando não há geração suficiente para atendimento total da demanda ou compensação das perdas nos circuitos elétricos. Dentre outras consequências, um sistema com desbalanço entre geração e carga sofre com queda progressiva da frequência, até que seja retomado o equilíbrio (mesmo que não seja o ponto de equilíbrio operativo inicial).

Corta-se carga para que seja possível atender parcela da demanda sem queda mensurável de qualidade de atendimento a esses pontos de consumo. Nessa dissertação, considera-se duas condições para realizar corte de carga (importante ressaltar que qualquer outro critério poderia ser utilizado):

1. Capacidade total de geração disponível é insuficiente para atendimento à carga amostrada. Essa condição independe da rede de transmissão e é verificada tão logo quanto o sorteio da amostra.

2. Exigência por geração de máquinas de barra swing além da capacidade. Essa condição é posterior a uma análise com fluxo de potência, no qual se determina as injeções ativa e reativa na barra swing. Caso os valores calculados sejam superiores a capacidade das máquinas significa que existe insuficiência de geração, devido a necessidade de se compensar as perdas elétricas dos circuitos ou atender parcela da carga.

Quando necessário o corte de carga, será considerada uma redução macro, em todas os pontos de carga proporcionalmente. Assim, seja $L$ a carga total amostrada, $G$ a capacidade total disponível e $P_{\text {perdas }}$ as perdas elétricas do sistema (quando da condição 1, essa última parcela é considerada nula). Considere $\alpha_{i}$ a parcela de contribuição do ponto de carga $i$ ao total $L$, dado por: 


$$
\alpha_{i}=\frac{L_{i}}{L}=\frac{L_{i}}{\sum_{i=1}^{N} L_{i}}
$$

A redução considerada de carga para essa barra $i$ é dada por:

$$
L_{i, \text { corte }}=\alpha_{i}\left[\left(L+P_{\text {perdas }}\right)-G\right]
$$

Em outras palavras, a carga total após o corte mantém a mesma proporção inicial por ponto de demanda e considera apenas insuficiência de geração.

\subsubsection{2}

\section{Função Despacho de Geração}

Sistemas elétricos interligados possuem mais do que uma máquina elétrica conectada (ou passível de conexão) ao sistema. Quando a capacidade instalada é superior a previsão de carga (o que é fundamental para a qualidade e segurança da operação) é necessário criar uma política de despacho de geração. Em outras palavras, precisa-se determinar quais máquinas estarão operando em período específico para atender a demanda corrente.

Política é um conjunto de regras específicas que, nesse caso, determina uma ordenação de prioridade de entrada e retirada de geradores da operação. Parâmetros como a capacidade nominal da máquina, seus custos de operação, custos de entrada e retirada e "facilidade" para entrada e retirada são usualmente analisados.

No caso dessa dissertação será utilizado o critério de ordem de mérito. Assim, geradores com custo (\$/MW) menores serão despachados preferencialmente. Acumula-se, então, geradores, por ordem crescente de custo, até que a capacidade despachada seja suficiente para atendimento à demanda. Considera-se, também, que as máquinas da barra swing operam para realizar o balanço de potência do sistema. Novamente, é importante ressaltar que qualquer outro critério poderia ser utilizado.

\subsubsection{3}

\section{Formulação de Simulação Monte Carlo para Estimativa de Eventos de Risco}

Seja um sistema elétrico definido, e dito com configuração constante, e um conjunto de variáveis aleatórias que determinam patamares de carga e disponibilidade de geração (o vetor $\mathbf{Y}$ ), regidas por um conjunto de funções de probabilidade $\{f(\cdot)\}$. Adota-se equações não lineares de fluxo de potência, pelo qual são calculados os vetores de estado $\mathbf{X}$ e o vetor de saída $\mathbf{Z}$. 
Pretende-se estimar a probabilidade $P$ de uma variável de saída $S(\mathbf{Y})$ (como o fluxo em um ramo, por exemplo) ser maior do que um determinado limite pré-especificado $S_{\text {limite }}$ (uma sobrecarga, por exemplo) e o valor esperado condicional VEC. Sempre que houver insuficiência de geração, será necessário proceder com corte de carga, conforme descrito na Seção 2.4.1.1. Os geradores são despachados conforme política descrita na Seção 2.4.1.2.

Pode-se, então, utilizar seguinte algoritmo para esse estimar a probabilidade $P$ e o valor esperado condicional $V E C$. Importante ressaltar que fluxo de potência é calculado por um método numérico iterativo, com máximo de iterações pré-estipulado. Assim, pode ocorrer não convergência do método. Nesses casos, descarta-se os resultados. Também não está ilustrado no algoritmo, porém é possível e recomendável que a etapa de verificação de convergência (atualização $\hat{E}[H]$ e $\beta$ ) seja feita a passos pré-estipulados, como 1000 iterações, para aumentar a eficiência computacional. Isso, pois não se tem diferenças numéricas mensuráveis nesses parâmetros em uma única iteração.

Como critério de convergência, adota-se duas possibilidades: número máximo de iterações $K_{\max }$ e coeficiente de confiança para estimador da probabilidade $\beta_{P}$ ser menor ou igual a uma tolerância $\beta_{\epsilon}$.

\section{Algoritmo de SMC para Estimativa de Probabilidade de Even- tos de Risco em FPP}

Passo 1. Defina um valor máximo de iterações $K_{\max }$ e um valor tolerância para o coeficiente de confiança $\beta_{\epsilon}$. Faça $k=0$ (contador de iterações)

Passo 2. Gere uma amostra para injeções nodais (patamares de carga e geração) $\mathbf{Y}$ a partir da família $\{f(\cdot)\}$.

Passo 3. Avalie a capacidade amostrada de geração $G$ e a carga total $L$. Caso $G-L<0$, realize procedimento de corte de carga.

Passo 4. Realize procedimento de despacho de geração.

Passo 5. Realize cálculo de fluxo de potência. Caso convergido, proceder ao Passo 6.; caso não convergido, descarte a amostra e retorne ao Passo 2.

Passo 6. Avalie se a geração injetada na barra swing é menor do que a capacidade de suas máquinas. Caso seja menor, prosseguir ao Passo 7.; caso não seja, realize procedimento de corte 
de carga, calcule novamente o fluxo de potência e avalie a convergência do fluxo.

Passo 7. Faça $k=k+1$. Avalie as funções de adequação $H(\mathbf{Y})$ e $H_{\mathrm{VEC}}(\mathbf{Y})$

Passo 8. Avalie $\hat{E}[H], \hat{E}_{\mathrm{VEC}}, \beta_{P}$ e $\beta_{\mathrm{VEC}}$. Caso $\beta_{P}>\beta_{\epsilon}$, retorne ao Passo 2.; caso contrário prosseguir ao Passo 9.

Passo 9. Faça $P=\hat{E}[H]$ e $\mathrm{VEC}=\hat{E}\left[H_{\mathrm{VEC}}\right]$.

\section{5}

\section{Comentários Finais}

Fluxo de potência probabilístico é uma poderosa ferramenta para mapeamento das incertezas na disponibilidade de geração e carga de um sistema elétrico em distribuições ou estimativa de risco de variáveis chave da rede. Para sua aplicação foram desenvolvidos métodos diversos de solução que se classificam entre analíticos e de simulação.

Os analíticos, como se discutiu na Seção 2.3, se caracterizam por requerem simplificações no processo estocástico estudado e por sintonia não fácil de parâmetros. Ao fim, não se sabe ao certo se a sintonia proposta (ou se as simplificações impostas) permitiu um resultado com qualidade aceitável, sendo usual a posterior comparação com os resultados advindos de SMC. Reduz-se o tempo exigido para os cálculos, porém não se sabe a priori o "custo" dessa redução em termos de precisão e usabilidade do resultado. São adotados exclusivamente para estimativa de distribuições nas variáveis de saída, visto que perdem precisão quando se trabalha com as "caudas" das distribuições.

Métodos de simulação são largamente mais flexíveis, podendo-se adotar as equações não lineares originais dos fluxo e outras estratégias de operação (como despacho e corte de carga). Além disso, podem ser utilizados tanto para estimativa de distribuição, quanto para índices de risco. Como grande desvantagem encontra-se a exigência computacional elevada. Esse fato é verdadeiro tanto para os cálculos da rotina em si, quanto para o número de amostras necessárias para convergência (quando adotado esse critério de utilização de $\mathrm{SMC})$.

Essa dissertação visa utilizar simulação Monte Carlo para estimativa de índices de risco, probabilidade e valor esperado condicional, em estudo de fluxo de potência probabilístico. Conforme discutido, a depender da raridade do evento alvo (que não se sabe a priori), podem ser necessárias muitas amostras para garantir a convergência da estimativa desejada. A fim de reduzir 
a exigência computacional, será utilizado o método da entropia cruzada, conforme será discutido no Capítulo 3. 


\section{Estimativa de Eventos com Monte Carlo e Entropia Cruzada}

\section{1}

\section{Introdução}

A simulação Monte Carlo (SMC) é uma ferramenta poderosa para estudos de processos estocásticos e estimativa de probabilidades de eventos alvos. Decorre, como discutido na Seção 2.4, de uma ampla amostragem do espaço de estados do processo, averiguando para cada amostra a resposta do sistema modelado. A cardinalidade do espaço amostral é proporcional ao esforço computacional exigido por SMC. Para garantir resultados com grau de confiança especificados, muitas amostras e simulações são usualmente necessárias. Por que então lançar mão de metodologia tão dispendiosa do ponto de vista computacional? A resposta é simples: elevado grau de precisão e flexibilidade de operação. As simplificações e limitações não são impostas pelo SMC, mas sim pelo escopo da análise a ser efetuada.

Nessa dissertação, se almeja estimar índices de probabilidade e valor esperado condicional de eventos de risco em tempo reduzido. Entende-se que uma ferramenta prática a ser utilizada por um analista deve ser capaz de gerar resultados confiáveis, precisos e em tempo reduzido. Se faz então necessário investigar métodos que mantenham as qualidades de SMC, ao passo que reduzem o fardo computacional. Importante ressaltar que não se sabe a priori a probabilidade a ser estimada e quanto mais raro o evento, maior será o número de amostras necessárias para garantir a qualidade do resultado estimado. Criase, então, as técnicas de redução de variância (variance reduction technique VRT). As VRT são metodologias que reduzem a variância da variável aleatória de saída, sem alterar o seu valor esperado. Assim, uma maior precisão pode ser obtida com o mesmo número de amostras ou a mesma precisão com um número menor de amostras [37].

Dentre as VRT, destacam-se as por amostragem por importância ( $\mathrm{im}$ portance sampling - IS), que distorcem o espaço amostral (as distribuições das variáveis de entrada) de forma a tornar, mais frequente, o "sorteio" de amostras que levem o sistema estudado a operar dentro da região alvo. Compensa-se devidamente a distorção realizada, garantindo um estimador não tendencioso. 
Assim, o número de amostras requeridas para estimativa de probabilidade de ocorrência de eventos se torna menor.

Uma das VRT criadas é baseada no conceito de entropia cruzada (CrossEntropy - CE) [2, 3]. Em 2002, Homem-de-Mello e Rubinstein publicam uma metodologia adaptativa, em dois estágios, baseada em amostragem por importância e função de Kullback-Liebler (conhecida como CE) [40]. Especificamente, o primeiro estágio realizaria um problema de otimização matemática, cujo resultado seriam parâmetros-chave das distribuições de entrada do processo estocástico estudado. O segundo estágio seria utilizar as novas distribuições, compensadas por funções de verosimilhança, para estimativa da probabilidade do evento alvo.

Nesse capítulo serão discutidas as VRT propostas na Seção 3.2. Destaque será dado ao método da entropia cruzada, na Seção 3.3. Essa seção também ilustrará como se aplica o método em fluxo de potência probabilístico. A formulação completa do problema estudo nessa dissertação, bem como a metodologia de solução proposta, será apresentada na Seção 3.4. A Seção 3.5 conclui o capítulo.

\section{2}

\section{Técnicas de Redução de Variância}

Técnicas de redução de variância são procedimentos utilizados em conjunto com a SMC, para reduzir o número de amostras necessárias para convergência da simulação, quando se adota um critério de precisão previamente definido. As VRT podem ser interpretadas como metodologias que utilizam a informação conhecida de um modelo para obter estimadores mais precisos de seu desempenho. Genericamente, quanto mais se conhece sobre um sistema, mais efetiva será a redução de variância [2].

Algumas das VRT mais utilizadas em estudos de sistemas de potência serão brevemente apresentadas nas seções seguintes.

\subsection{1}

\section{Variáveis Antitéticas}

Sejam X e $\mathbf{Y}$ variáveis aleatórias com funções de probabilidade acumulada conhecidas, $F$ e $G$, respectivamente. Suponha que se almeja estimar $\hat{l}=E[X-Y]$ através de SMC [2]. Pode-se obter amostras para as duas variáveis através das Equações 3.1. 


$$
\begin{aligned}
& x=F^{-1}\left(U_{1}\right), \quad U_{1} \sim U(0,1) \\
& y=G^{-1}\left(U_{2}\right), \quad U_{2} \sim U(0,1)
\end{aligned}
$$

A variância do estimador é dada pela Equação 3.2 e pode ser minimizada caso se utilize $U_{2}=1-U_{1}$ (origem do nome variável antitética) [2]. Assim, obtém-se uma variância menor do que se utilizando SMC convencional.

$$
\operatorname{Var}(X-Y)=\operatorname{Var}(X)+\operatorname{Var}(Y)-2 \operatorname{Cov}(X, Y)
$$

Agora, simplificadamente, considere que se deseja realizar a estimativa de $l=E[\mathbf{W}=S(\mathbf{X})]$, onde $x=F^{-1}\left(U_{1}\right), U_{1} \sim U(0,1)$ e $F$ é função de probabilidade acumulada. Adota-se então $y=F^{-1}\left(U_{2}\right), U_{2}=1-U_{1}$. Faz-se $Z=(S(x)+S(y)) / 2$ e, ao final, estima-se $\hat{\theta}=E[\mathbf{Z}]$. A amostra $\mathbf{Z}$ possui variância menor do que $\mathbf{W}$. Algumas aplicações de variáveis antitéticas em estudos de confiabilidade de sistemas elétricos foram publicadas em [37, 38].

\subsection{2}

\section{Variáveis de Controle}

Suponha que se pretende estimar $l=E[S(\mathbf{X})]$. Considere que se saiba $E[\mathbf{Z}]$, sendo que existe correlação entre $\mathbf{X}$ e $\mathbf{Z}$ e a última é dita variável de controle da primeira. Podemos, então construir o estimador não tendencioso dado pela Equação 3.3, onde $c$ é algum número real conhecido como coeficiente de controle.

$$
\hat{l}=S(\mathbf{X})+c(\mathbf{Z}-E[\mathbf{Z}])
$$

A variância para $\hat{l}$ é dada pela seguinte equação:

$$
\operatorname{Var}(\hat{l})=\operatorname{Var}(S(\mathbf{X}))+c^{2} \operatorname{Var}(\mathbf{Z})+2 c \operatorname{Cov}(S(\mathbf{X}), \mathbf{Z})
$$

Como se possui controle sobre $c$, é preferível escolher um valor que minimize a variância dada pela Equação 3.4. O valor ótimo $c^{*}$ é dado por: 


$$
c^{*}=\frac{\operatorname{Cov}(S(\mathbf{X}), \mathbf{Z})}{\operatorname{Var}(\mathbf{Z})}
$$

Um valor aproximado para $c^{*}$ pode ser obtido através de uma présimulação com número limitado de amostras. Algumas aplicações em confiabilidade de sistemas elétricos podem ser encontrados em [37, 38] e detalhes matemáticos podem ser estudados em [2].

\subsection{3}

\section{Amostragem por Importância}

Amostragem por importância envolve adotar uma distribuição que favoreça amostragem de elementos importantes [2]. Seja o objetivo de análise estimar $l$, onde:

$$
l=E_{f}[H(\mathbf{X})]=\int H(x) f(x)
$$

onde $H$ é uma função conhecida e $f(\cdot)$ é a densidade de probabilidade de $\mathbf{X}$. Seja, agora, outra função $g(\cdot)$ tal que, quando $H(x) f(x)=0$, se tem $g(x)=0($ diz-se que $g(\cdot)$ domina $H(\cdot) f(\cdot))$. Tem-se:

$$
l=\int H(x) \frac{f(x)}{g(x)} g(x) d x=E_{g}\left[H(\mathbf{X}) \frac{f(\mathbf{X})}{g(\mathbf{X})}\right]
$$

Consequentemente, se $\mathbf{X}$ é um conjunto de amostras independentes e identicamente distribuídas (iid) da função $g(\cdot)$, pode-se adotar o estimador não tendencioso $\hat{l}$ dado por:

$$
\hat{l}=\frac{1}{N} \sum_{k=1}^{N} H\left(X_{k}\right) \frac{f\left(X_{k}\right)}{g\left(X_{k}\right)}
$$

O estimador é chamado estimador por amostragem por importância.

Defini-se a função de verosimilhança $W$ pela equação:

$$
W(x)=\frac{f(x)}{g(x)}
$$

O problema fundamental encontrado durante a implementação de amos- 
tragem por importância é a escolha correta desta nova distribuição de amostragem [50]. É preciso determinar uma distribuição $g(\cdot)$ que minimize a variância do estimador $\hat{l}$ dado pela Equação 3.7, resultando no seguinte problema de otimização matemática:

$$
\min _{g(\cdot)} \operatorname{Var}_{g}\left(H(\mathbf{X}) \frac{f(\mathbf{X})}{g(\mathbf{X})}\right)
$$

A solução é dada pela Equação 3.11 [2].

$$
g^{*}(x)=\frac{|H(x)| f(x)}{\int|H(x)| f(x) d x}
$$

Em particular, caso $H(\cdot)$ seja estritamente positiva, tem-se:

$$
g^{*}(x)=\frac{H(x) f(x)}{l}
$$

Em outras palavras, caso se saiba a priori o valor $l$, é possível determinar analiticamente a distribuição que minimiza a variância. Porém, pretende-se justamente elaborar um estimador não tendencioso e numericamente eficiente que permita estimar $\hat{l}$. Ou seja, não se sabe a priori o valor de $l$ e não se pode determinar facilmente a função $g^{*}(\cdot)$. Alguns métodos para determinação dessa distribuição foram abordados em [39, 51]. O Método da Entropia Cruzada é uma aplicação particular de determinação da função $g(\cdot)$ e será discutido na Seção 3.3.

\section{3}

\section{Método da Entropia Cruzada}

A amostragem por importância é uma metodologia, utilizada em procedimento de simulação, que visa adotar uma nova distribuição que aumente a frequência de ocorrência de amostragem de eventos que recaiam sobre a região alvo a ser estimada. Conforme discutido na Seção 3.2.3, é possível determinar analiticamente a função $g(\cdot)$ que minimize a variância do novo estimador não tendencioso, porém esse cálculo depende do próprio valor a ser estimado $\hat{l}$. Assim, se faz necessário elaborar uma estratégia de minimização da variância do estimador de amostragem por importância. Uma metodologia proposta para esse fim é encontrar os parâmetros que minimizem a "distância" entre a distribuição de amostragem por importância e a distribuição ótima de variância nula, utilizando a função Kullback-Liebler (função de Entropia Cruzada) [40]. 
O método da entropia cruzada (CE) foi originalmente proposto em [40] para estimação de eventos raros. Foi estendida, porém, para procedimentos de otimização combinatória [2, 3]. Nessa seção será discutida a formulação matemática para utilização de $\mathrm{CE}$ em estimação de eventos raros (contexto dessa dissertação), o algoritmo de composto de SMC e CE (dito SMC-CE) e alguns exemplos introdutórios para expandir a sensibilidade gerada pela formulação matemática.

\subsection{1}

\section{Formulação Matemática para Estimação de Eventos Raros com Entropia Cruzada}

Seja $\mathbf{X}=\left(X_{1}, \cdots, X_{n}\right)$ um vetor aleatório que assume valores de um espaço $\mathcal{X}$. Seja $\{f(\cdot, \mathbf{v})\}$ uma família de funções de densidade de probabilidade em $\mathcal{X}$, com respeito a um vetor de parâmetros $\mathbf{v}$, com valores reais. Para qualquer função mensurável $H(\cdot)$, tem-se

$$
E[H(\mathbf{X})]=\int_{\mathcal{X}} H(x) f(x, v) d x
$$

Pretende-se determinar $l$ que é a probabilidade, sob $f(\cdot, \mathbf{u})$, de um evento $S(\mathbf{X}) \geq \gamma$ ocorrer, onde $S(\cdot)$ é uma função real em $\mathcal{X}$ e $\gamma$ é um valor real prédeterminado, .

$$
l=P_{\mathbf{u}}[S(\mathbf{X}) \geq \gamma]=E_{\mathbf{u}}\left[I_{\{S(\mathbf{X}) \geq \gamma\}}\right]
$$

Sendo a probabilidade $l$ muito pequena (como por exemplo $1 \times 10^{-5}$ ), o evento estudado pode ser considerado raro. A função lógica $I(\cdot)$ é um índice de adequação da amostra ao objetivo proposto, podendo ser matematicamente expressa por:

$$
I(x)= \begin{cases}1 & , \text { se } x \geq \gamma \\ 0 & , \text { caso contrário }\end{cases}
$$

Para aumentar a eficiência computacional da SMC, a estimativa de $l$ será realizada através de um estimador por amostragem por importância. Seja uma amostra aleatória $X_{1}, \cdots, X_{N}$ de uma função de densidade $g(\cdot)$ em $\mathcal{X}$. Utiliza-se o estimador: 


$$
\hat{l}=\frac{1}{N} \sum_{i=1}^{N}\left[I_{\left\{S\left(X_{i}\right) \geq \gamma\right\}} \frac{f\left(X_{i}, \mathbf{u}\right)}{g\left(X_{i}\right)}\right]
$$

O problema reside em encontrar uma boa distribuição $g(\cdot)$ que reduza a variância do estimador para $l$ e aumente a eficiência computacional da simulação. É conveniente adotar $g(\cdot)$ como pertencente a família de funções $\{f(\cdot, \mathbf{v})\}[2]$. A ideia é obter um vetor de parâmetros $\mathbf{v}$ tal que a distância entre $g^{*}(\cdot)$ e $f(\cdot, \mathbf{v})$ seja mínima. Um medida conveniente para duas funções de densidade $f_{1}(\cdot)$ e $f_{2}(\cdot)$ é a Distância Kullback-Leibler [50], também conhecida como a entropia cruzada das densidades. A distância é matematicamente definida como:

$$
\begin{aligned}
\mathcal{D}\left(f_{1}, f_{2}\right) & =E_{f_{1}}\left[\ln \left(\frac{f_{1}(\mathbf{X})}{f_{2}(\mathbf{X})}\right)\right] \\
& =\int f_{1}(x) \ln \left(f_{1}(x)\right) d x-\int f_{1}(x) \ln \left(f_{2}(x)\right) d x
\end{aligned}
$$

Minimizar a distância entre $g^{*}(\cdot)$ e $f(\cdot, \mathbf{v})$ é adotar um valor para $\mathbf{v}$, tal que o segundo termo integral da Equação 3.17 seja mínimo [2]. O resultado é o seguinte problema de maximização:

$$
\max _{\mathbf{v}} \int g^{*}(x) \ln (f(\mathbf{x}, \mathbf{v})) d x
$$

Pode-se demonstrar [2] que o problema definido pela Equação 3.18 é equivalente ao seguinte problema de otimização:

$$
\max _{\mathbf{v}} E_{\omega}\left[I_{\{S(\mathbf{X}) \geq \gamma\}} W(\mathbf{X}, \mathbf{u}, \omega) \ln (f(\mathbf{X}, \mathbf{u}))\right]
$$

onde $W(\cdot, \mathbf{u}, \omega)$ é definida, para um conjunto de parâmetros $\omega$, em um ponto $\mathbf{x}$, como a função de verosimilhança entre $f(\cdot, \mathbf{u})$ e $f(\cdot, \omega)$. Tem-se:

$$
W(\mathbf{x}, \mathbf{u}, \omega)=\frac{f(\mathbf{x}, \mathbf{u})}{f(\mathbf{x}, \omega)}
$$

A solução para o problema descrito na Equação 3.19 é dado por: 


$$
\mathbf{v}^{*}=\underset{\mathbf{v}}{\operatorname{argmax}} E_{\omega}\left[I_{\{S(\mathbf{X}) \geq \gamma\}} W(\mathbf{X}, \mathbf{u}, \omega) \ln (f(\mathbf{X}, \mathbf{v}))\right]
$$

Pode-se estimar $\mathbf{v}^{*}$ resolvendo o seguinte problema de otimização estocástica [2]:

$$
\max _{\mathbf{v}} \frac{1}{N} \sum_{i=1}^{N}\left[I_{\left\{S\left(\mathbf{X}_{\mathbf{i}}\right) \geq \gamma\right\}} W\left(\mathbf{X}_{\mathbf{i}}, \mathbf{u}, \mathbf{w}\right) \ln \left(f\left(\mathbf{X}_{\mathbf{i}}, \mathbf{v}\right)\right)\right]
$$

onde $\mathbf{X}_{\mathbf{1}}, \cdots, \mathbf{X}_{\mathbf{N}}$ são amostras de $f(\cdot, \omega)$. Em aplicações típicas, a função a ser maximizada, descrita na Equação 3.22, é convexa e diferenciável em relação ao parâmetro $\mathbf{v}$ [2] e a solução pode ser obtida através do seguinte sistema de equações:

$$
\frac{1}{N} \sum_{i=1}^{N}\left[I_{\left\{S\left(\mathbf{X}_{\mathbf{i}}\right) \geq \gamma\right\}} W\left(\mathbf{X}_{\mathbf{i}}, \mathbf{u}, \mathbf{w}\right) \nabla \ln \left(f\left(\mathbf{X}_{\mathbf{i}}, \mathbf{v}\right)\right)\right]=\mathbf{0}
$$

onde o gradiente é calculado em relação ao parâmetro v.

O problema definido pela Equação 3.22 pode ser difícil de ser solucionado, dependendo da raridade do evento a ser estimado (lembrando que não se sabe a priori o grau de raridade do evento). Um algoritmo multinível pode ser utilizado para superar essa dificuldade [2]. A ideia é evoluir os valores para $\left\{\mathbf{v}_{\mathbf{t}}, t \geq 1\right\}$ e alvos $\left\{\gamma_{t}, t \geq 1\right\}$ ao mesmo passo iterativo $t$. Mais detalhes matemáticos podem ser encontrados em $[2,3]$.

\subsubsection{1}

\section{Otimização Adaptativa Multinível}

Para realizar com eficiência e robustez numérica o problema definido pela Equação 3.22, um algoritmo multinível foi proposto [2]. Atualiza-se, no primeiro estágio um valor para o alvo $\gamma_{t}$ e, no segundo, os parâmetros $\mathbf{v}_{\mathbf{t}}$ da distribuição por amostragem por importância.

Inicializa-se o processo adotando um valor (usualmente entre 0.1 e 0.01 ) para $\rho$, que determinará a atualização de $\gamma_{t}$ a partir do $(1-\rho)$-quantil de $S(\mathbf{X})$. Faz-se, também, $\mathbf{v}_{\mathbf{0}}=\mathbf{u}[2]$.

\section{Atualização adaptativa de $\gamma_{t}$}

Para um conjunto $\mathbf{v}_{\mathbf{t}-\mathbf{1}}$, seja $\gamma_{t}$ o $(1-\rho)$-quantil de $S(\mathbf{X})$, amostrado de $f\left(\cdot, \mathbf{v}_{\mathbf{t}-\mathbf{1}}\right)$. Um estimador $\hat{\gamma}_{t}$ para $\gamma_{t}$ pode ser obtido amostrando $X_{1}, \cdots, X_{N}$ 
de $f\left(\cdot, \mathbf{v}_{\mathbf{t}-\mathbf{1}}\right)$, calculando $S(\mathbf{X})$ para todas os elementos da amostra e ordenando do menor ao maior. Finalmente, avalia-se:

$$
\hat{\gamma}_{t}=S_{[(1-\rho) N]}
$$

\section{Atualização adaptativa de $\mathrm{v}_{\mathrm{t}}$}

Seja um valor determinado $\gamma_{t}$ e um vetor de parâmetros $\mathbf{v}_{\mathbf{t}-\mathbf{1}}$, deseja-se calcular o vetor $\mathbf{v}_{\mathbf{t}}$ através do seguinte problema:

$$
\max _{\mathbf{v}} E_{\mathbf{v}_{\mathbf{t}-\mathbf{1}}}\left[I_{\left\{S(\mathbf{X}) \geq \gamma_{t}\right\}} W\left(\mathbf{X}, \mathbf{u}, \mathbf{v}_{\mathbf{t}-\mathbf{l}}\right) \ln (f(\mathbf{X}, \mathbf{v}))\right]
$$

Esse problema, para valores conhecidos de $\hat{\gamma}_{t}$ e $\hat{v}_{t-l}$ pode ser modelado como:

$$
\max _{\mathbf{v}}=\frac{1}{N} \sum_{i=1}^{N} I_{\left\{S\left(\mathbf{X}_{\mathbf{i}}\right) \geq \hat{\gamma} t\right\}} W\left(\mathbf{X}_{\mathbf{i}}, \mathbf{u}, \hat{\mathbf{v}}_{\mathbf{t}-\mathbf{1}}\right) \ln \left(f\left(\mathbf{X}_{\mathbf{i}}, \mathbf{v}\right)\right)
$$

A fórmulas para resolução adaptativa da Equação 3.26 serão discutidas na Seção 3.3.1.2

\subsubsection{2}

\section{Solução de problema de otimização e definição de parâmetros}

O problema definido pela Equação 3.26 define os parâmetros para a distribuição de amostragem por importância que será utilizada no estimador de eventos raros. Quando a família de distribuições $\{f(\cdot, \mathbf{v})\}$ pertence família das exponenciais, existe solução analítica para o problema. Nesse caso, recaem duas distribuições pertinentes a essa dissertação: normais e binomiais. Distribuições discretas, que também fazem parte do escopo dessa dissertação, são tratadas de maneira análoga e serão discutidas também nessa seção.

Nos sistemas elétricos estudados, as distribuições binomiais são adequadas para modelar a disponibilidade de máquinas em estações de geração, já as normais e discretas são utilizadas para descrever a incerteza em pontos de carga.

\section{Distribuição Binomial}


Seja uma distribuição binomial $\operatorname{Bin}(n, p)$, a distribuição por amostragem por importância será uma distribuição também binomial dada por $\operatorname{Bin}\left(n, p_{d}\right)$. O valor final para $p_{d}$ é resultado do problema matemático dado pela Equação 3.26 e é resolvido iterativamente. A cada iteração $t$, faz-se a seguinte atualização [2]:

$$
p_{t}=\frac{\sum_{i=1}^{N} I_{\left\{S\left(\mathbf{X}_{\mathbf{i}}\right) \geq \gamma_{t}\right\}} W\left(\mathbf{X}_{\mathbf{i}}, p, p_{t-1}\right) X_{i}}{\sum_{i=1}^{N} I_{\left\{S\left(\mathbf{X}_{\mathbf{i}}\right) \geq \gamma_{t}\right\}} W\left(\mathbf{X}_{\mathbf{i}}, p, p_{t-1}\right)}
$$

onde a função de verosimilhança $W$ em um ponto $x$ é dada por:

$$
W\left(x, p, p_{t-1}\right)=\frac{f(x, p)}{f\left(x, p_{t-1}\right)}
$$

Sendo que, para uma distribuição binomial, a função densidade de probabilidade é dada por:

$$
f(x, p)=\left(\begin{array}{l}
n \\
x
\end{array}\right) p^{x}(1-p)^{n-x}
$$

\section{Distribuição Normal}

Seja uma função de densidade normal definida por $\mathrm{N}(\mu, \sigma)$. Pretendese encontrar uma função densidade por amostragem por importância que minimize a variância do estimador de eventos a ser utilizado em ambiente de simulação. No contexto de entropia cruzada, pretende encontrar os parâmetros para média e desvio. Em ambiente multidimensional (com muitas distribuições envolvidas), percebeu-se que se ganha em robustez numérica caso apenas a média seja calculada para a distribuição a ser utilizada, mantendo-se o valor original para o desvio padrão.

Em uma iteração $t$ do método da entropia cruzada, atualiza-se o valor para a média de uma distribuição pela seguinte equação:

$$
\mu_{t}=\frac{\sum_{i=1}^{N} I_{\left\{S\left(\mathbf{X}_{\mathbf{i}}\right) \geq \gamma_{t}\right\}} W\left(\mathbf{X}_{\mathbf{i}}, \mu, \mu_{t-1}\right) X_{i}}{\sum_{i=1}^{N} I_{\left\{S\left(\mathbf{X}_{\mathbf{i}}\right) \geq \gamma_{t}\right\}} W\left(\mathbf{X}_{\mathbf{i}}, \mu, \mu_{t-1}\right)}
$$

onde a função de verosimilhança $W$ em um ponto $x$ é dada por: 


$$
W\left(x, \mu, \mu_{t-1}\right)=\frac{f(x, \mu)}{f\left(x, \mu_{t-1}\right)}
$$

Sendo que, para uma distribuição normal, a função densidade de probabilidade (lembrando que consideramos sempre $\sigma$ constante e igual ao valor da distribuição original) é dada por:

$$
f(x, \mu)=\frac{1}{\sigma \sqrt{2 \pi}} \exp \left(-\frac{(x-\mu)^{2}}{2 \sigma}\right)
$$

\section{Distribuição Discreta Genérica}

Seja $X$ uma variável aleatória que pode assumir um número finito de valores $\alpha_{1}, \cdots, \alpha_{m}$ (diz-se de suporte finito). Seja $u_{i}=P\left[X=\alpha_{i}\right], i=1, \cdots, m$ e defina $\mathbf{u}=\left(u_{1}, \cdots, u_{m}\right)$. A distribuição é parametrizada pelo vetor $\mathbf{u}$ da seguinte forma [2]:

$$
f(x, \mathbf{u})=\sum_{i=1}^{m} u_{i} I_{\left\{x=\alpha_{i}\right\}}
$$

Deve-se, então, realizar a definição do parâmetro v que estará associado a distribuição por amostragem por importância resultado do método da entropia cruzada. Em outras palavras, há alteração nas probabilidades que os valores $\alpha_{1}, \cdots, \alpha_{m}$ podem assumir. Cada elemento $i$, na iteração $t$ do $\mathrm{CE}$, deve ser atualizado pela seguinte equação [2]:

$$
v_{i, t}=\frac{\sum_{i=1}^{N} I_{\left\{S\left(\mathbf{X}_{\mathbf{i}}\right) \geq \gamma_{t}\right\}} W\left(\mathbf{X}_{\mathbf{i}}, \mathbf{u}, \mathbf{v}_{\mathbf{t}-\mathbf{1}}\right) I_{\left\{X_{i}=\alpha_{i}\right\}}}{\sum_{i=1}^{N} I_{\left\{S\left(\mathbf{X}_{\mathbf{i}}\right) \geq \gamma_{t}\right\}} W\left(\mathbf{X}_{\mathbf{i}}, \mathbf{u}, \mathbf{v}_{\mathbf{t}-\mathbf{1}}\right)}
$$

\subsubsection{3}

\section{Parâmetro de Suavização de Atualização}

Ao invés de atualização o vetor de parâmetros $\mathbf{v}_{\mathbf{t}-\mathbf{1}}$ diretamente ao vetor $\mathbf{v}_{\mathbf{t}}$, pode ser vantajosa a utilização de um parâmetro de suavização $\alpha$. A ideia é principalmente aplicada em distribuições discretas, em que se pretende evitar a geração de 1 e 0 no vetor de referência. Matematicamente, tem-se:

$$
\mathbf{v}_{\mathbf{t}}=\alpha \cdot \mathbf{v}_{\mathbf{t}}+(1-\alpha) \mathbf{v}_{\mathbf{t}-\mathbf{1}}
$$


Caso o valor configurado para $\alpha$ seja unitário, é fácil perceber que a regra de atualização desconsidera a suavização.

\subsubsection{4}

\section{Comentários Adicionais e Degeneração de Função de Verosimilhança}

Pesquisas recentres mostram que, em configurações multidimensionais, como é o caso dos problemas tratados nessa dissertação, existe a possibilidade de haver degeneração da função de verosimilhança e o estimador por amostragem por importância resultante do algoritmo de entropia cruzada se torna não confiável [52]. A publicação [52] discute um algoritmo de uma única iteração que promete reduzir deterioração do "acúmulo" de distorções ocasionadas pelo CE.

A degeneração pode ser observada pela qualidade final do resultado e pela variação não monotonicamente decrescente do coeficiente de variação $\beta$. Nesses casos, a evolução do $\beta$ ao longo das iterações é preenchida por "saltos" relevantes de grande magnitude. Alguns "filtros" podem ser inseridos ao algoritmo para auxiliar a mitigar o problema, como excluir amostras que elevem demasiadamente o $\beta$ e/ou retornar às distribuições originais para os casos nos quais pequenas distorções forem realizadas.

Nessa dissertação, nenhum dos "filtros" citados necessitou ser utilizado, porém percebeu-se maior robustez do procedimento quando o desvio padrão de funções normais não é distorcido (apenas a média).

\subsection{2}

\section{Algoritmo para Simulação Monte Carlo e Entropia Cruzada}

Considere que se deseja estimar a probabilidade $l=P[S(\mathbf{X}) \geq \gamma]$ através de simulação. Seja também u um vetor de parâmetros de uma família de funções densidade $\{f(\cdot, \mathbf{u})\}$. Para aumento da eficiência computacional, ao invés do padrão, será utilizado um estimador por amostragem por importância. Será apresentado nessa seção, uma versão de algoritmo com aplicação de CE em estimação de probabilidade de eventos [2].

\section{Algoritmo de aplicação de CE em estimação de eventos:}

Passo 1. Defina $\hat{\mathbf{v}}_{\mathbf{0}}=\mathbf{u}$. Faça $t=1$ (contador de iterações).

Passo 2. Gere uma amostra $\mathbf{X}_{\mathbf{1}}, \cdots, \mathbf{X}_{\mathbf{N}}$ a partir da família $\left\{f\left(\cdot, \hat{\mathbf{v}}_{\mathbf{t}-\mathbf{1}}\right)\right\}$.

Passo 3. Avalie $S(\mathbf{X})$ e ordene em ordem crescente. Avalie $\hat{\gamma}_{t}=$ $S_{[(1-\rho) N]}$. Se $\hat{\gamma}_{t} \geq \gamma$, então $\hat{\gamma}_{t}=\gamma$ 
Passo 4. Utilize a mesma amostra $\mathbf{X}_{1}, \cdots, \mathbf{X}_{\mathbf{N}}$ para resolver o problema de otimização estocástica 3.22 e definir o parâmetro atualizado $\hat{\mathbf{v}}_{\mathbf{t}}$.

Passo 5. Caso $\hat{\gamma}_{t}<\gamma$, retorne ao Passo 2.; caso contrário avance ao Passo 6..

Passo 6. Avalie a estimativa de $l$ utilizando:

$$
\hat{l}=\frac{1}{N_{1}} \sum_{i=1}^{N_{1}} I_{\left\{S\left(\mathbf{X}_{\mathbf{i}}\right) \geq \gamma\right\}} W\left(\mathbf{X}_{\mathbf{i}}, \mathbf{u}, \hat{\mathbf{v}}_{\mathbf{T}}\right)
$$

onde $T$ é a iteração final $t=T$.

Importante ressaltar que dependendo da família de distribuições utilizadas, o Passo 4. deve ser calculado através das Equações 3.27, 3.30 ou 3.34. Também nesse Passo 4., pode-se utilizar o processo de suavização explorado na Seção 3.3.1.3, utilizando $\alpha \neq 1$.

\subsection{3}

\section{Exemplos Introdutórios}

Nessa seção, será explorado e ilustrado o funcionamento da CE frente a exemplos introdutórios. Considerando distribuições que iremos utilizar nos sistemas verdadeiramente estudados nessa dissertação (discretas e normais), pretende-se gerar sensibilidade acerca do funcionamento da metodologia e das distorções resultantes.

\subsubsection{1}

\section{Distribuição Normal}

Considere uma função de distribuição de probabilidade normal, com média $\mu=100$ e desvio padrão $\sigma=30$. A curva de probabilidade é ilustrada na Figura 3.1. 


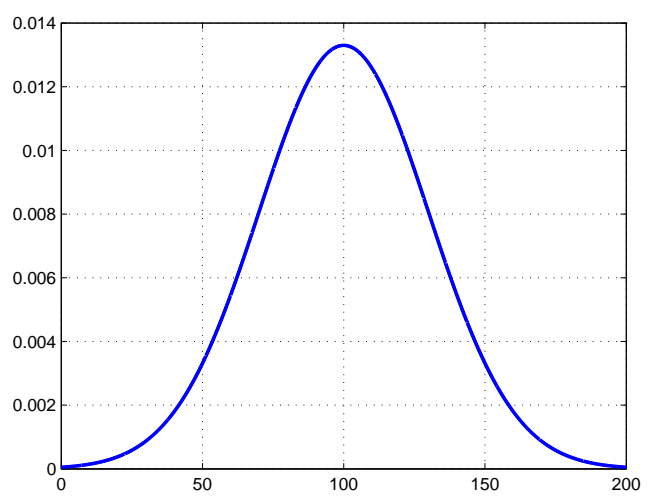

Figura 3.1: Distribuição normal $N(100,30)$.

Seja, então, um conjunto com $N=1 \times 10^{5}$ amostras $\mathbf{X}$, tais que $\mathbf{X} \sim N(100,30)$. Considere que se pretende avaliar a probabilidade $P[S(x)=$ $x^{2} \geq$ Alvo], tal que $x \in \mathbf{X} \sim N(100,30)$ e Alvo $=4 \times 10^{4}$. A partir do conjunto de $N$ amostras realizadas, é possível estimar o valor para tal probabilidade. Para isso, basta elevar ao quadrado cada elemento da amostra e estimar a proporção que possui valor maior do que o alvo determinado. $\mathrm{O}$ valor encontrado é $\hat{P}=4,4 \times 10^{-4}$.

Pretende-se, porém, estudar as potencialidades de se utilizar Entropia Cruzada. Faz-se então duas simulações para estimativa dessa probabilidade: SMC e SMC-CE. A simulação para CE é realizada de acordo com o exposto na Seções 3.3.1 e 3.3.2.

As iterações da pré-simulação (etapa Entropia Cruzada) são ilustradas nas Tabelas 3.1 (para $\rho=0,01$ ). Conforme descrito, são necessárias duas iterações para convergência do algoritmo e a função distorcida resultante é uma normal com média 208, 4068. Como já se discutiu, não se distorce o desvio padrão. Esta etapa requer 0,05 s.

A Tabela 3.2 ilustra os desempenhos de cada simulação e a Figura 3.2 ilustra os histogramas para $S(x)=x^{2}$ para $x \in \mathbf{X} \sim N(100,30)$ (esquerda) e $x \in \mathbf{X} \sim N(208,4068,30)$ (direita). Percebe-se um speedup de aproximadamente 528 vezes. O histograma resultante da distribuição distorcida é esclarecedora no que tange a maior frequência de amostragem de elementos dentro da região alvo. 
Tabela 3.1: Evolução das Iterações para Simulação com Entropia Cruzada

\begin{tabular}{ccc} 
Iteração & $\gamma_{t}$ & $\mu_{t}$ \\
\hline 0 & - & 100 \\
1 & 27.394 & 174,7516 \\
2 & 40.000 & 208,4068 \\
\hline
\end{tabular}

Tabela 3.2: Desempenho de SMC e SMC-CE para Estimativa de Probabilidade Alvo

\begin{tabular}{ccc}
\hline & SMC & SMC-CE $\mid \rho=0,01$ \\
\hline $\mathcal{P}$ & $4,2698 \times 10^{-4}$ & $4,3413 \times 10^{-4}$ \\
$\beta$ & 0,0100 & 0,0099 \\
Amostras & 23.411 .000 & 38.000 \\
tempo & $2.843 \mathrm{~s}$ & $5 \mathrm{~s}$ \\
\hline
\end{tabular}
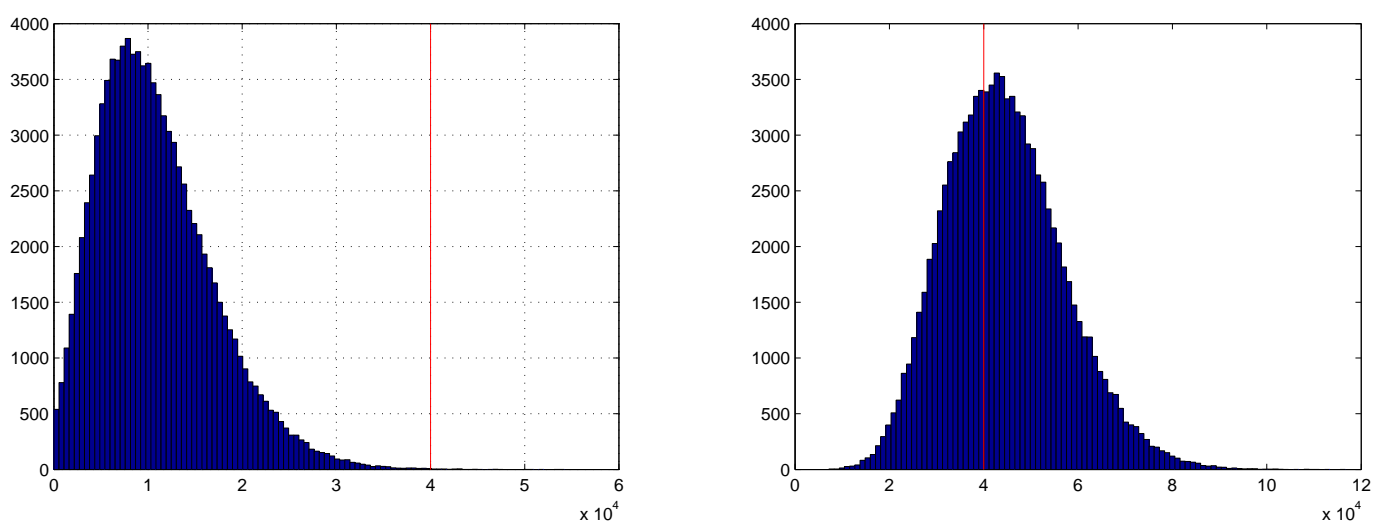

Figura 3.2: Histograma para $S(x)=x^{2}$ para $x \in \mathbf{X} \sim N(100,30)$ (esquerda) e $x \in \mathbf{X} \sim N(208,4068,30)$ (direita).

\subsubsection{2}

\section{Distribuição Discreta}

Considere agora uma distribuição discreta $d(k)$, conforme ilustrada na Figura 3.3. 


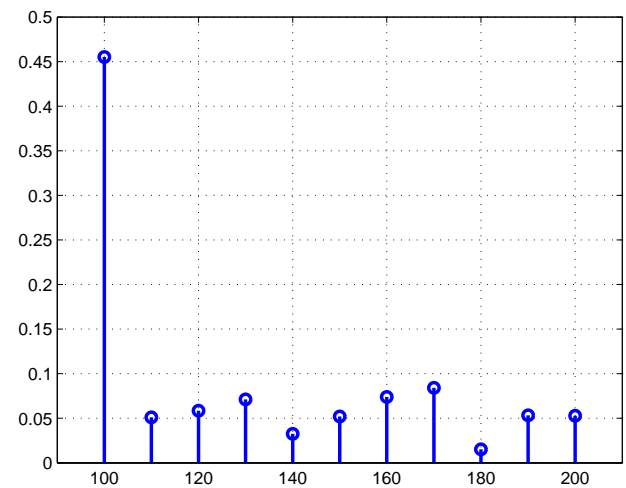

Figura 3.3: Distribuição discreta.

Conforme fez-se na Seção 3.3.3.1, o objetivo é ilustrar o comportamento do algoritmo CE para estimativa de probabilidade de evento. Adota-se, então a função $S(x)=x^{2}$, onde $x \in \mathbf{X} \sim d(k)$ e o Alvo $=3,8 \times 10^{4}$. É possível perceber que apenas as amostras com valor $x=200$ recaem sobre a região alvo, já que se $x=190$, tem-se $x^{2}=3,61 \times 10^{4}<$ Alvo $=3,8 \times 10^{4}$.

Adotando as estratégias discutidas nas Seções 3.3.1 e 3.3.2. e para parâmetro $\rho=0,1$, o algoritmo CE necessita de 2 iterações para convergência e retorna com a distribuição ilustrada na Figura 3.4. O processo requer 0.03 s. Conforme se podia imaginar, a distorção anula qualquer probabilidade de elementos $x<200$, já que apenas para $x=200$ se pode ter $x^{2} \geq$ Alvo $=$ $3,8 \times 10^{4}$. A Tabela 3.3 ilustra a comparação de desempenho entre SMC e SMC-CE. O speed-up observado é de 1.335 vezes e a distribuição distorcida requer apenas uma iteração convergência da SMC-CE.

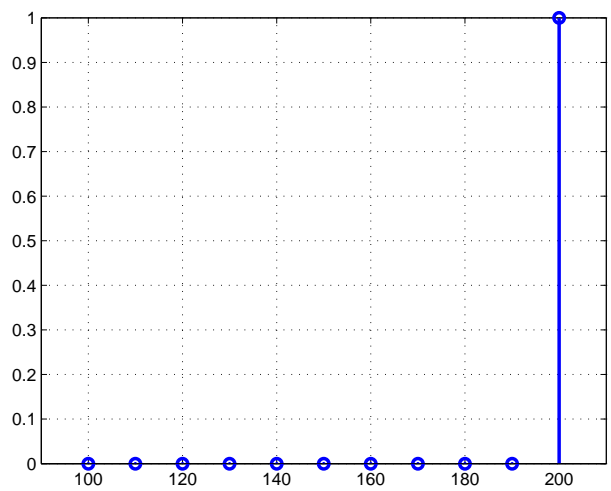

Figura 3.4: Distribuição discreta após a distorção com CE. 
Tabela 3.3: Desempenho de SMC e SMC-CE para Estimativa de Probabilidade Alvo

\begin{tabular}{ccc}
\hline & SMC & SMC-CE $\mid \rho=0,1$ \\
\hline $\mathcal{P}$ & 0,0530 & 0,0528 \\
$\beta$ & 0,0100 & 0 \\
Amostras & 178.753 & 1 \\
tempo & $8,5434 \mathrm{~s}$ & $0,0064 \mathrm{~s}$ \\
\hline
\end{tabular}

\section{4}

\section{Formulação Completa do Problema e Metodologia Proposta}

Seja então uma rede elétrica, com topologia e parâmetros constantes, para a qual se deseja avaliar probabilidade e o valor esperado condicional para eventos de risco como sobrecarga em ramos e/ou sub ou sobretensão em barramentos. Considere conhecidas as distribuições de densidade de probabilidade para as incertezas de capacidades de geração em estações e de cargas para pontos de demanda. Essas densidades são binominais para patamares de geração e normais e discretas para a incerteza de carga nos pontos de demanda. Não há, porém, restrições que impeçam a utilização de outras formas de distribuição.

A proposta dessa dissertação é utilizar a combinação de simulação Monte Carlo e entropia cruzada para aumento da eficiência computacional e garantia da flexibilidade e precisão dos resultados para as estimativas necessárias. Divide-se a metodologia de solução em duas etapas: uma "présimulação" com o método da entropia cruzada, para determinar as distribuições por amostragem por importância; e uma etapa de simulação Monte Carlo, utilizando as distribuições da "pré-simulação" e compensação adequada com função de verosimilhança.

Considere Y um vetor de injeções nodais, amostrado a partir das distribuições de geração e carga. Deseja-se expandir essa incerteza ao vetor de estado (magnitudes e ângulos de tensões nodais) $\mathbf{X}$ e ao vetor de saída $\mathbf{Z}$, utilizando as equações não lineares originais de fluxo de potência. Para pontos de carga, é considerado o fator de potência constante. Dessa forma, amostrando um valor para a demanda de potência ativa, tem-se a demanda de potência reativa. $\mathrm{O}$ algoritmo, porém, permite que se utilize distribuições distintas para cada parcela da carga.

Dado um evento alvo (em $\mathbf{X}$ ou $\mathbf{Z}$ ), pré-selecionado, pretende-se calcular a probabilidade e o valor esperado condicional para sua ocorrência.

Por questões de clareza de apresentação, considere que o objetivo é calcular a probabilidade de sobrecarga, em um ramo $i$, e o valor esperado 
condicional frente ao valor nominal de segurança $\gamma=S_{i \text {,imite. As ideias pro- }}$ postas podem ser facilmente transpostas a problemas de sub ou sobretensão em barramento, perdas de potência, injeção de reativo em barras de geração e injeções em barras swing.

\section{Algoritmo proposto, com SMC e CE, para avaliação de evento de risco em FPP}

Passo 1. Defina $\hat{\mathbf{v}}_{\mathbf{0}}=\left\{\mu, \mathbf{u}, \mathbf{d}_{\mathbf{k}}\right\}$, onde $\left\{\mu, \mathbf{u}, \mathbf{d}_{\mathbf{k}}\right\}$ é um conjunto de vetores de parâmetros-chave das distribuições originais: média das normais, indisponibilidade de binomiais e impulsos para as discretas. Faça $t=1$ (contador de iterações).

Passo 2. Gere uma amostra $\mathbf{Y}_{\mathbf{1}}, \cdots, \mathbf{Y}_{\text {Nce }}$ a partir das famílias de distribuições utilizando $\hat{\mathbf{v}}_{\mathbf{t}-\mathbf{1}}$.

Passo 3. Avalie $S(\mathbf{Y})$ (fluxo aparente no ramo $i$, levando em consideração a necessidade de se avaliar a convergência do fluxo de carga e de corte de carga por insuficiência de geração) e ordene em ordem crescente. Avalie $\hat{\gamma}_{t}=S_{[(1-\rho) N c e]}$. Se $\hat{\gamma}_{t} \geq \gamma$, então $\hat{\gamma}_{t}=\gamma$

Passo 4. Utilize a mesma amostra $\mathbf{Y}_{1}, \cdots, \mathbf{Y}_{\text {Nce }}$ para resolver o problema de otimização estocástica 3.22 e definir o parâmetro atualizado $\hat{\mathbf{v}}_{\mathbf{t}}$.

Passo 5. Caso $\hat{\gamma}_{t}<\gamma$, retorne ao Passo 2.; caso contrário avance ao Passo 6..

Passo 6. Avalie a estimativa de $l$ utilizando:

$$
\begin{aligned}
\hat{P} & =\frac{1}{N_{1}} \sum_{i=1}^{N_{1}} I_{\left\{S\left(\mathbf{Y}_{\mathbf{i}}\right) \geq \gamma\right\}} W\left(\mathbf{Y}_{\mathbf{i}},\left\{\mu, \mathbf{u}, \mathbf{d}_{\mathbf{k}}\right\}, \hat{\mathbf{v}_{\mathbf{T}}}\right) \\
\mathrm{VEC} & =\frac{1}{N_{1}} \sum_{i=1}^{N_{1}} H_{\left\{S\left(\mathbf{Y}_{\mathbf{i}}\right) \geq \gamma\right\}} W\left(\mathbf{Y}_{\mathbf{i}},\left\{\mu, \mathbf{u}, \mathbf{d}_{\mathbf{k}}\right\}, \hat{\mathbf{v}_{\mathbf{T}}}\right)
\end{aligned}
$$

onde $T$ é a iteração final $t=T, I(\cdot)$ é função teste de pertinência ao alvo e $H(\cdot)$ é função teste de valor condicional frente ao alvo.

Alguns detalhes adicionais se fazem necessários: 
- Para a "pré-simulação" especifica-se previamente o número de amostras que serão utilizadas $N c e$. Como, para determinadas amostras, pode ser necessário descarte por não convergência de fluxo de potência, é recomendável que se amostre um número maior do que $N c e$ e se aproveite os Nce resultados com convergência;

- Mesmo na "pré-simulação", é necessário realizar corte de carga por insuficiência de geração, despacho de unidades geradoras e avaliação de convergência de fluxo de potência. Esses procedimentos são conforme discutidos no Capítulo 2;

- As distorções realizadas na etapa CE são focadas na estimativa da probabilidade. Estudos mostram pouca perda de qualidade de desempenho adotando essa estratégia [43, 45, 47].

\section{5}

\section{Comentários Finais}

Conforme se torna raro os eventos estudados, mais dispendiosa se torna a simulação para avaliação de sua características probabilísticas. Faz-se necessário, então, elaborar estratégias e metodologias que permitam manter a precisão e flexibilidade permitidas por SMC, com menor esforço computacional. As VRT reduzem a variância do estimador aumentando a eficiência de amostragem.

Dentre as TRV, destaca-se a entropia cruzada, técnica de amostragem por importância, como um algoritmo multinível, cujo resultado é um conjunto de parâmetros para as distribuições por amostragem por importância. Nesse capítulo, foram discutidos e estruturados os passos necessários para se definir as distribuições a serem utilizadas por um estimador por amostragem por importância. Também foram ilustrados exemplos introdutórios que vislumbram enorme redução de fardo computacional, mantendo a precisão dos resultados.

A combinação de simulação Monte Carlo e entropia cruzada, discutida nessa capítulo, é a base da ferramenta proposta para estimativa de eventos de risco relacionados a fluxo de potência probabilístico. Nesse dissertação, serão utilizados alguns sistemas testes para averiguar a eficiência resultante da proposta, bem como as possíveis análises decorrentes de sua aplicação. Os sistemas estudados, simulações e resultados são apresentados no Capítulo 4. 


\section{4}

\section{Simulações e Resultados}

\section{1 \\ Introdução}

O objetivo desse capítulo é apresentar o desempenho da metodologia proposta - simulação Monte Carlo e entropia cruzada (SMC-CE) - frente a eventos selecionados em sistemas teste IEEE. Para isso, utilizam-se três sistemas: 14 barras, RTS 79 e 118 barras.

Pela sua simplicidade, o sistema IEEE 14 barras é ideal para familiarização inicial e construção de sensibilidade acerca das potencialidades e possíveis desvantagens do método em proposição. Já o sistema IEEE RTS 79 é mais adequado para averiguar com maior critério as qualidades de se utilizar SMC-CE. Dessa forma, maior parte da análise será concentrada no estudo desse sistema. O IEEE 118 barras fornece contexto adequado para entendimento do funcionamento do método frente a um sistema de maior porte. Como será discutido, em todos os casos, há ganho em se utilizar SMC-CE.

Nesse capítulo, serão apresentadas as considerações gerais para simulação (as metodologias, o hardware e softwares utilizados) na Seção 4.2. Os resultados e análises para os três sistemas são ilustrados nas Seções 4.3 (IEEE 14 barras), 4.4 (IEEE RTS 79) e 4.5 (IEEE 118 barras). Os comentários finais são apresentados na Seção 4.6 .

\section{2}

\section{Considerações Gerais de Simulação}

Existem três metodologias, baseadas em simulação Monte Carlo, que serão utilizadas para comparação de desempenho nessa dissertação. São elas:

- Pré-definição de um número fixo de amostras a serem avaliadas (receberá o nome de simulação Monte Carlo por Amostragem Fixa - SMC-AF). Nesse caso, o objetivo geral é a construção de curvas de densidade (histogramas) para as variáveis de saídas de fluxo. Pode-se avaliar eventos a partir dos histogramas construídos, porém não é possível garantir resultados dentro de um intervalo de confiança escolhido. Quanto maior o número de amostras pré-selecionado, maior será a precisão dos 
resultados. Porém, as "caudas" das distribuições resultantes serão sempre as regiões com menor precisão; justamente a região cuja área se pretende estimar para calcular índices de risco.

- Seleção de eventos alvos e adoção de critério de parada por máximas iterações ou estimativa dentro de limites de confiança (SMC). Essa é a simulação Monte Carlo em sua versão convencional para estimativa de probabilidade de eventos.

- Combinação de simulação Monte Carlo e entropia cruzada (SMC-CE). Proposta nessa dissertação, essa metodologia visa permitir a flexibilidade e precisão advindas da SMC, com melhor desempenho computacional permitida por se definir distribuições por amostragem por importância, através do método da entropia cruzada.

As simulações SMC-AF serão úteis para se ter por base o mesmo método que é usualmente utilizado como forma geral de comparação sempre que se lança uma nova proposição de solução. Faz sentindo, também, comparar com o desempenho de SMC e SMC-CE para que seja possível avaliar quantitativamente o ganho em se adotar a estratégia dessa dissertação.

Os testes foram realizados em CPU Intel Core i7-6500U 2.5GHz, em plataforma MATLAB 2013.a e utilizando o package MATPOWER 6.0 para realização dos cálculos de fluxo de potência [53]. De forma geral, para a geração de números pseudo-aleatórios foi utilizada a seed 3000, e, acerca do fluxo de potência, a tolerância dos resíduos de potência foi definida em $1 \times 10^{-4}$, sendo o número máximo de iterações para o método de Newton especificado em 10.

\section{3}

\section{IEEE 14 Barras}

O IEEE 14 barras [54] é um sistema simples para análises introdutórias do que se pretende estudar. Há apenas duas centrais de geração, sendo uma delas conectada à barra considerada de referência. A regra de despacho utilizada é simples: especifica-se a geração da barra 2 no patamar de sua disponibilidade e o balanço final é realizado pela barra 1 (swing). Não há limites de fluxos em linha determinados e nem de geração para a barra swing. Dessa forma, utilizase esse sistema para compreensão inicial das potencialidades de se utilizar o método proposto, mesmo que nem todas as sua funcionalidades (e eventuais desafios) sejam postos a prova.

Os dados de rede são encontrados em [54] e os modelos probabilísticos para carga e geração são apresentados no Apêndice A. Em resumo, tem-se 2 centrais de geração e 3 compensadores síncronos. Das 14 barras do sistema, 11 
possuem conexão de carga (10 modeladas por distribuição normal e 1 modelada por distribuição discreta). A geração da barra 2 é regida por uma distribuição binomial.

\subsection{1}

\section{Exemplo Detalhado}

Considere que se deseja avaliar índices de risco para sobrecarga na linha 6, entre os barras 3 e 4 . Não há, por imposição dos dados do sistema, um valor limite definido para a linha a ser utilizado. Dessa forma, determina-se um valor considerando o fluxo no ramo, com os dados do caso base, acrescido de $50 \%$. Nesse caso, configura-se sobrecarga na linha, fluxos acima de 36.2224 MVA.

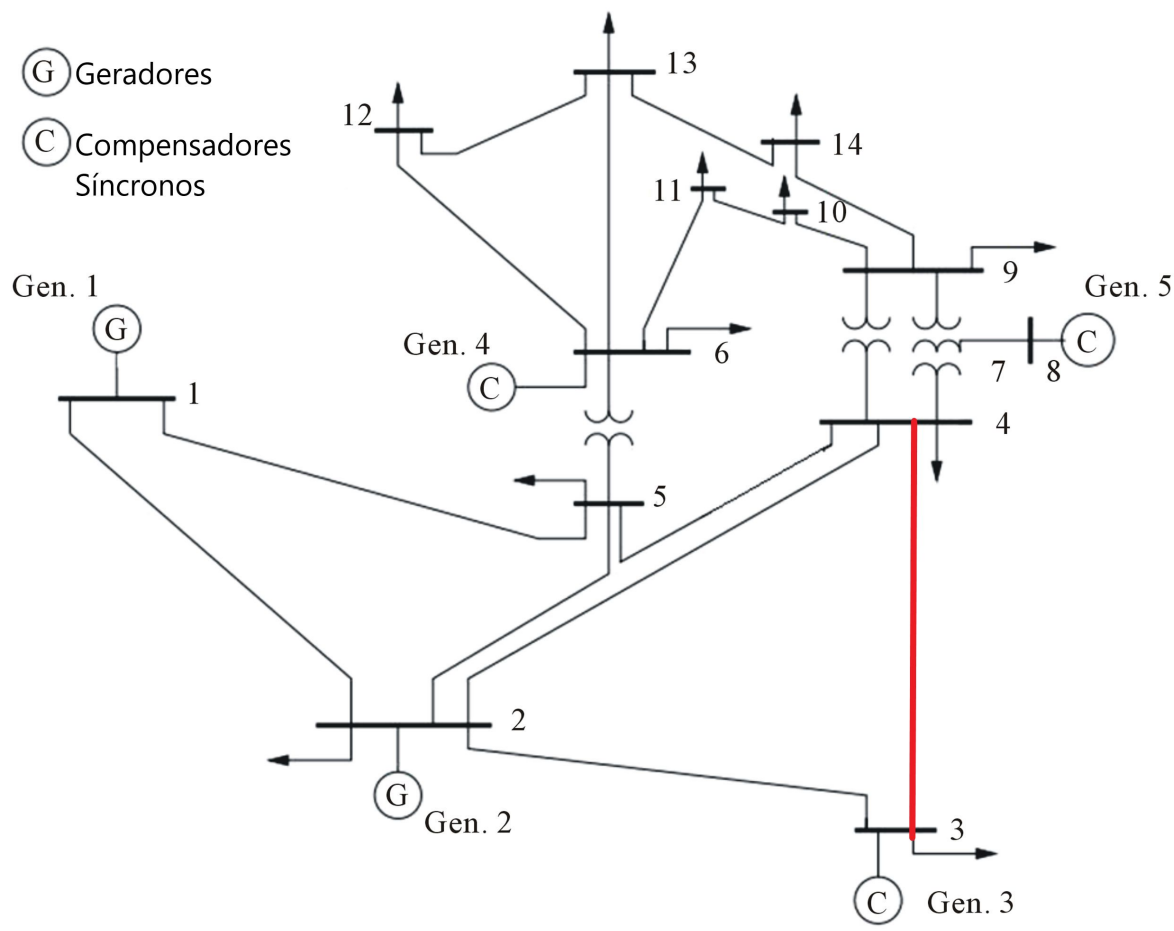

Figura 4.1: Diagrama unifilar para sistema IEEE 14 barras, com destaque para linha 3-4.

Nessa seção, serão comparados os resultados de 4 diferentes alternativas para estimativas desses índices: SMC-AF (com 5000 e 100000 amostras fixas), SMC e SMC-CE. Pretende-se avaliar o desempenho comparativo dentre essas estratégias de simulação. As simulações SMC e SMC-CE são interrompidas quando o coeficiente de variação da estimativa da probabilidade é igual ou menor do que 1\%. Estima-se a probabilidade de ocorrência de sobrecarga nessa linha $(P)$, o coeficiente de variação da estimativa da probabilidade $\left(\beta_{P}\right)$, o valor esperado condicional VEC (valor médio da sobrecarga) e o coeficiente de 
variação da estimativa da VEC ( $\left.\beta_{\mathrm{VEC}}\right)$. Para SMC-CE, utiliza-se $N c e=5000$, $\rho=0.01$ e $\alpha=0.999$. Chega-se, então, ao seguinte cenário:

Tabela 4.1: Resultados Comparativos para Estimativa de Probabilidade de Sobrecarga na Linha 3-4.

\begin{tabular}{ccccccc}
\hline & Amostras & tempo & $P$ & $\beta_{P}$ & $\begin{array}{c}\text { VEC } \\
\left(\times 10^{-3} \mathrm{MVA}\right)\end{array}$ & $\begin{array}{c}\beta_{\mathrm{VEC}} \\
(\%)\end{array}$ \\
\hline SMC-AF & 5.000 & 25 & 7,800 & 15,9502 & 12,1620 & 25,2605 \\
SMC-AF & 100.000 & 482 & 7,3500 & 3,6750 & 12,3080 & 4,8302 \\
SMC & 1.584 .001 & 7.010 & 6,2746 & 0,9999 & 9,7596 & 1,3685 \\
SMC-CE & 34.001 & $221^{*}$ & 6,4142 & 0,9871 & 9,8355 & 0,6901 \\
\hline
\end{tabular}

* Incluindo 49s da etapa da entropia cruzada.

A Tabela 4.1 ilustra a enorme vantagem computacional adquirida ao se utilizar a metodologia proposta nessa dissertação (SMC-CE) frente às demais alternativas, mesmo que se necessitem 49 segundos para a etapa da entropia cruzada. Em comparação com a simulação Monte Carlo convencional (SMC), têm-se resultados numéricos parecidos para os índices, com speedup de 32 vezes. Já as simulações SMC-AF, com 5.000 ou 100.000 amostras, não conseguem garantir a estimativa dentro de um valor especificado para o coeficiente de variação. Assim, os resultados dessas simulações não possuem precisão adequada.

Os produtos principais da SMC-CE são índices de risco, com precisão pré-determinada e em tempo reduzido. Porém, alguns subprodutos são interessantes de serem analisados. Por exemplo, as Tabelas 4.2 e 4.3 realizam uma comparação entre os valores esperados das distribuições originais e das por amostragem por importância (resultantes da simulação CE, chamadas aqui de distorcidas) para as cargas e geração. É possível perceber que a carga ativa do barra 3 possui a maior distorção relativa. Pode-se interpretar esse resultado como uma maior sensibilidade do fluxo aparente na linha 3-4 em relação a esse ponto de carga. Além disso, como visto na Tabela 4.3, o valor esperado da geração no barra 2 é reduzido, aumentando a necessidade de atendimento da carga na barra 3 a partir da linha 3-4. Também é possível perceber uma redução no valor esperado para a carga no barra 4, aumentando o fluxo direcionado para a linha. 
Tabela 4.2: Comparação entre Valores Esperados Normais e Distorcidos para Cargas Ativas e Reativas.

\begin{tabular}{ccccccc}
\hline barra & \multicolumn{3}{c}{ Carga Ativa } & \multicolumn{3}{c}{ Carga Reativa } \\
& Original & Distorcido & $\%$ & Original & Distorcido & $\%$ \\
\hline 2 & 21,74 & 21,7288 & $-0,0517$ & 12,70 & 12,7092 & 0,0728 \\
3 & 94,20 & 119,6328 & 26,9987 & 19,00 & 18,9862 & $-0,0724$ \\
4 & 47,80 & 47,1125 & $-1,4384$ & $-3,90$ & $-3,9044$ & 0,1140 \\
5 & 7,60 & 7,6047 & 0,1276 & 1,60 & 1,5978 & $-0,1362$ \\
6 & 11,20 & 11,1969 & $-0,0275$ & 7,50 & 7,4969 & $-0,0409$ \\
9 & 29,50 & 29,5769 & 0,2606 & 16,60 & 16,4638 & $-0,8204$ \\
10 & 9,00 & 9,0030 & 0,0338 & 5,80 & 5,8067 & 0,1160 \\
11 & 3,50 & 3,4824 & $-0,5036$ & 1,80 & 1,8033 & 0,1809 \\
12 & 6,10 & 6,0934 & $-0,1089$ & 1,60 & 1,5995 & $-0,0320$ \\
13 & 13,50 & 13,4811 & $-0,1401$ & 5,80 & 5,7838 & $-0,2800$ \\
14 & 14,90 & 14,9255 & 0,1710 & 5,00 & 5,0020 & 0,0404 \\
\hline
\end{tabular}

Tabela 4.3: Comparação entre Valores Esperados Normais e Distorcidos para Geração Ativa.

\begin{tabular}{cccc}
\hline barra & \multicolumn{3}{c}{ Geração Ativa } \\
& Original & Distorcido & $\%$ \\
\hline 2 & 40,04 & 39,7056 & $-0,8351$ \\
\hline
\end{tabular}

As Tabelas 4.4 e 4.5 mostram o impacto da distorção no fluxo ativo e reativo na linha e na potência injetada na barra swing, respectivamente. Percebe-se que as distribuições distorcidas aumentam drasticamente a média dos fluxos ativos e reativo. Aumenta-se também a injeção de potência na barra swing, fortalecendo atendimento a carga na barra 3, a partir da linha 3-4.

Tabela 4.4: Comparação entre Valores Esperados para Fluxo na Linha 3-4.

\begin{tabular}{cccc}
\hline Fluxo & Original & Distorcido & $\%$ \\
\hline$P_{3-4}$ Médio (MW) & $-23,15$ & $-34,68$ & 49,6056 \\
$Q_{3-4}$ Médio (MVAR) & 6,37 & 11,22 & 76,1381 \\
\hline
\end{tabular}


Tabela 4.5: Comparação entre Valores Esperados para Potência Injetada na Barra Swing.

\begin{tabular}{cccc}
\hline Potência Injetada & Original & Distorcido & $\%$ \\
\hline$P$ Médio (MW) & 232,65 & 261,50 & 12,4006 \\
$Q$ Médio (MVAR) & $-15,61$ & $-21,30$ & 36,4510 \\
\hline
\end{tabular}

A Figura 4.2 ilustra histogramas para o fluxo aparente na linha 3-4, a partir de sorteios da distribuições original (esquerda) e distorcida (direita). Como se percebe, a região de sobrecarga é muito mais recorrentemente amostrada quando se utilizam as distribuições por amostragem por importância.
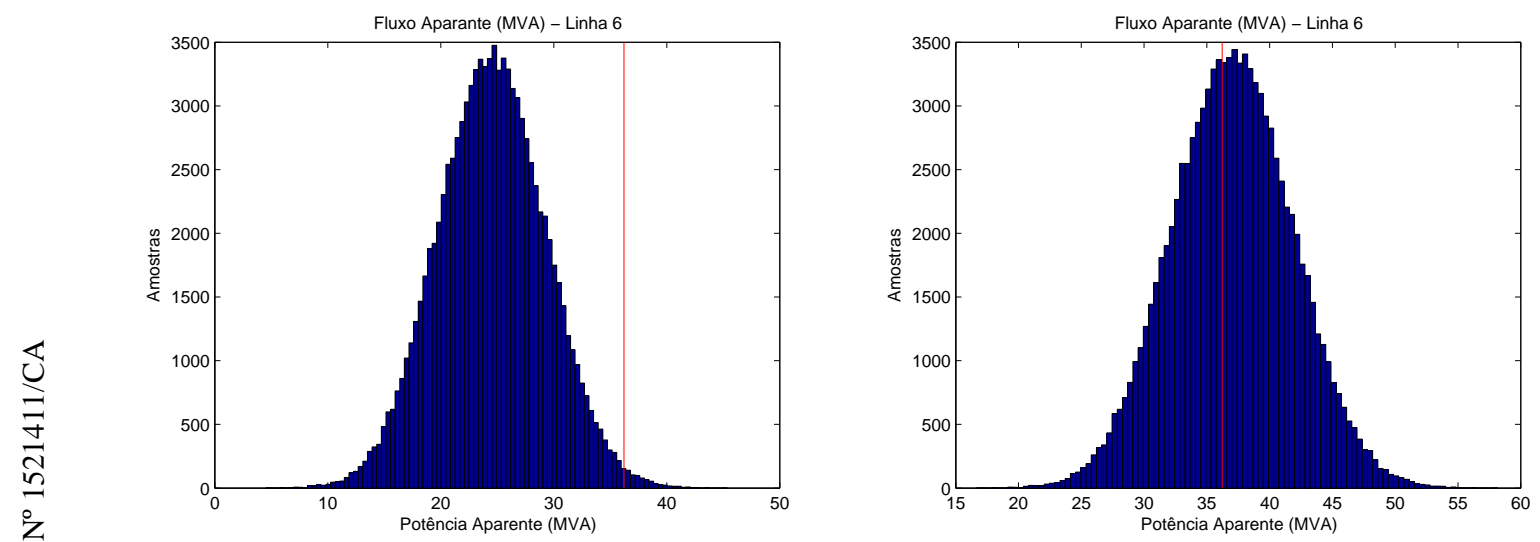

Figura 4.2: Histograma para fluxo aparente na linha 3-4, a partir das distribuições original (esquerda) e distorcida (direita).

\section{4}

\section{IEEE RTS 79}

O sistema IEEE RTS 79 é objeto de diversos estudos em sistemas de energia elétrica, também utilizado em questões que tangem análises probabilísticas e confiabilidade. Os dados de rede podem ser encontrado em [55, 57]. No Apêndice B são apresentados os modelos probabilísticos utilizados.

Esse sistema é mais completo e abrangente para que seja possível avaliar, quantitativa e qualitativamente, a ferramenta proposta nessa dissertação. De maneira geral, têm-se 32 unidades de geração, com capacidade nominal entre 12 a 400 MW. Ao contrário do que se teve com IEEE 14 barras, é necessário aqui avaliar se a geração requerida total está disponível para ser despachada. Em outras palavras, a injeção pelas unidades conectadas na barra de referência precisa respeitar seus limites máximos, ao mesmo tempo que essas unidades não podem funcionar como cargas. 
As regras operativas da função despacho, por ordem de mérito, e corte de carga (por insuficiência de geração) são colocadas em funcionamento. Aproxima-se, dessa forma, de uma condição de simulação mais próximas as realizadas em etapas de planejamento. Outro fator importante é a manutenção do fator de potência constante para os pontos de carga, amostrando-se apenas a potência ativa e, a partir desse valor, determinando-se a reativa.

Para aumentar o carregamento do sistema, os patamares de carga e geração foram multiplicados por um fator de 1,5.

\subsection{1}

\section{Exemplo Detalhado}

Considere que se deseja avaliar índices de risco de subtensão (magnitude menor do que 0.95 p.u.) para o barra 4 do sistema. A Figura 4.3 ilustra o diagrama unifilar, com destaque para o barra em questão.

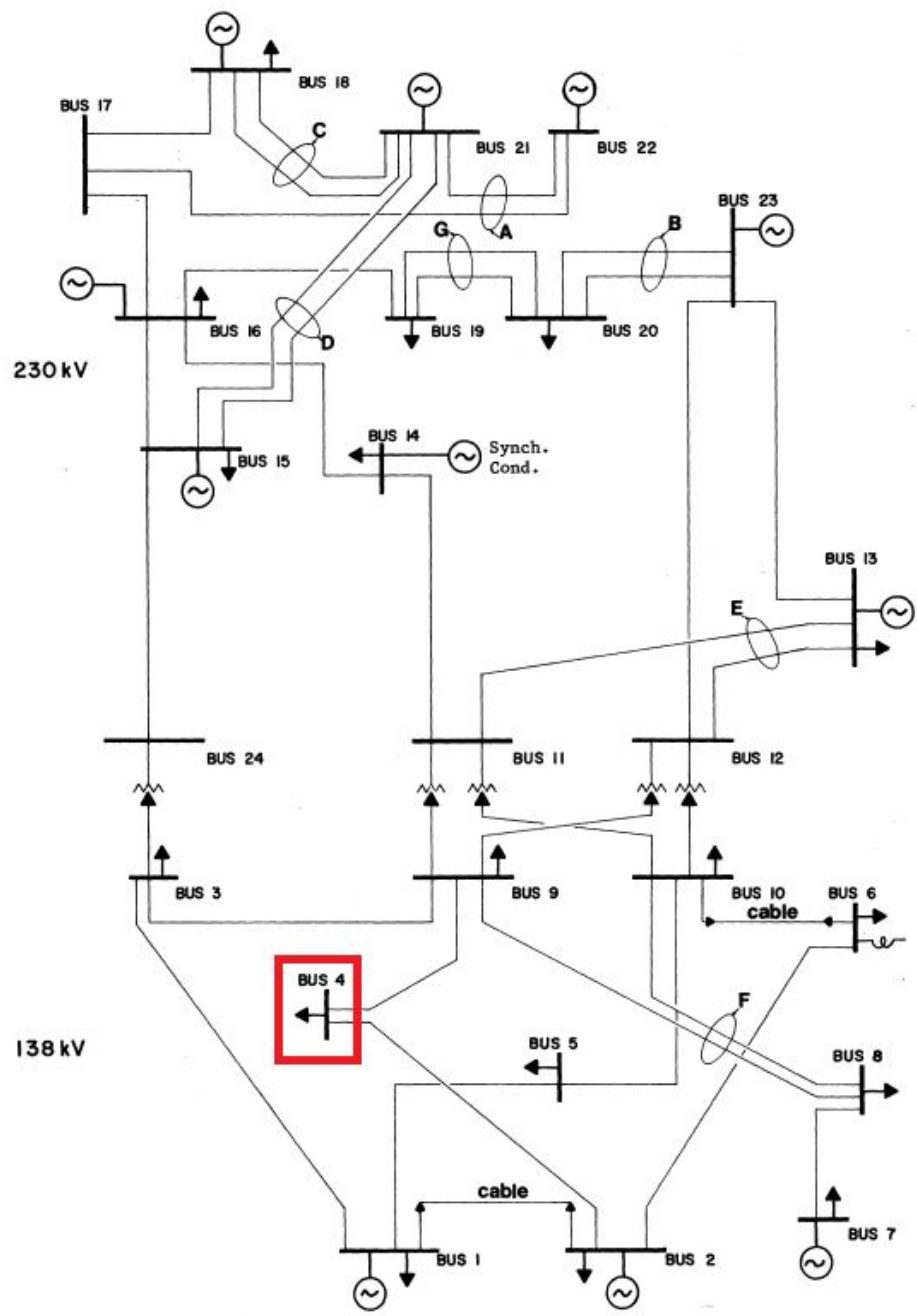

Figura 4.3: Diagrama unifilar para sistema IEEE RTS 79, com destaque para barra 4 . 
Novamente, são realizados 4 alternativas de simulação e os resultados gerais são apresentados na Tabela 4.6.

Tabela 4.6: Resultados Comparativos para Estimativa de Probabilidade de Subtensão na Barra 4.

Amostras tempo $P \quad \beta_{P} \quad$ VEC $\quad \beta_{\mathrm{VEC}}$

\begin{tabular}{ccccccc} 
& & $(\mathrm{s})$ & $\left(\times 10^{-3}\right)$ & $(\%)$ & $\left(\times 10^{-5}\right.$ p.u. $)$ & $(\%)$ \\
\hline SMC-AF & 5.000 & 47 & 3,6000 & 23,5278 & $-1,0734$ & 30,5609 \\
SMC-AF & 100.000 & 1.002 & 2,7201 & 6,0551 & $-1,1132$ & 8,1125 \\
SMC & 3.565 .913 & 32.827 & 2,7968 & 0,9999 & $-1,1811$ & 1,3867 \\
SMC-CE & 228.403 & $2.480^{*}$ & 2,7773 & 0,9986 & $-1,1502$ & 1,0469 \\
\hline
\end{tabular}

* Incluindo 115 s da etapa da entropia cruzada.

Pela Tabela 4.6, percebe-se (contando com a etapa da entropia cruzada) um speed-up de 13 vezes entre SMC e SMC-CE, para mesma precisão resultados.

A simulação com entropia cruzada ainda permite análise interessante do funcionamento do sistema. Pela Tabela 4.7, percebe-se pouco impacto do uso de distribuições por amostragem por importância no valor esperado de carga nos pontos de demanda. A maior distorção é causada na própria barra 4, aumentado a carga esperada nesse ponto, o que aumenta o carregamento de potência para supri-la, acarretando em problemas de tensão. A análise mais proveitosa é a distorção no perfil de geração do sistema. Como se percebe na Tabela 4.8, para estressar a rede elétrica, a ponto de prejudicar a manutenção da tensão do barra 4 dentre a faixa nominal, a geração é transferida para os pontos mais distantes eletricamente dessa barra. As centrais de geração mais próximas têm seu valor esperado reduzido, enquanto as mais distantes aumentam (até 29\%) a média de geração com as distribuições distorcidas. 
Tabela 4.7: Comparação entre Valores Esperados Normais e Distorcidos para Cargas Ativa.

\begin{tabular}{cccc}
\hline barra & \multicolumn{3}{c}{ Carga Ativa Esperada } \\
& Original & Distorcido & $\%$ \\
\hline 1 & 162,0 & 162,4281 & 0,2643 \\
2 & 145,5 & 145,7952 & 0,2029 \\
3 & 270,0 & 271,9830 & 0,7344 \\
4 & 111,0 & 112,2245 & 1,1032 \\
5 & 106,5 & 106,7960 & 0,2779 \\
6 & 204,0 & 204,6422 & 0,3148 \\
7 & 187,5 & 188,1217 & 0,3316 \\
8 & 256,5 & 258,2482 & 0,6815 \\
9 & 262,5 & 262,4685 & $-0,012$ \\
10 & 292,5 & 294,1969 & 0,5801 \\
13 & 397,5 & 396,4771 & $-0,2573$ \\
14 & 291,0 & 289,8978 & $-0,3788$ \\
15 & 475,5 & 474,5885 & $-0,1917$ \\
16 & 150,0 & 150,3072 & 0,2048 \\
18 & 499,5 & 499,4193 & $-0,0162$ \\
19 & 271,5 & 271,6086 & 0,0567 \\
20 & 192,0 & 191,6086 & $-0,2038$ \\
\hline
\end{tabular}

Tabela 4.8: Comparação entre Valores Esperados Normais e Distorcidos para Geração Ativa.

\begin{tabular}{cccc}
\hline \multirow{2}{*}{ barra } & \multicolumn{3}{c}{ Geração Ativa Esperada } \\
& Original & Distorcido & $\%$ \\
\hline 1 & 267,5712 & 253,2231 & $-5,3624$ \\
2 & 267,5712 & 255,6697 & $-4,4480$ \\
7 & 414,7200 & 324,8080 & $-21,6802$ \\
13 & 800,0662 & 800,5025 & 0,0545 \\
15 & 300,7080 & 312,1682 & 3,8111 \\
16 & 214,2720 & 223,8038 & 4,4485 \\
18 & 464,6400 & 599,9808 & 29,1281 \\
21 & 464,6400 & 599,9808 & 29,1281 \\
22 & 441,0450 & 440,5394 & $-0,1146$ \\
23 & 872,9040 & 967,4399 & 10,8301 \\
\hline
\end{tabular}


As Tabelas 4.9 e 4.10 também corroboram com o fato de haver mudança no perfil de atendimento à demanda na barra 4. Após a distorção, há acréscimo mais significativo no fluxo esperado da linha 8, entre os barras 9 e 4 .

Tabela 4.9: Comparação entre Valores Esperados para Fluxo na Linha 4 (barra 2 para 4$)$.

\begin{tabular}{cccc}
\hline Fluxo & Original & Distorcido & $\%$ \\
\hline$P_{2-4}$ Médio (MW) & 65,11 & 62,58 & $-3,8857$ \\
$Q_{2-4}$ Médio (MVAR) & 41,32 & 45,26 & 9,5353 \\
\hline
\end{tabular}

Tabela 4.10: Comparação entre Valores Esperados para Fluxo na Linha 8 (barra 9 para 4 ).

\begin{tabular}{cccc}
\hline Fluxo & Original & Distorcido & $\%$ \\
\hline$P_{9-4}$ Médio (MW) & 47,69 & 52,52 & 10,1279 \\
$Q_{9-4}$ Médio (MVAR) & $-14,75$ & $-17,32$ & 17,4237 \\
\hline
\end{tabular}

A Figura 4.4 ilustra histogramas para a magnitude de tensão na barra 4, a partir de sorteios da distribuições original (esquerda) e distorcida (direita). Como se percebe, a região de subtensão é muito mais recorrentemente amostrada quando se utilizam as distribuições por amostragem por importância.
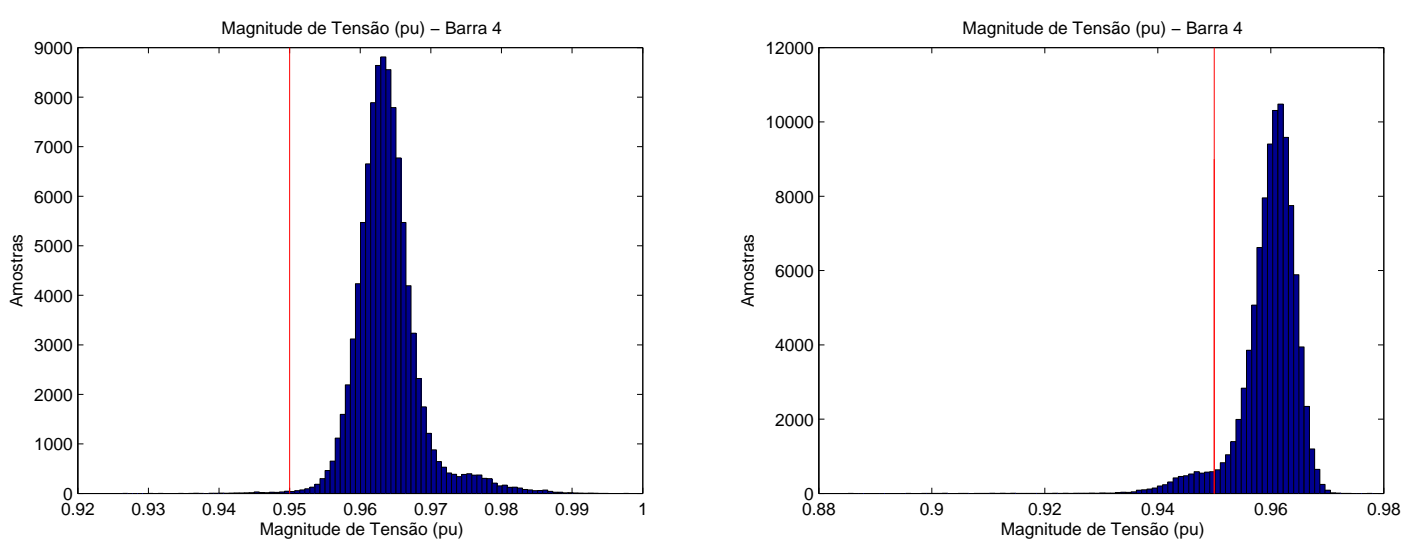

Figura 4.4: Histograma para magnitude de tensão na barra 4, a partir das distribuições original (esquerda) e distorcida (direita).

\subsection{2}

\section{Outros Resultados}

Nessa seção, alguns resultados adicionais são apresentados para os eventos: subtensão nas barras 8, 11 e 12, Tabelas 4.11, 4.12 e 4.13, respectivamente; e sobrecarga nas linhas 8-9 e 16-17, Tabelas 4.14 e 4.15, respectivamente. 
Tabela 4.11: Resultados Comparativos para Estimativa de Probabilidade de Subtensão em Barra 8.

\begin{tabular}{ccccccc} 
& Amostras & tempo & $P$ & $\beta_{P}$ & $\begin{array}{c}\text { VEC } \\
(\times)\end{array}$ & $\begin{array}{c}\beta_{\mathrm{VEC}} \\
\left(\times 10^{-4} \text { p.u. }\right)\end{array}$ \\
& & $(\mathrm{s})$ & & $(\%)$ \\
\hline SMC-AF & 5.000 & 47 & 0,1500 & 3,3665 & $-3,7640$ & 6,5270 \\
SMC-AF & 100.000 & 1.002 & 0,1576 & 0,7310 & $-3,7153$ & 1,4759 \\
SMC & 54.940 & 545 & 0,1564 & 0,9907 & $-3,6669$ & 1,9858 \\
SMC-CE & 21.996 & $287^{*}$ & 0,1566 & 0,9966 & $-3,9103$ & 3,8755 \\
\hline
\end{tabular}

* Incluindo $54 \mathrm{~s}$ da etapa da entropia cruzada.

Tabela 4.12: Resultados Comparativos para Estimativa de Probabilidade de Subtensão em Barra 11.

$\begin{array}{lllll}\text { Amostras } & \text { tempo } & P & \beta_{P} & \text { VEC }\end{array}$

\begin{tabular}{ccccccc} 
& & $(\mathrm{s})$ & $\left(\times 10^{-4}\right)$ & $(\%)$ & $\left(\times 10^{-6}\right.$ p.u. $)$ & $(\%)$ \\
\hline SMC-AF & 5.000 & 47 & 6,0000 & 57,7177 & $-1,1802$ & 78,4457 \\
SMC-AF & 100.000 & 1.002 & 7,2002 & 11,7809 & $-2,0760$ & 17,2799 \\
SMC & 13.694 .152 & 118.350 & 7,2973 & 0,9999 & $-2,3239$ & 1,6434 \\
SMC-CE & 275.237 & $3.225^{*}$ & 7,4439 & 0,9986 & $-2,3806$ & 1,2127 \\
\hline
\end{tabular}

* Incluindo $176 \mathrm{~s}$ da etapa da entropia cruzada.

Tabela 4.13: Resultados Comparativos para Estimativa de Probabilidade de Subtensão em Barra 12.

\begin{tabular}{ccccccc} 
& Amostras & tempo & $P$ & $\beta_{P}$ & VEC & $\beta_{\mathrm{VEC}}$ \\
& & $(\mathrm{s})$ & $\left(\times 10^{-3}\right)$ & $(\%)$ & $\left(\times 10^{-6}\right.$ p.u. $)$ & $(\%)$ \\
\hline SMC-AF & 5.000 & 47 & 1,6000 & 35,3270 & $-6,0960$ & 42,4307 \\
SMC-AF & 100.000 & 1.002 & 1,6100 & 7,8748 & $-6,7186$ & 11,0036 \\
SMC & 6.221 .231 & 53.350 & 1,6051 & 0,9999 & $-7,0828$ & 1,4922 \\
SMC-CE & 184.384 & $2.374^{*}$ & 1,5868 & 0,9992 & $-7,0141$ & 1,0966 \\
\hline
\end{tabular}

* Incluindo 169 s da etapa da entropia cruzada. 
Tabela 4.14: Resultados Comparativos para Estimativa de Probabilidade de Sobrecarga em Linha 8-9.

\begin{tabular}{ccccccc}
\hline & Amostras & tempo & $P$ & $\beta_{P}$ & $\begin{array}{c}\text { VEC } \\
\left(\times 10^{-2} \mathrm{MVA}\right)\end{array}$ & $\begin{array}{c}\beta_{\mathrm{VEC}} \\
(\%)\end{array}$ \\
\hline SMC-AF & 5.000 & 47 & 0,8000 & 49,9800 & 0,3818 & 55,7440 \\
SMC-AF & 100.000 & 1.002 & 1,5400 & 8,0520 & 1,3632 & 11,3425 \\
SMC & 7.058 .408 & 60.846 & 1,4150 & 0,9999 & 1,1768 & 1,6425 \\
SMC-CE & 300.937 & $3.751^{*}$ & 1,4640 & 0,9993 & 1,2134 & 1,4237 \\
\hline
\end{tabular}

* Incluindo $137 \mathrm{~s}$ da etapa da entropia cruzada.

Tabela 4.15: Resultados Comparativos para Estimativa de Probabilidade de Sobrecarga em Linha 16-17.

\begin{tabular}{ccccccc}
\hline & Amostras & $\begin{array}{c}\text { tempo } \\
(\mathrm{s})\end{array}$ & $\begin{array}{c}P \\
\left(\times 10^{-2}\right)\end{array}$ & $\begin{array}{c}\beta_{P} \\
(\%)\end{array}$ & $\begin{array}{c}\text { VEC } \\
(\mathrm{MVA})\end{array}$ & $\begin{array}{c}\beta_{\mathrm{VEC}} \\
(\%)\end{array}$ \\
\hline SMC-AF & 5.000 & 47 & 3,7000 & 7,2148 & 0,2108 & 12,4961 \\
SMC-AF & 100.000 & 1.002 & 3,8510 & 1,6399 & 0,1896 & 2,9519 \\
SMC & 264.776 & 2.275 & 3,6484 & 0,9987 & 0,2093 & 1,8513 \\
SMC-CE & 66.000 & $871^{*}$ & 3,5986 & 0,9996 & 0,1791 & 2,2560 \\
\hline
\end{tabular}

* Incluindo $118 \mathrm{~s}$ da etapa da entropia cruzada.

É possível perceber pelos resultados mostrados que, quanto mais raro for o evento a ser estimado, maior será a vantagem computacional de se utilizar a metodologia proposta. Por exemplo, a Tabela 4.11 mostra estimativa de probabilidade de ordem $10^{-1}$ e SMC-CE permitiu speed-up de aproximadamente 2 vezes. Já a Tabela 4.12 ilustra estimativa de probabilidade de ordem $10^{-4}$, sendo o speed-up de 37 vezes, quando utilizada SMC-CE.

Assim, por mais que a diferença em se utilizar a metodologia proposta se torne mais evidente para eventos mais raros, ainda existe benefício em se empregar a ferramenta para estimativa de probabilidades mais elevadas.

\section{5}

\section{IEEE 118 barras}

Para avaliar a metodologia proposta frente a um sistema com maior número de elementos e, por consequência, com maior dimensão de espaço de estados, o sistema IEEE 118 barras é adotado. Os dados de rede são encontrados em [56] e o Apêndice C apresenta os modelos probabilísticos utilizados e a ordem de mérito criada para despacho dos geradores. 
Novamente, esse sistema requer a utilização das regras operativas apresentadas para corte de carga por insuficiência de geração e despacho de geradores, por ordem de mérito.

Além disso, os testes realizados são considerando um fator de multiplicação de 2,0, para aumentar o carregamento do sistema. 


\subsection{1}

\section{Exemplo Detalhado}

Considere que se deseja avaliar índices de sobrecarga na linha de transmissão 117, entre os barras 74 e 75. A Figura 4.5 ilustra o diagrama unifilar, com destaque para o ramo em questão. Considera-se sobrecarga nesse ramo, fluxos acima de 106 MVA.

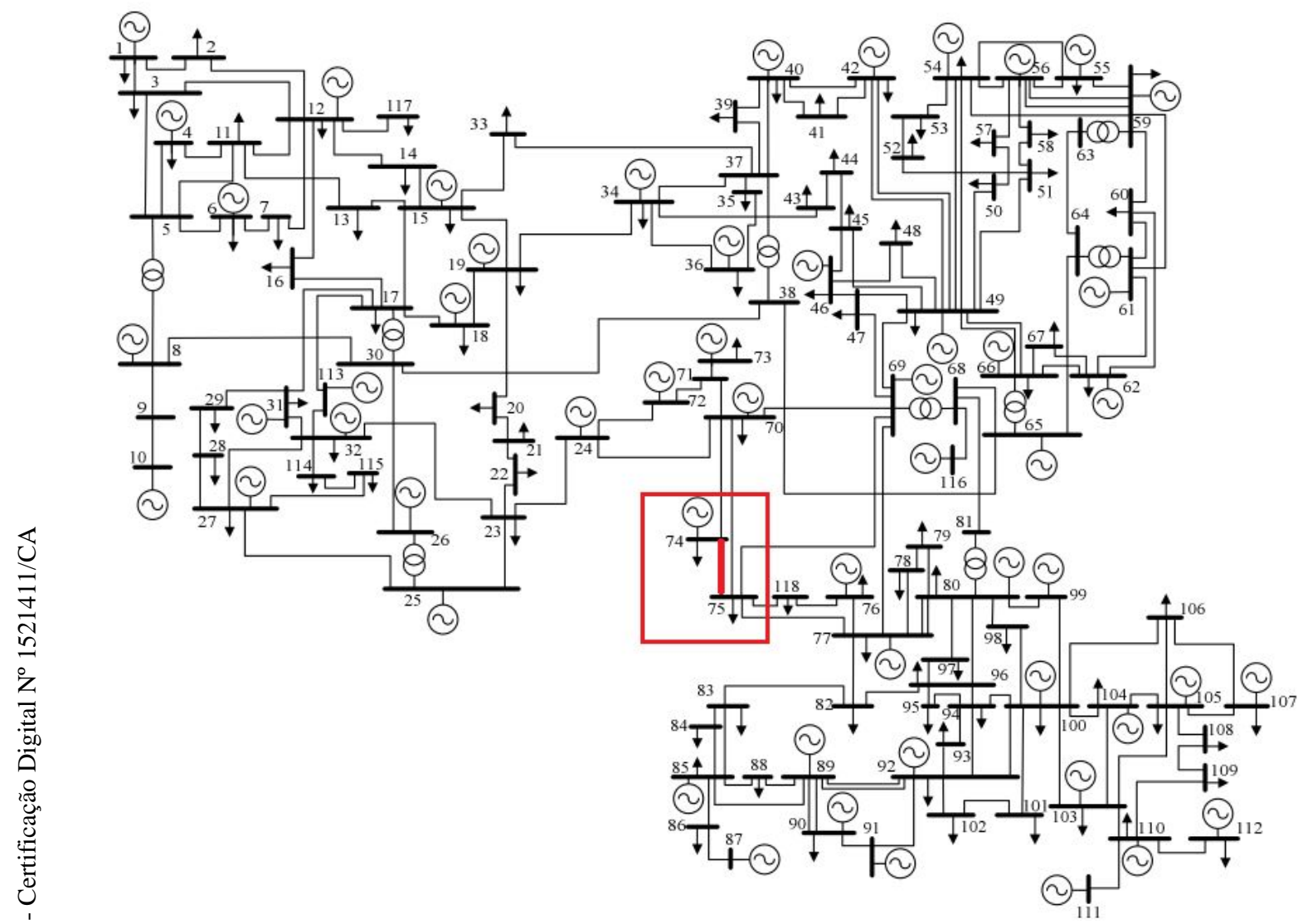

Figura 4.5: Diagrama unifilar para sistema IEEE 118 barras, com destaque para linha $74-75$

A Tabela 4.16 apresenta os resultados de estimativa de probabilidade e valor esperado condicional para a ocorrência de sobrecarga no ramo 74-75, com quatro alternativas de simulação. 
Tabela 4.16: Resultados Comparativos para Estimativa de Probabilidade de Sobrecarga na Linha 74-75.

\begin{tabular}{ccccccc}
\hline & Amostras & tempo & $P$ & $\beta_{P}$ & $\begin{array}{c}\text { VEC } \\
(\mathrm{s})\end{array}$ & $\begin{array}{c}\beta_{\mathrm{VEC}} \\
\left(\times 10^{-3}\right)\end{array}$ \\
& & $\%)$ & $\left(\times 10^{-2} \mathrm{MVA}\right)$ & $(\%)$ \\
\hline SMC-AF & 5.000 & 109 & 4,6000 & 20,8034 & 1,2652 & 28,0637 \\
SMC-AF & 100.000 & 2.165 & 5,3800 & 4,2997 & 1,6176 & 6,0598 \\
SMC & 1.851 .000 & 25.832 & 5,3776 & 0,9999 & 1,7186 & 1,4384 \\
SMC-CE & 228.403 & $3.401^{*}$ & 5,3908 & 0,9984 & 1,7432 & 1,0301 \\
\hline
\end{tabular}

* Incluindo 258s da etapa da entropia cruzada.

Contabilizando o tempo necessário para a etapa da entropia cruzada, há um speed-up de 8 vezes da metodologia proposta, frente a simulação Monte Carlo convencional. Em relação às simulações SMC-AF, com 5.000 ou 100.000 amostras, novamente há que se ressaltar que os valores estimados não se encontram dentro da faixa adotada para coeficiente de variação (menor ou igual a $1 \%$ ).

Em relação à distribuições por amostragem por importância, não há distorções relevantes no tanger das cargas, porém, novamente, há uma alteração no perfil de geração. Como se percebe na Tabela 4.17, há redução da geração esperada de centrais distantes eletricamente da linha 74-75 e aumento nas barras mais próxima, estressando os ramos dessa área elétrica. 
Tabela 4.17: Comparação entre Valores Esperados Normais e Distorcidos para Geração Ativa.

\begin{tabular}{cccc}
\hline barra & \multicolumn{3}{c}{ Geração Ativa Esperada } \\
& Original & Distorcido & $\%$ \\
\hline 10 & 873,00 & 855,7380 & $-1,9773$ \\
12 & 168,30 & 168,2223 & $-0,0462$ \\
25 & $1.067,00$ & $1.014,2202$ & $-4,9466$ \\
26 & 602,88 & 516,3107 & $-14,3593$ \\
31 & 13,86 & 13,8676 & 0,0547 \\
46 & 37,62 & 37,4407 & $-0,4766$ \\
49 & 395,76 & 399,5465 & 0,9568 \\
54 & 95,04 & 95,2658 & 0,2376 \\
59 & 306,90 & 307,2395 & 0,1106 \\
61 & 313,60 & 317,3663 & 1,2010 \\
65 & 768,00 & 787,9208 & 2,5939 \\
66 & 768,32 & 773,9835 & 0,7371 \\
69 & 999,10 & $1.010,5338$ & 1,1444 \\
80 & 915,84 & 950,8177 & 3,8192 \\
87 & 7,92 & 8,0000 & 1,0101 \\
89 & $1.173,70$ & $1.205,2142$ & 2,6850 \\
100 & 493,92 & 502,8869 & 1,8155 \\
103 & 79,20 & 79,4778 & 0,3507 \\
111 & 142,56 & 142,8281 & 0,1881 \\
\hline & & &
\end{tabular}

A Tabela 4.18 mostra o impacto da distorção no fluxo ativo e reativo na linha 74-75. Percebe-se que as distribuições distorcidas aumentam drasticamente a média dos fluxos ativos e reativo.

Tabela 4.18: Comparação entre Valores Esperados para Fluxo na Linha 74-75.

\begin{tabular}{cccc}
\hline Fluxo & Original & Distorcido & $\%$ \\
\hline$P_{74-75}$ Médio (MW) & $-73,93$ & $-83,41$ & 12,8229 \\
$Q_{74-75}$ Médio (MVAR) & 29,15 & 33,17 & 13,7907 \\
\hline
\end{tabular}

A Figura 4.6 ilustra histogramas para o fluxo aparente na linha 74-75, a partir de sorteios da distribuições originais (esquerda) e distorcidas (direita). Como se percebe, a região de sobrecarga é muito mais recorrentemente amostrada quando se utilizam as distribuições por amostragem por importância. 

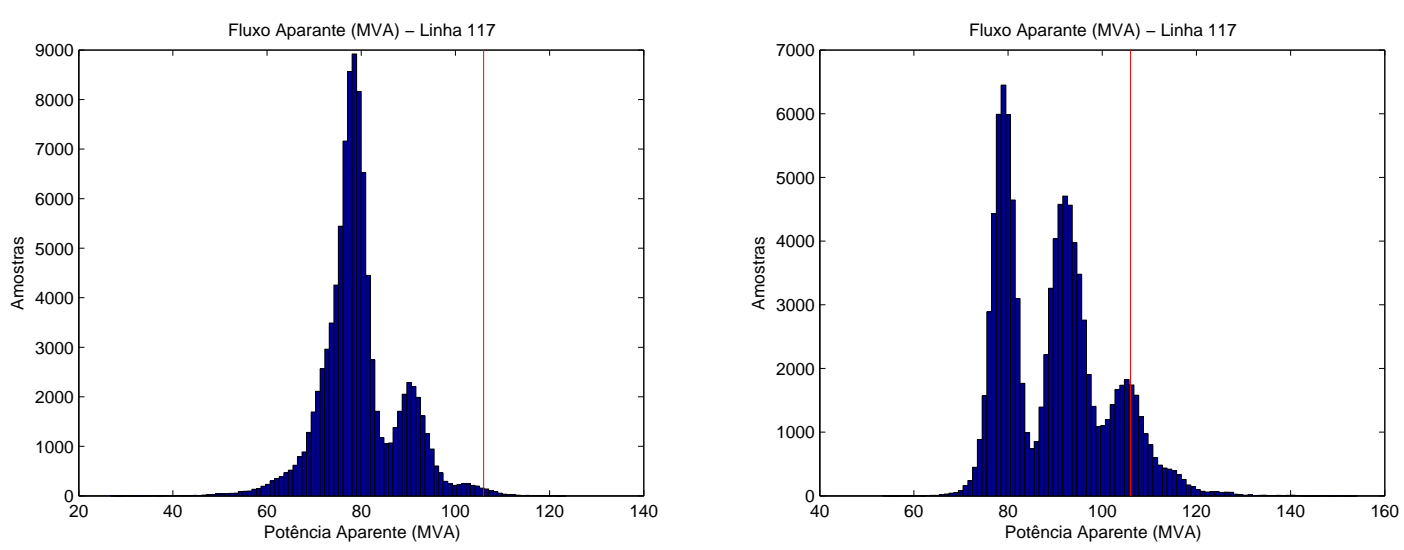

Figura 4.6: Histograma para fluxo aparente na linha 74-75, a partir das distribuições originais (esquerda) e distorcidas (direita).

\section{6}

\section{Comentários Finais}

Nesse capítulo foram apresentados os resultados da metodologia proposta (SMC-CE) para estimativa de eventos de risco, em sistema de energia, em comparação com outras alternativas (SMC e SMC-AF). Os sistemas avaliados são os IEEE 14 barras, RTS 79 e 118 barras. Há ganho em se utilizar a entropia cruzada, não só no tampo computacional exigido para convergência (houve speed-up de até 37 vezes), mas também em análise de sensibilidade a partir das distorções das distribuições de probabilidade ocasionadas pela etapa de amostragem por importância. Há que se ressaltar quanto mais raro o evento analisado, maior será o speed-up decorrente da utilização de SMC-CE.

Os resultados para os índices estão dentro de coeficiente de variação préestipulado, o que garante a precisão de seus valores. Dessa forma, a metodologia é recomendada para avaliação de cenários de risco, em etapas de planejamento. As metodologias SMC-AF, com 5.000 ou 100.000 amostras, geram resultados ainda imprecisos, pois não estão focando em um evento específico e impondo a necessidade de convergência da estimativa.

As distribuições por amostragem por importância são distorcidas com foco em um evento determinado (um equipamento e um alvo). Assim, para mapeamentos generalistas, no quais não se pretende obter resultados com precisão adequada, recomenda-se utilizar SMC-AF, com número elevado de amostras fixas (como 100.000).

A metodologia também pode ser utilizada para detecção de eventos raríssimos ou improváveis. Ainda na etapa da entropia cruzada, se após um número determinado de iterações, o número de ocorrências do evento analisado for muito menor do que o número de amostras utilizadas na otimização (por 
exemplo menor do que 1\%), o evento pode ser considerado raríssimo ou improvável e a simulação interrompida. Entende-se que eventos dessa ordem não são relevantes para analistas em etapas de planejamento. 


\section{5}

\section{Conclusões}

Nessa dissertação foi apresentada uma metodologia que combina simulação Monte Carlo e o método da entropia cruzada como estratégia de estimativa de eventos de risco em sistema de energia elétrica. Entende-se que, em etapas de planejamento da expansão ou operação, faz sentido avaliar probabilidade de ocorrência de eventos anormais, como sobrecarga e desvios de tensão da região normal. Para tanto, propõe-se uma ferramenta que gera resultados com precisão pré-estipulada, em tempo computacional reduzido.

É possível considerar que, conforme foram apresentados no Capítulo 2, as técnicas analíticas de fluxo de potência probabilístico não são adequadas para estimativa de caudas de distribuições e, desse modo, não são recomendadas para estudos de análise de risco. Além disso, a maioria dessas técnicas requerem simplificações e hipóteses que limitam a qualidade de seus resultados. Em muitos casos, também, há a necessidade de se comparar o modelo proposto com a simulação Monte Carlo, para avaliar a sintonia dos parâmetros pertinentes.

Discutiu-se, também, que, apesar de garantir enorme flexibilidade e não requisitar simplificações (pode-se, por exemplo, adotar as equações originais não lineares de fluxo de potência), a simulação Monte Carlo convencional (SMC) demanda enorme recurso computacional, ocasionando em tempo de simulação elevado.

A ferramenta proposta, então, permite manter as vantagens da utilização de SMC, enquanto aprimora seu ponto fraco: tempo computacional exigido. Viu-se, no Capítulo 4, que existe uma diferença mensurável entre o número de amostras necessários para convergência de SMC e SMC-CE, sempre com vantagem para a última. Ao reduzir a exigência de amostras, reduz-se o tempo necessário.

Porém, é importante ressaltar que a metodologia proposta é, por enquanto, adequada para análises de eventos específicos e pré-determinados, visto que a etapa da entropia cruzada realiza uma otimização das distribuições focando apenas no alvo selecionado. Diferentes eventos possuem diferentes distribuições ótimas para amostragem por importância. Assim, se o objetivo for um mapeamento generalista do risco em um sistema elétrico, sem preocupação com a precisão dos resultados, recomenda-se utilizar a simulação Monte Carlo, 
com número fixo de amostras (chamada PPF, nessa dissertação).

Por fim, considera-se vantajosa a utilização da entropia cruzada por, não somente os resultados precisos em tempo reduzido, aumentar a sensibilidade do analista quanto às alterações que maior impacto causam nos eventos estudados. Viu-se, por exemplo, Seção 4.4.1, que se aumenta drasticamente o problema de subtensão no barramento 4 quando o perfil de geração dos sistema elétrico é alterado para pontos distantes, eletricamente, da barra em questão.

\section{1}

Propostas para trabalhos futuros

O objetivo dessa dissertação era propor um método para estimativa de eventos de risco, com precisão e em tempo reduzido. Ao invés de o objeto ser a estimativa das distribuições das variáveis de saída, pretende-se avaliar a cauda dessas, com precisão elevada e pré-determinada.

Entende-se que muitas aplicações e alternativas não foram exploradas nesse trabalho. Pode-se citar:

- Inserção de fontes renováveis de geração para avaliação dos impactos destas na rede elétrica e os eventos de risco relacionados. Essa aplicação é pertinente em etapa de planejamento de construção de novas fazendas eólicas, por exemplo, e da rede de transmissão necessária para a captação da energia gerada nessas centrais;

- Explorar índices de riscos de áreas elétricas, aos invés de se focar apenas em um elemento do sistema de energia;

- Avaliação de probabilidade de ultrapassagem de montante de uso de sistema de transmissão (MUST) ou uso do sistema de distribuição (MUSD), em sistemas elétricos de distribuição. Concessionárias de distribuição são anualmente requisitadas a realizar contratação de MUST e/ou MUSD para cada fronteira de seu sistema com a rede básica de transmissão ou outras concessionárias de distribuição. O evento avaliado nesse caso, seria a probabilidade da injeção de potência nos barramentos de fronteira ser maior do que o contratado. Além do índice por si, ganhar-se-ia a sensibilidade dos equipamentos que possuem maior impacto na ocorrência da ultrapassagem do valor contrato, a partir das distribuições por amostragem por importância;

- Aplicação da metologia proposta em sistemas reais de grande porte, para avaliação dos resultados estimados, tempo computacional e da sensibilidade gerada a partir das distorções ocorridas na etapa da entropia cruzada; 
- Explorar a possibilidade de adoção de outras técnicas de redução de variância que possam fazer frente a entropia cruzada em aplicações de sistemas de energia elétrica. 


\section{Referências bibliográficas}

[1] BORKOWSKA, B.. Probabilistic load flow. IEEE Transactions on Power Apparatus and Systems, PAS-93(3):752-759, May 1974.

[2] RUBINSTEIN, R. Y.; KROESE, D. P.. Simulation and the Monte Carlo Method (Wiley Series in Probability and Statistics). Wiley, 2 edition, 2007.

[3] RUBINSTEIN, R. Y.; KROESE, D. P.. The Cross Entropy Method: A Unified Approach To Combinatorial Optimization, Monte-carlo Simulation (Information Science and Statistics). Springer-Verlag New York, Inc., Secaucus, NJ, USA, 2004.

[4] BILLINTON, R.; ALLAN, R. N.. Reliability Evaluation of Power Systems. Springer US, Boston, MA, 1996.

[5] SCHILLING, M. T.; LEITE DA SILVA, A. M.; BILLINTON, R. ; EL-KADY, M. A.. Bibliography on power system probabilistic analysis (196288). IEEE Transactions on Power Systems, 5(1):1-11, Feb 1990.

[6] CHEN, P.; CHEN, Z. ; BAK-JENSEN, B.. Probabilistic load flow: A review. In: 2008 Third International Conference on Electric Utility Deregulation and Restructuring and Power Technologies, p. 1586-1591, April 2008.

[7] MARTINEZ, J. A.; MAHSEREDJIAN, J.. Load flow calculations in distribution systems with distributed resources. a review. In: 2011 IEEE Power and Energy Society General Meeting, p. 1-8, July 2011.

[8] CAI, D.; LI, X.; ZHOU, K.; XIN, J. ; CAO, K.. Probabilistic load flow algorithms considering correlation between input random variables: A review. In: 2015 IEEE 10th Conference on Industrial Electronics and Applications (ICIEA), p. 1139-1144, June 2015.

[9] ALLAN, R. N.; BORKOWSKA, B. ; GRIGG, C. H.. Probabilistic analysis of power flows. Electrical Engineers, Proceedings of the Institution of, 121(12):1551-1556, December 1974. 
[10] DOPAZO, J. F.; KLITIN, O. A. ; SASSON, A. M.. Stochastic load flows. IEEE Transactions on Power Apparatus and Systems, 94(2):299-309, Mar 1975.

[11] ALLAN, R. N.; GRIGG, C. H. ; AL-SHAKARCHI, M. R. G.. Numerical techniques in probabilistic load flow problems. International Journal for Numerical Methods in Engineering, 10(4):853-860, 1976.

[12] ALLAN, R. N.; LEITE DA SILVA, A. M. ; BURCHETT, R. C.. Evaluation methods and accuracy in probabilistic load flow solutions. IEEE Transactions on Power Apparatus and Systems, PAS-100(5):2539-2546, May 1981.

[13] ALLAN, R. N.; LEITE DA SILVA, A. M.. Probabilistic load flow using multilinearisations. IEE Proceedings C - Generation, Transmission and Distribution, 128(5):280-287, September 1981.

[14] BRUCOLI, M.; TORELLI, F. ; NAPOLI, R.. Quadratic probabilistic load flow with linearly modelled dispatch. International Journal of Electrical Power \& Energy Systems, 7(3):138 - 146, 1985.

[15] LeITE DA SILVA, A. M.; ALLAN, R. N.; SOARES, S. M. ; ARIENTI, V. L.. Probabilistic load flow considering network outages. IEE Proceedings C - Generation, Transmission and Distribution, 132(3):139-145, May 1985.

[16] LeITE DA SILVA, A. M.; ARIENTI, V. L.. Probabilistic load flow by a multilinear simulation algorithm. IEE Proceedings C - Generation, Transmission and Distribution, 137(4):276-282, Jul 1990.

[17] LEITE DA SILVA, A. M.; RIBEIRO, S. M. P.; ARIENTI, V. L.; ALLAN, R. N. ; FILHO, M. B. D. C.. Probabilistic load flow techniques applied to power system expansion planning. IEEE Transactions on Power Systems, 5(4):1047-1053, Nov 1990.

[18] JORGEnSEN, P.; CHRISTENSEN, J. S. ; TANDE, J. O.. Probabilistic load flow calculation using monte carlo techniques for distribution network with wind turbines. In: 8th International Conference on Harmonics and Quality of Power. Proceedings (Cat. No.98EX227), volumen 2, p. 1146-1151 vol.2, Oct 1998.

[19] ZHANG, P.; LEE, S. T.. Probabilistic load flow computation using the method of combined cumulants and gram-charlier expansion. IEEE Transactions on Power Systems, 19(1):676-682, Feb 2004. 
[20] HATZIARGYRIOU, N. D.; KARAKATSANIS, T. S. ; LORENTZOU, M. I.. Voltage control settings to increase wind power based on probabilistic load flow. In: 2004 International Conference on Probabilistic Methods Applied to Power Systems, p. 737-741, Sept 2004.

[21] SU, C.-L.. Probabilistic load-flow computation using point estimate method. IEEE Transactions on Power Systems, 20(4):1843-1851, Nov 2005.

[22] MORALES, J. M.; PEREZ-RUIZ, J.. Point estimate schemes to solve the probabilistic power flow. IEEE Transactions on Power Systems, 22(4):1594-1601, Nov 2007.

[23] MIN, L.; LEE, S. T.; ZHANG, P.; ROSE, V. ; COLE, J.. Short-term probabilistic transmission congestion forecasting. In: 2008 Third International Conference on Electric Utility Deregulation and Restructuring and Power Technologies, p. 764-770, April 2008.

[24] BIE, Z.; LI, G.; LIU, H.; WANG, X. ; WANG, X.. Studies on voltage fluctuation in the integration of wind power plants using probabilistic load flow. In: 2008 IEEE Power and Energy Society General Meeting - Conversion and Delivery of Electrical Energy in the 21st Century, p. 1-7, July 2008 .

[25] YU, H.; CHUNG, C. Y.; WONG, K. P.; LEE, H. W. ; ZHANG, J. H.. Probabilistic load flow evaluation with hybrid latin hypercube sampling and cholesky decomposition. IEEE Transactions on Power Systems, 24(2):661-667, May 2009.

[26] LIU, Y.; GAO, S.; CUI, H. ; YU, L.. Probabilistic load flow considering correlations of input variables following arbitrary distributions. Electric Power Systems Research, 140:354 - 362, 2016.

[27] OKE, O. A.; THOMAS, D. W. P.; ASHER, G. M. ; DE MENEZES, L. R. A. X.. Probabilistic load flow for distribution systems with wind production using unscented transform method. In: ISGT 2011, p. 1-7, Jan 2011.

[28] AIEN, M.; FOTUHI-FIRUZABAD, M. ; AMINIFAR, F.. Probabilistic load flow in correlated uncertain environment using unscented transformation. IEEE Transactions on Power Systems, 27(4):2233-2241, Nov 2012. 
[29] TANG, J.; NI, F.; PONCl, F. ; MONTI, A.. Dimension-adaptive sparse grid interpolation for uncertainty quantification in modern power systems: Probabilistic power flow. IEEE Transactions on Power Systems, 31(2):907-919, March 2016.

[30] WANG, X.; GONG, Y. ; JIANG, C.. Regional carbon emission management based on probabilistic power flow with correlated stochastic variables. IEEE Transactions on Power Systems, 30(2):1094-1103, March 2015.

[31] HONG, Y. Y.; LIN, F. J.; LIN, Y. C. ; HSU, F. Y.. Chaotic pso-based var control considering renewables using fast probabilistic power flow. IEEE Transactions on Power Delivery, 29(4):1666-1674, Aug 2014.

[32] DAGUR, D.; PARIMI, M. ; WAGH, S. R.. Prediction of cascade failure using probabilistic approach with ac load flow. In: 2014 IEEE Innovative Smart Grid Technologies - Asia (ISGT ASIA), p. 542-547, May 2014.

[33] NIKMEHR, N.; RAVADANEGH, S. N.. Heuristic probabilistic power flow algorithm for microgrids operation and planning. IET Generation, Transmission Distribution, 9(11):985-995, 2015.

[34] MELHORN, A. C.; MCKENNA, K.; KEANE, A.; FLYNN, D. ; DIMITROVSKI, A.. Autonomous plug and play electric vehicle charging scenarios including reactive power provision: a probabilistic load flow analysis. IET Generation, Transmission Distribution, 11(3):768-775, 2017.

[35] BILLINTON, R.; FOTUHI-FIRUZABAD, M. ; BERTLING, L.. Bibliography on the application of probability methods in power system reliability evaluation 1996-1999. IEEE Transactions on Power Systems, 16(4):595-602, Nov 2001.

[36] PINTO, L. M. V. G.; PEREIRA, M. V. F.. A variance reduction technique to the reliability analysis of a generation/transmission system. In: 1991., IEEE International Sympoisum on Circuits and Systems, p. 892-895 vol.2, Jun 1991.

[37] BILLINTON, R.; JONNAVITHULA, A.. Variance reduction techniques for use with sequential monte carlo simulation in bulk power system reliability evaluation. In: Proceedings of 1996 Canadian Conference on Electrical and Computer Engineering, volumen 1, p. 416-419 vol.1, May 1996. 
[38] BILLINTON, R.; JONNAVITHULA. Composite system adequacy assessment using sequential monte carlo simulation with variance reduction techniques [power networks]. IEE Proceedings - Generation, Transmission and Distribution, 144(1):1-6, Jan 1997.

[39] LIEBER, D.; NEMIROVSKII, A. ; RUBINSTEIN, R. Y.. A fast monte carlo method for evaluating reliability indexes. IEEE Transactions on Reliability, 48(3):256-261, Sep 1999.

[40] DE MELLO, T. H.; RUBINSTEIN, R. Y.. Estimation of rare event probabilities using cross-entropy. In: Proceedings of the Winter Simulation Conference, volumen 1, p. 310-319 vol.1, Dec 2002.

[41] ERNST, D.; GLAVIC, M.; STAN, G. B.; MANNOR, S. ; WEHENKEL, L.. The cross-entropy method for power system combinatorial optimization problems. In: 2007 IEEE Lausanne Power Tech, p. 12901295, July 2007.

[42] BELMUDES, F.; ERNST, D. ; WEHENKEL, L.. Cross-entropy based rare-event simulation for the identification of dangerous events in power systems. In: Proceedings of the 10th International Conference on Probablistic Methods Applied to Power Systems, p. 1-7, May 2008.

[43] LEITE DA SILVA, A. M.; FERNANDEZ, R. A. G. ; SINGH, C.. Generating capacity reliability evaluation based on monte carlo simulation and cross-entropy methods. IEEE Transactions on Power Systems, 25(1):129-137, Feb 2010.

[44] LeITE DA SILVA, A. M.; MElO, A. C. G. ; CUNHA, S. H. F.. Frequency and duration method for reliability evaluation of large-scale hydrothermal generating systems. IEE Proceedings C - Generation, Transmission and Distribution, 138(1):94-102, Jan 1991.

[45] GONZALEZ-FERNANDEZ, R. A.; LEITE DA SILVA, A. M.. Reliability assessment of time-dependent systems via sequential crossentropy monte carlo simulation. IEEE Transactions on Power Systems, 26(4):2381-2389, Nov 2011.

[46] D. M. CARVALHO, L.; GONZÁLEZ-FERNÁNDEZ, R. A.; LEITE DA SILVA, A. M.; DA ROSA, M. A. ; MIRANDA, V.. Simplified cross-entropy based approach for generating capacity reliability assessment. IEEE Transactions on Power Systems, 28(2):1609-1616, May 2013. 
[47] GONZÁLEZ-FERNÁNDEZ, R. A.; LEITE DA SILVA, A. M.; RESENDE, L. C. ; SCHILLING, M. T.. Composite systems reliability evaluation based on monte carlo simulation and cross-entropy methods. IEEE Transactions on Power Systems, 28(4):4598-4606, Nov 2013.

[48] LEITE DA SILVA, A. M.; GONZÁLEZ-FERNÁNDEZ, R. A.; FLÁVIO, S. A. ; MANSO, L. A. F.. Composite reliability evaluation with renewable sources based on quasi-sequential monte carlo and cross entropy methods. In: 2014 International Conference on Probabilistic Methods Applied to Power Systems (PMAPS), p. 1-6, July 2014.

[49] LEITE DA SILVA, A. M.; CASTRO, J. F. C. ; GONZÁLEZ-FERNÁNDEZ, R. A.. Spinning reserve assessment under transmission constraints based on cross-entropy method. IEEE Transactions on Power Systems, 31(2):1624-1632, March 2016.

[50] FERNÁNDEZ, R. A. G.. Aplicações do Método da Entropia Cruzada na Confiabilidade de Sistema Elétricos de Potência. Tese de doutorado, Universidade Federal de Itajubá, Itajubá - MG, 2012.

[51] ZHAOHONG, B.; XIFAN, W.. Studies on variance reduction technique of monte carlo simulation in composite system reliability evaluation. Electric Power Systems Research, 63(1):59 - 64, 2002.

[52] CHAN, J. C. C.; KROESE, D. P.. Improved cross-entropy method for estimation. Statistics and Computing, 22(5):1031-1040, Sep 2012.

[53] ZIMMERMAN, R. D.; MURILLO-SANCHEZ, C. E. ; THOMAS, R. J.. Matpower: Steady-state operations, planning, and analysis tools for power systems research and education. IEEE Transactions on Power Systems, 26(1):12-19, Feb 2011.

[54] UNIVERSITY OF WASHINGTON. Power system test case archive. IEEE 14 Bus. Acesso em: Julho de 2017.

[55] UNIVERSITY OF WASHINGTON. Power system test case archive. IEEE RTS 79. Acesso em: Julho de 2017.

[56] UNIVERSITY OF WASHINGTON. Power system test case archive. IEEE 118 Bus. Acesso em: Julho de 2017.

[57] SUBCOMMITTEE, P. M.. IEEE reliability test system. IEEE Transactions on Power Apparatus and Systems, PAS-98(6):2047-2054, Nov 1979. 
A

\section{Dados de Sistema IEEE 14 Barras}

Nesse apêndice são apresentados os dados probabilísticos utilizados em estudo do sistema IEEE 14 Barras. Os dados de rede são encontrados em [54]. O diagrama unifilar do sistema é ilustrado na Figura A.1. As Tabelas A.1, A.2 e A.3 apresentam os dados para modelos de distribuição normal, binomial e discreta, respectivamente.

(G) Geradores

(C) Compensadores Síncronos

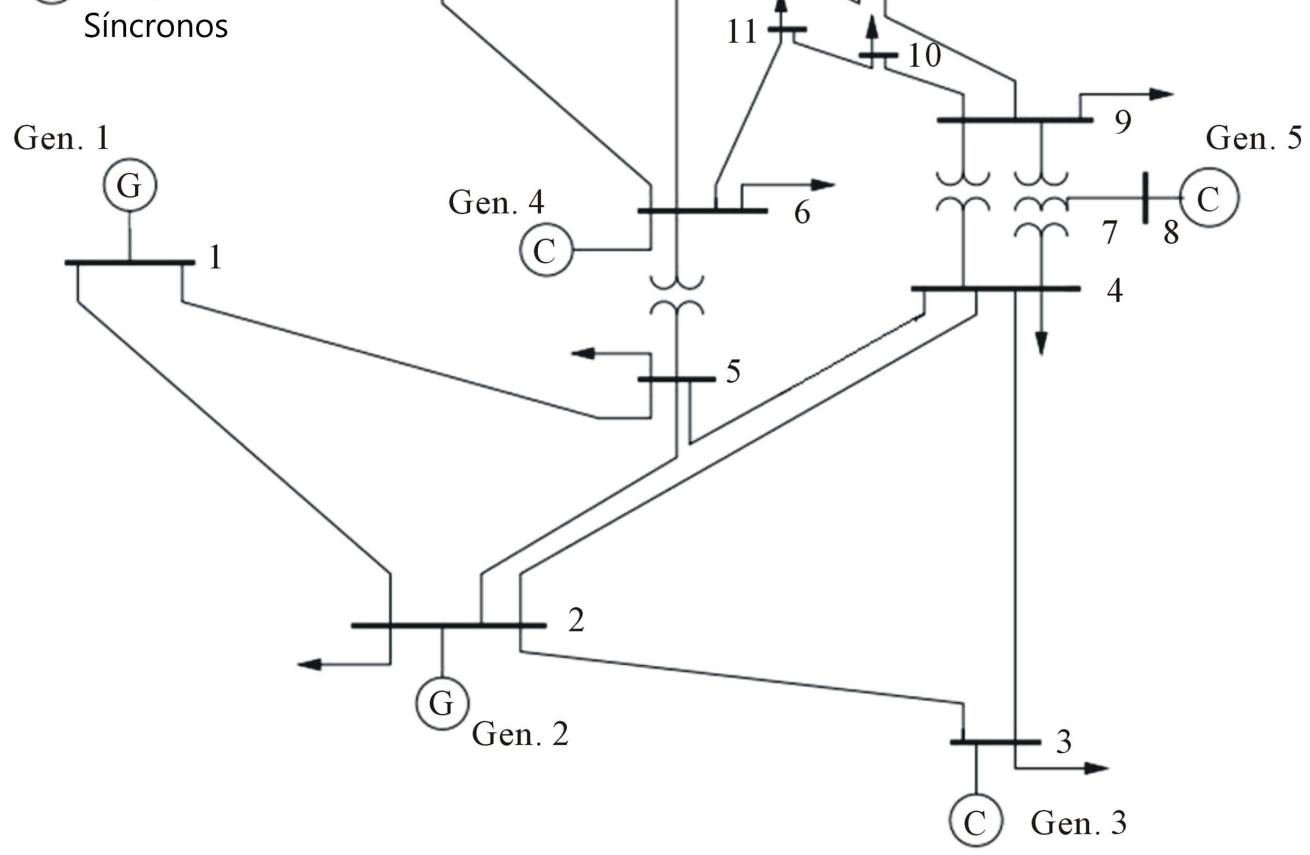

Figura A.1: Diagrama unifilar para sistema IEEE 14 barras 
Tabela A.1: Dados Nodais Probabilísticos - Distribuições Normais

\begin{tabular}{ccccccc}
\hline \multicolumn{2}{c}{ Barra } & Tensão & \multicolumn{2}{c}{ Potência Ativa } & \multicolumn{2}{c}{ Potência Reativa } \\
No & Tipo & p.u. & $\mu(\mathrm{MW})$ & $\sigma(\%)$ & $\mu(\mathrm{MVAR})$ & $\sigma(\%)$ \\
\hline 2 & PV & 1,045 & $-21,74$ & 9,00 & $-12,70$ & 9,20 \\
3 & PV & 1,010 & $-94,20$ & 10,00 & $-19,00$ & 10,50 \\
4 & PQ & & $-47,80$ & 11,00 & $-3,90$ & 9,70 \\
5 & PQ & & $-7,60$ & 5,00 & $-1,60$ & 5,00 \\
6 & PV & 1,070 & $-11,20$ & 6,00 & $-7,50$ & 6,30 \\
7 & PQ & & 0,00 & 0,00 & 0,00 & 0,00 \\
8 & PV & 1,090 & 0,00 & 0,00 & 0,00 & 0,00 \\
10 & PQ & & $-9,00$ & 10,00 & $-5,80$ & 10,00 \\
11 & PQ & & $-3,50$ & 9,50 & $-1,80$ & 9,50 \\
12 & PQ & & $-6,10$ & 7,60 & $-1,60$ & 8,60 \\
13 & PQ & & $-13,50$ & 10,50 & $-5,80$ & 9,50 \\
14 & PQ & & $-14,90$ & 8,60 & $-5,00$ & 8,60
\end{tabular}

Tabela A.2: Dados Nodais Probabilísticos - Distribuições Binomiais

Barra Tensão Potência Unitária Taxa de Saída No Unidades

\begin{tabular}{cccccc} 
No & Tipo & p.u & MW & forçada & \\
\hline 2 & PV & 1,045 & 22,00 & 0,09 & 2
\end{tabular}

Tabela A.3: Dados Nodais Probabilísticos - Distribuições Discretas

\begin{tabular}{cccccc}
\hline \multicolumn{2}{c}{ Barra } & \multicolumn{2}{c}{ Potência Ativa } & \multicolumn{2}{c}{ Potência Reativa } \\
No & Tipo & MW & prob. & MVAR & prob. \\
\hline 9 & PQ & $-13,4$ & 0,10 & $-7,5$ & 0,10 \\
& & $-19,6$ & 0,15 & $-11,0$ & 0,15 \\
& & $-30,2$ & 0,30 & $-17,0$ & 0,30 \\
& $-34,8$ & 0,25 & $-19,6$ & 0,25 \\
& $-37,3$ & 0,20 & $-21,0$ & 0,20
\end{tabular}




\section{B \\ Dados de Sistema IEEE RTS 79}

Nesse apêndice são apresentados os dados probabilísticos utilizados em estudo do sistema IEEE RTS 79. Os dados de rede são encontrados em [55, 57]. O diagrama unifilar do sistema é ilustrado na Figura B.1. Os dados de geradores são obtidos em [57]. Para os modelos probabilísticos da carga, considera-se os dados do caso base em [55] como a média de uma distribuição normal, cujo desvio padrão é 5\%. A exceção são as cargas das barras 9 e 18, regidas por distribuições discretas, cujos valores esperados são os do caso base em [55] e apresentados na Tabela B.1.

Outro fator importante é a manutenção de fator de potência constante para os pontos de carga, amostrando-se apenas a potência ativa e, a partir desse valor, determinando-se a reativa.

Os custos necessários para realização do despacho das unidades de geração são encontrados em [57].

Os patamares de carga e geração, para os testes realizados com esse sistema, são multiplicados por um fator igual a 1,5, para aumentar o carregamento do sistema. 


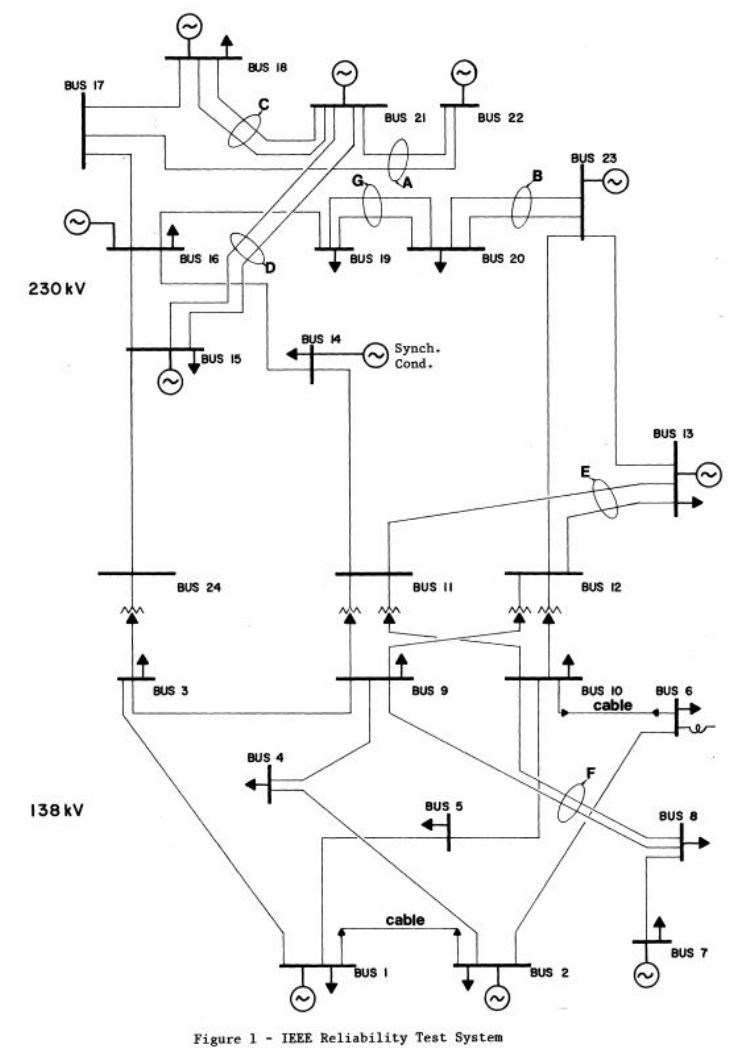

U

Figura B.1: Diagrama unifilar para sistema IEEE RTS 79

Tabela B.1: Dados Nodais Probabilísticos - Distribuições Discretas

\begin{tabular}{cccc}
\hline \multicolumn{2}{c}{ Barra } & \multicolumn{2}{c}{ Potência Ativa } \\
No & Tipo & MW & prob. \\
\hline 9 & PQ & -165 & 0,10 \\
& & -170 & 0,15 \\
& & -175 & 0,40 \\
& & -180 & 0,35 \\
\hline 18 & PQ & -330 & 0,35 \\
& & -333 & 0,50 \\
& & -340 & 0,15 \\
\hline
\end{tabular}




\section{C \\ Dados de Sistema IEEE 118 Barras}

Nesse apêndice são apresentados os dados probabilísticos utilizados em estudo do sistema IEEE 118 Barras. Os dados de rede são encontrados em [56]. O diagrama unifilar do sistema é ilustrado na Figura C.1. Os modelos de carga, regidos por distribuições normais, são criados a partir do caso base apresentado em [56]. Os valores do caso base são considerados como média de distribuições normais, com desvio padrão de $2 \%$. Para aumentar a complexidade a ser enfrentada pela metodologia proposta, alguns pontos de carga são considerados como regidos por distribuições discretas (cujas médias são os valores do caso base), conforme apresentado na Tabela C.1. A Tabela C.2 apresenta os dados de indisponibilidade e a ordem de mérito (considerando menor valor, como máquina preferencial para despacho), criados para testes nessa dissertação.

Os limites de sobrecarga criados são calculados a partir do fluxo realizado no caso base, acrescido de 50\%. Para aumentar o carregamento do sistema, todos os patamares de carga e geração são multiplicados por um fator igual a 2 , nos testes a serem apresentados para esse sistema. 


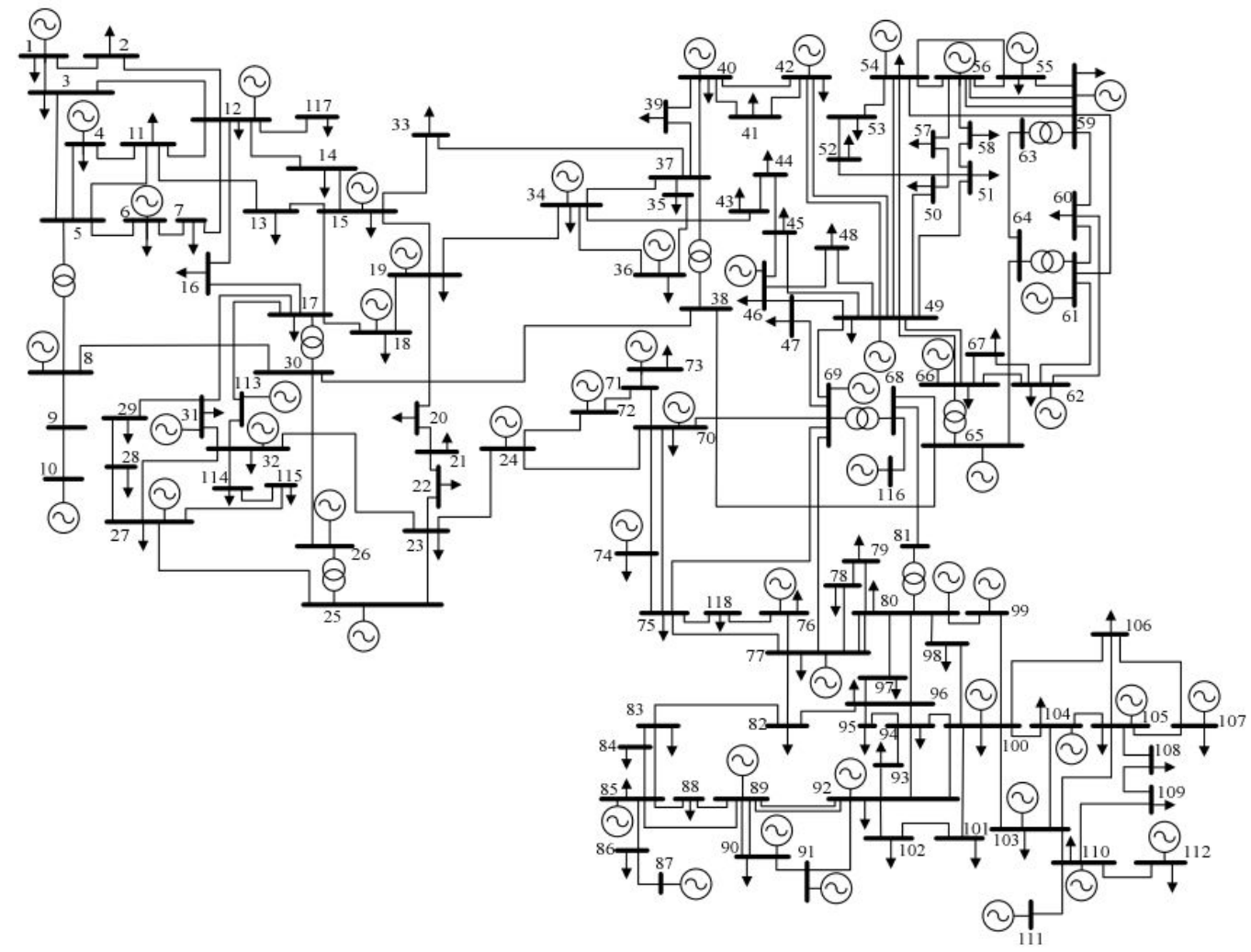

Figura C.1: Diagrama unifilar para sistema IEEE 118 barras 
Tabela C.1: Dados Nodais Probabilísticos - Distribuições Discretas

\begin{tabular}{cccc}
\hline \multicolumn{2}{c}{ Barra } & \multicolumn{2}{c}{ Potência Ativa } \\
No & Tipo & MW & prob. \\
\hline 7 & PQ & -17 & 0,10 \\
& & -18 & 0,20 \\
& & -19 & 0,30 \\
& & -20 & 0,40 \\
\hline 28 & PQ & -15 & 0,05 \\
& & -16 & 0,20 \\
& & -17 & 0,50 \\
& & -18 & 0,20 \\
& & -19 & 0,05 \\
\hline 33 & PQ & -22 & 0,40 \\
& & -23 & 0,30 \\
& & -24 & 0,20 \\
& & -25 & 0,10 \\
\hline 44 & PQ & -14 & 0,20 \\
& & -15 & 0,05 \\
& & -16 & 0,30 \\
& & -17 & 0,45 \\
\hline 51 & PQ & -16 & 0,30 \\
& & -17 & 0,40 \\
& & -18 & 0,30 \\
\hline 109 & PQ & -7 & 0,30 \\
& & -8 & 0,40 \\
& & -9 & 0,30 \\
\hline & & & \\
& & \\
& & & \\
& & & \\
& & & \\
& & \\
& &
\end{tabular}


Tabela C.2: Dados de Geração - Indisponibilidade e Ordem de Mérito

\begin{tabular}{ccccc}
\hline Barra & No Máquinas & $\begin{array}{c}\text { Cap. Nominal } \\
\text { (por máquina) }\end{array}$ & Indisponibilidade & Ordem de Mérito \\
\hline 10 & 3 & 150 & 0,03 & 2 \\
12 & 5 & 17 & 0,01 & 4 \\
25 & 5 & 110 & 0,03 & 2 \\
26 & 2 & 157 & 0,04 & 1 \\
31 & 1 & 7 & 0,01 & 4 \\
46 & 1 & 19 & 0,01 & 4 \\
49 & 2 & 102 & 0,03 & 2 \\
54 & 2 & 24 & 0,01 & 4 \\
59 & 5 & 31 & 0,01 & 4 \\
61 & 2 & 80 & 0,02 & 3 \\
65 & 2 & 200 & 0,04 & 3 \\
66 & 4 & 98 & 0,02 & 2 \\
69 & 5 & 103 & 0,03 & 1 \\
80 & 3 & 159 & 0,04 & 4 \\
87 & 1 & 4 & 0,01 & 2 \\
89 & 5 & 121 & 0,03 & 3 \\
100 & 3 & 84 & 0,02 & 4 \\
103 & 2 & 20 & 0,01 & 0,01 \\
111 & 2 & 36 & & 4 \\
\hline & & & & 4 \\
\hline
\end{tabular}

